\title{
Genomic constitution of gametes and preimplantation embryos
}

Citation for published version (APA):

Coonen, E. (1995). Genomic constitution of gametes and preimplantation embryos. [Doctoral Thesis, Maastricht University]. Datawyse / Universitaire Pers Maastricht. https://doi.org/10.26481/dis.19950323ec

Document status and date:

Published: 01/01/1995

DOI:

$10.26481 /$ dis. $19950323 e c$

Document Version:

Publisher's PDF, also known as Version of record

\section{Please check the document version of this publication:}

- A submitted manuscript is the version of the article upon submission and before peer-review. There can be important differences between the submitted version and the official published version of record.

People interested in the research are advised to contact the author for the final version of the publication, or visit the DOI to the publisher's website.

- The final author version and the galley proof are versions of the publication after peer review.

- The final published version features the final layout of the paper including the volume, issue and page numbers.

Link to publication

\footnotetext{
General rights rights.

- You may freely distribute the URL identifying the publication in the public portal. please follow below link for the End User Agreement:

www.umlib.nl/taverne-license

Take down policy

If you believe that this document breaches copyright please contact us at:

repository@maastrichtuniversity.nl

providing details and we will investigate your claim.
}

Copyright and moral rights for the publications made accessible in the public portal are retained by the authors and/or other copyright owners and it is a condition of accessing publications that users recognise and abide by the legal requirements associated with these

- Users may download and print one copy of any publication from the public portal for the purpose of private study or research.

- You may not further distribute the material or use it for any profit-making activity or commercial gain

If the publication is distributed under the terms of Article $25 \mathrm{fa}$ of the Dutch Copyright Act, indicated by the "Taverne" license above, 


\section{Genomic constitution of gametes and preimplantation embryos}




\section{CIP-GEGEVENS KONINKLIJKE BIBLIOTHEEK, DEN HAAG}

\section{Coonen, Edith}

Genomic constitution of gametes and preimplantation embryos / Edith Coonen. - Maastricht : Universitaire Pers

Maastricht. - III.

Thesis Rijksuniversiteit Limburg Maastricht. - With ref. With summary in Dutch.

ISBN 90-5278-176-1

Subject headings: human embryos ; preimplantation diagnosis / human embryos ; genetic analysis.

(C) E Coonen, Maastricht 1995

cover illustration : 3D autostereogram of an 8-cell embryo by Wil Loots cover design : Datawyse, Wendy Verhagen 
Genomic constitution of gametes and preimplantation embryos

\author{
Proefschrift
}

ter verkrijging van de graad van doctor aan de Rijksuniversiteit Limburg te Maastricht, op gezag van de Rector Magnificus, Prof. mr. M.J. Cohen, volgens het besluit van het College van Dekanen, in het openbaar te verdedigen op donderdag 23 maart 1995 om 12.00 uur

door

\title{
Edith Coonen
}

geboren op 27 april 1967 te Roermond 
Promotores: Prof. dr F.C.S. Ramaekers

Prof. dr J.P.M. Geraedts

Co-promotor: Dr A.H.N. Hopman

Beoordelingscommissie:

Prof. dr J.W. Arends (voorzitter)

Prof. dr J. Drukker

Prof. dr J.L.H. Evers

Prof. dr I. Liebaers (Vrije Universiteit Brussel, België)

Prof. dr R.M.L. Winston (Hammersmith Hospital London, UK) 



\section{CONTENTS}

Chapter 1 General Introduction
1.1 Introduction
1.2 Methodology
1.3 Genomic constitution of human preimplantation embryos
1.4 Objectives of this thesis
1.5 References

Chapter 2 Nonisotopic in situ hybridisation as a method for nondisjunction studies in human spermatozoa
2.1 Introduction
2.2 Materials \& Methods
2.3 Results
2.4 Discussion
2.5 Addendum
2.6 References

Chapter 3 Optimal preparation of preimplantation embryo interphase nuclei for analysis by fluorescence in situ hybridisation
3.1 Introduction
3.2 Materials \& Methods
3.3 Results
3.4 Discussion
3.5 References

Chapter 4 Fluorescence in situ hybridisation using cosmid probes to detect unique sequences in human embryonic cells; Implications for preimplantation diagnosis
4.1 Introduction
4.2 Materials \& Methods
4.3 Results
4.4 Discussion
4.5 References

Chapter 5 Identification of the sex of human preimplantation embryos in two hours using an improved spreading method and fluorescence in situ hybridisation (FISH) using directly labelled probes
5.1 Introduction
5.2 Materials \& Methods
5.3 Results
5.4 Discussion
5.5 References 
Chapter 6 Presence of chromosomal mosaicism in abnormal preimplantation embryos detected by

fluorescence in situ hybridisation

6.1 Introduction

6.2 Materials \& Methods

6.3 Results

6.4 Discussion

6.5 References

Chapter 7 Detection of sex chromosome and autosome mosaicism in normally fertilised preimplantation human embryos
7.1 Introduction
7.2 Materials \& Methods
7.3 Results
7.4 Discussion
7.5 References

Chapter $8 \quad$ Future Perspectives
8.1 Structural aberrations
8.2 Combined genotypic and phenotypic analyses
8.3 Comparative Genomic Hybridisation
8.4 FISH analysis of ICSI failures
8.5 Analysis of spermatozoa
8.6 References

Summary

Samenvatting

Curriculum vitae

Publications and abstracts 



\title{
General introduction
}

\author{
(adapted from)
}

Application of in situ hybridisation techniques for the study of human preimplantation embryos; relevance to human preimplantation diagnosis

Edith Coonen, Anton HN Hopman, Joep PM Geraedts

\& Frans CS Ramaekers

Submitted, 1995

The scope of the introduction to this thesis is to outline the research and diagnostic applications of single- and multi-label (fluorescence) in situ hybridisation [( $\mathrm{F}) \mathrm{ISH}]$ in the study of the chromosomal content of preimplantation embryos and to discuss the implications for human preimplantation diagnosis. Current hybridisation techniques are described, including the capabilities and pitfalls of this approach when applied to embryonic cells. Possibilities for future application of the (F)ISH technique to study the genomic constitution of preimplantation embryos will be discussed in the last section of this thesis.

\subsection{Introduction}

In vitro fertilization (IVF), followed by the diagnosis of inherited characteristics of the embryos, may offer new perspectives to couples at risk of transmitting inherited diseases to their offspring (Edwards et al., 1988). Such diagnosis is performed at early preimplantation stages and is therefore referred to as preimplantation diagnosis. This analysis requires access to gametes (spermatozoa and oocytes), cleaving (pre)embryos or blastocysts, efficient and safe biopsy methods, as well as sensitive and reliable procedures for the analysis of the genomic constitution of single or few cells (Brambati, 1993).

Inherited diseases are caused by a number of genetic aberrations, ranging from numerical chromosomal abnormalities to single gene defects. Molecular techniques, such as the (fluorescence) in situ hybridisation (F)ISH) and the polymerase chain reaction (PCR) can be applied to examine genetic material for the presence of such aberrations. 


\section{Practical aspects of preimplantation diagnosis}

The DNA material needed for preimplantation diagnosis is obtained by biopsy procedures (Tarin et al., 1993). Three general approaches are in use to obtain the embryonic material needed for diagnosis: 1) removal of the first polar body from the unfertilized oocyte (Verlinsky and Kuliev, 1992). However, removal of the first polar body and its subsequent analysis yields only information on aberrations present in the maternal genome and could suffer from a false diagnosis due to recombination of homologous chromosomes before extrusion of the first polar body. The same holds true for errors due to nondisjunction at meiosis I (Angell et al., 1991, Angell et al., 1994) 2) biopsy of one or more blastomeres at the cleavage stage (Handyside and Delhanty, 1993). Biopsy of cleavage stage human embryos is usually performed three days after IVF at the 6- to 10-cell stage, allowing the analysis of one or two blastomeres. Recent studies have suggested that reduction of blastomere number by biopsy at day two (2- to 4- cell stage) reduces the inner cell mass (ICM) at later stages of development (Tarin et al., 1992), indicating that the quality of the embryo might be affected. Preimplantation development seems not affected when blastomere biopsy is performed on day three (Hardy et al., 1990) and in this case pregnancy rates following embryo transfer are within the normal range (Handyside et al., 1990). 3) biopsy of the trophectoderm at the blastocyst stage (Dokras et al., 1990). Biopsy of the trophectoderm offers the possibility to analyse multiple cells without interfering with the integrity of the embryo proper. However, only a relatively low percentage of embryos resulting from normal fertilization reaches the blastocyst stage in vitro (Hardy, 1991), and it is not known at present whether the differentiated trophoblast cells still fully represent the embryo proper (Benkhalifa et al., 1993)

Multiple oocytes can be obtained through ovulation induction and can be fertilised and cultured in vitro to obtain cleavage stage embryos. Blastocysts can be recovered from the uterus by flushing the uterine cavity (Buster et al., 1985). However, attempts to increase the number of blastocysts retrieved after uterine lavage by superovulation were not successful (Carson et al., 1991). The use of coculture systems (applying feedinglayers) might increase the proportion of blastocysts developing from the pronuclear stage in vitro (Bongso et al., 1991a). Micromanipulation of day three preimplantation embryos does not adversely affect embryonic development and provides access to single blastomeres in a nondestructive fashion, thereby allowing a genetic diagnosis prior to transfer and subsequent implantation of the embryo. However, time and amount of embryonic material available for genetic diagnosis are limited and place restrictions on the methods used. At the same time the efficiency and reliability of the methods must be absolutely high, as a diagnosis must be made on basis of the analysis of only one or two cells.

\section{Genetic defects to be analysed by preimplantation diagnosis}

Human preimplantation diagnosis is primarily useful in examining embryos for the presence of DNA characteristics specific for inherited diseases with a high recurrence risk.

Structural aberrations: Structural aberrations, such as translocations and inversions, 
play a major role in the vast majority of cytogenetic abnormalities with a high recurrence risk. Couples in which one of the partners carries a balanced translocation, and which have a history of miscarriage with unbalanced chromosomal rearrangements are at risk of having another affected pregnancy. The level of recurrence risk depends on the chromosomes involved in the translocation, the location of the breakpoints and the sex of the translocation carrier and can vary between only 1 or $2 \%$ and $100 \%$ (in case of Robertsonian translocations). Preimplantation diagnosis can select the normal or balanced embryos, thereby preventing transfer of affected, i.e. unbalanced embryos.

Single gene defects: The risk of repetitious affected pregnancies associated with certain single gene defects, is often very high and is determined by the pattern of inheritance. Specific diagnosis is being attempted for prevalent gene defects, especially those caused by a predominant or a limited number of DNA mutations. As many recessive disorders are female $\mathrm{X}$-linked, chances on a normal male child are theoretically $50 \%$. Preimplantation diagnosis to investigate the presence of a gene mutation in a male embryo allows selection of unaffected male embryos for transfer, next to the transfer of normal female embryos.

Sex-linked diseases: For those sex-linked pathological conditions that are not well characterized or that can be caused by too many DNA mutations, no specific methods for DNA diagnosis at the single cell level are available. Hence, indiscriminate termination of all male pregnancies remains the only option for people at risk. Preimplantation sex diagnosis offers an alternative in case of these $\mathrm{X}$-linked diseases by selecting only female embryos for transfer.

Aneuploidies: Chromosomal abnormalities, especially aneuploidies, are present in a considerable fraction of embryos. The most common abnormalities are made up by aneuploidy of the sex chromosomes and trisomies of the autosomes 13,18 and 21. Together they comprise over $95 \%$ of all numerical aberrations present in life born children. These aneuploidies are only in a minority of the cases compatible with development to term but do cause congenital abnormalities of varying severity. By performing preimplantation diagnosis to determine the ploidy status of these chromosomes, birth of affected offspring can be prevented. The majority of the mentioned aneuploidies arise de novo, in embryos from couples without previously known risk. Although it is unlikely that such couples participate in a diagnostic program, preimplantation diagnosis to determine ploidy status would be of benefit to older women ( $>35$ years), who are at increased risk of trisomies, probably due to non-disjunction at maternal meiosis I (Hassold et al., 1993).

Monosomies are generally lethal in early development (except in a few cases of Turner's syndrome $45, \mathrm{XO}$ ) but have been found in human preimplantation embryos (Delhanty et al., 1993).

\section{Diagnostic methods in preimplantation diagnosis}

Biochemical assays: Genetic disease can be diagnosed either directly from the DNA or indirectly from the gene product. If this product is an enzyme, the secretion into the culture medium can be measured to provide information on the genotype of the embryo. Assays have been developed for measuring enzyme activity of mouse embryos at varying stages of development (Monk et al., 1987; Sermon et al., 1991). 
However, attempts at implementing these technologies in a human embryo model have so far been unsuccessful (Braude et al., 1989; Sermon et al., 1992). The human embryonic genome is activated relatively late, i.e. between the 4- and 8-cell stage (Braude et al., 1988). Therefore, measurable enzyme activities in early cleavage stages will predominantly be maternally derived and will obscure embryonic gene activity.

Karyotyping: For the detection of chromosomal abnormalities, cytogenetic analysis of banded metaphase chromosomes would be the method of choice. However, this procedure is time consuming, labourious and rather inefficient due to difficulties in obtaining adequate metaphase preparations, especially in the case that only one or two cells are available for analysis. Furthermore, problems with chromosome spreading and banding, due to the compact nature of embryonic chromosomes, have so far prevented the development of reproducible procedures for a reliable karyotyping of human embryo nuclei. Nevertheless, much of what is known to date on the genomic constitution of human preimplantation embryos is derived from cytogenetic karyotyping studies (for references see table 1).

Polymerase chain reaction (PCR): The PCR procedure facilitates the in vitro synthesis of multiple copies of a specific DNA fragment and is sufficiently sensitive as to allow the detection of unique DNA sequences from a single cell (Saiki et al., 1985; Li et al., 1988). DNA amplification from single cells has been achieved by developing sensitive, nested-primer strategies. Unfortunately, its powerful sensitivity based on DNA amplification is also one of the most significant limitations of the procedure: contaminating DNA sequences may be co-amplified and contribute to a false diagnosis. Several strategies have been reported to address this limitation (Kwok and Higuchi, 1989). A second problem in using the PCR method for single blastomere analysis is amplification failure, especially when the diagnosis is based on the absence of a signal after DNA amplification (Handyside and Delhanty, 1993). Alternatively, simultaneous amplification of multiple DNA loci on the same or different chromosomes may circumvent this problem and prevent false negative results (Strom et al., 1991; Chong et al., 1993). Although the PCR method has been successfully applied to determine the sex of embryonic nuclei (Handyside et al., 1989, 1990; Grifo et al., 1992b; Liu et al., 1994), its particular strength lies in the detection of single gene defects causing diseases as cystic fibrosis (Coutelle et al., 1989; Strom et al., 1990; Handyside et al., 1992; Liu et al., 1992, 1993; Verlinsky et al., 1992), Duchenne muscular dystrophy (Kristjansson et al., 1994), Tay-Sachs disease (Morsy et al., 1992), sickle cell anaemia (Pickering et al., 1992; Sheardown et al., 1992; Muggleton-Harris et al., 1993) and B-thalassaemia (Holding and Monk, 1989; Varawalla et al., 1991)

Fluorescence in situ hybridisation (FISH): The most reliable technique, probably offering the widest scope for the detection of chromosomal abnormalities in preimplantation diagnosis is to use in situ hybridisation with DNA probes for identifying the genotype of human embryos (Jones et al., 1987; West et al., 1987). The FISH method permits analysis of both numerical and structural aberrations in metaphase chromosomes as well as interphase nuclei (Lichter et al., 1991; Tkacuk et al., 1991). Although the information obtained by using FISH is limited to the DNA targets examined, it has the advantage that virtually every nucleus in an embryo is informative (Coonen et al., 1994b), in contrast to conventional karyotyping. 
Furthermore, the FISH procedure is not hampered by contamination, which is a distinct advantage over the PCR method for analysis of single cells. An improved spreading method for embryonic cells (Coonen et al.,1994a) combined with the use of directly labelled DNA probes in a short hybridisation procedure (Harper et al., 1994) have made the FISH technique an efficient, fast and easy to perform procedure for preimplantation diagnosis of chromosomal disease.

\subsection{Methodology}

\section{Spreading and pretreatment of embryonic cells}

Whole embryos or single blastomeres need to be pretreated to achieve successful hybridisation. Untill recently, Tarkowski's method (1966) was the one most frequently used for spreading of whole embryos or single blastomeres. It involves cell fixation with methanol/acetic acid (3:1) often preceded by a hypotonic swelling step. However, the application of this method for preparation of human blastomeres has some drawbacks. The procedure suffers from frequent loss of cells due to the critical timing of the subsequent fixation steps and loss of cell morphology, resulting in nuclei which are useless for evaluation (Griffin et al., 1992). These factors greatly decrease the reliability and reproducibility of this method. In case of preimplantation diagnosis, where the availability of material is usually limited to one or two blastomeres, this is obviously a great disadvantage. We have recently described a novel method to prepare single embryonic interphase nuclei, that offers a high reproducibility, a good morphology of embryonic nuclei and a high hybridisation efficiency (Coonen et al., 1994a). This improved cell spreading method is based on the disaggregation of whole embryos or single blastomeres in a solution containing $0.01 \mathrm{~N} \mathrm{HCl} / 0.1 \%$ Tween 20 . Initial studies have revealed that this method, in combination with the use of probes specific for repeated sequences, is a sensitive and reliable procedure that can be used for sex and ploidy determination of blastomeres in preimplantation diagnosis (Coonen et al., 1994b, Harper et al., 1994a, Harper et al., 1994b).

\section{Methodological aspects of ISH techniques}

The ISH technique can be used to visualize specific DNA sequences, both in metaphase chromosomes and in interphase nuclei. Metaphase chromosomes can only be obtained after culturing and mitotic arrest of cells and is, because of time pressure, not suitable for use in preimplantation diagnosis. Chromosomes in interphase nuclei are generally organized in distinct domains so that their location, number and integrity can be assessed using FISH with DNA probes specifically recognizing the involved chromosomes or parts thereof. This enables detection of numerical as well as structural aberrations. It may be clear that the clinical utility of FISH in preimplantation diagnosis strongly depends on the availability and quality of probes that bind specifically to regions of genetic interest.

DNA probes: The DNA probes currently in use can be divided into three general categories. 
The first group consists of probes specific for repeated DNA sequences found primarily in the centromeric region of only one pair of chromosomes. The major application for such probes is chromosome enumeration. Most studies to date on interphase embryonic cells have been accomplished using chromosome-specific probes that recognize repeated (centromeric) sequences to determine the sex or ploidy status of human blastomeres (for an overview and references see table 1). When using centromere-specific DNA probes to study interphase nuclei, the number of chromosomes present is inferred from the number of hybridisation signals observed. FISH with probes specific for repeated DNA sequences does not allow analysis of structural aberrations in interphase nuclei unless the aberrations happen to involve the repeated unit of the affected chromosome(s). This might be the case in Robertsonian translocations.

The second categorie is made up by chromosome subregion-specific probes (for example yeast artificial chromosomes (YAC's) and whole chromosome probes, made from chromosome-specific recombinant DNA libraries. Such painting probes are in fact mixtures of DNA probes that have homology at multiple contiguous sites along the target chromosome. As chromosomes are thought to occupy domains in an interphase nucleus, the presence of a chromosome after FISH with whole chromosome probes will be indicated by a relatively large fluorescent area. Whole chromosome probes are useful for analysis of both structural and numerical aberrations in metaphase chromosomes but are usually less applicable in interphase cells. Although they enable detection of numerical aberrations and major translocations in (near)-diploid cells, they are not likely to be useful for analysis of human embryos. This applies in particular to polypronucleate embryos because their blastomeres are often genomically heterogeneous (Coonen et al., 1994b) and can contain many copies of one chromosome, resulting in the formation of multiple domains. However, DNA probes specific for chromosomal subregions have been suggested to be useful for analysis of structural aberrations in human blastomeres (Coonen et al., 1994c).

The last categorie of DNA probes are those homologous to unique DNA sequences, recognizing particular loci. Probes flanking or spanning a chromosomal breakpoint may be used to diagnose specific genetic diseases or previously identified chromosomal re-arrangements in human blastomeres (Coonen et al., 1994c). To accomplish a dependable FISH analysis, it is necessary to thoroughly investigate the characteristics (efficiency, signal appearance, polymorphism) of each probe before applying it in preimplantation diagnosis.

Labelling of DNA probes: Visualization of DNA-DNA hybrids is achieved by chemical modification of the probe DNA. The first ISH studies performed were based on radioactively-labelled probes and subsequent detection of hybrids by autoradiography (Gall and Pardue, 1969; John et al., 1969). This isotopic approach was first described for sexing of human embryos by Jones et al. (1987) and West et al. $(1987,1988)$ who used a radioactively labelled probe specific for the Ychromosome. To overcome the main disadvantages of the autoradiographic method (hazardous, low spatial resolution and time-consuming) (Langer et al., 1981), biotinylated probes that could be enzymatically detected, were introduced. Although safer and quicker, enzymatic hybrid detection offered less spatial resolution. Application of this non-isotopic probe labelling for the ISH sex analysis of human 
embryos was reported by Penketh et al. (1989). Fluorescence visualization of DNADNA hybrids finally combined the advantages of both previous methods (Manuelidis et al., 1982), i.e. non-hazardous, relatively quick and offering a good spatial resolution. In 1990 the first reports appeared on the use of FISH to analyse human blastomeres (Grifo et al., 1990; Pieters et al., 1990). Recently, Harper et al. (1994a) presented the application of directly-labelled DNA probes for gender determination of human blastomeres. The use of this approach eliminates the need for immunocytochemical detection of the formed hybrids, thereby reducing the time required for analysis.

In general, fluorescence detection of DNA-DNA hybrids is preferred over enzymatic visualization because of better spatial resolution, the ability to quantitate fluorescence signals by photon counting and a greater potential for simultaneous multi-probe analysis. The number of different DNA regions that can be investigated simultaneously in an in situ hybridisation reaction depends on the possibility to modify the required DNA probes in such a way that they can be unequivocally distinguished from one another after visualisation. Biotin and digoxygenin labelling combined with fluorescence detec-tion is currently the most widely used procedure for indirect visualisation of DNA-DNA hybrids. They can also be directly visualised by using DNA probes that have incorporated a fluorochrome during chemical modification. In addition, DNA probes can be modified with combinations of different (in)direct labels, thereby increasing the number of DNA targets that can be examined simultaneously and in the same preparation upto 12 (Dauwerse et al., 1992). Although the fluorescence approach is mostly used, enzymatic hybrid detection results in non-fading, permanent hybridisation signals that can be analysed in a routine setting with brightfield microscopy. Moreover, recent improvements in retaining the discreteness of hybridisation signals and the development of doubleand triple- target ISH based on stable enzyme-substrate precipitates, offers new perspectives for multiple target ISH analyses and for the combination of ISH and the immunocytochemical detection of relevant antigens (Speel et al., 1994).

Hybridisation procedure: Preimplantation diagnosis of genetic disorders based on the analysis of small cell numbers requires sensitive tests. Therefore, the efficiency of obtaining blastomeres in optimal condition for ISH analyis, as well as the ISH proce-dure itself, must be very high. For an outline of current hybridisation protocols see figure 1.The hybridisation conditions must be carefully chosen and controlled to prevent interaction of probes with DNA regions other than the target sequences. Most centromeric DNA probes available are highly specific and do not require extensive precautions to prevent cross- hybridisation. Chances on aspecific crosshybridisation rise with increasing probe length, because of interspersed repetitive sequences, which are shared by other chromosomes. To achieve the desired staining contrast, these repeated sequences are blocked by adding unlabelled DNA (human genomic DNA, Cot I DNA) to the probe mixture.

Pitfalls in the interpretation of FISH signals in embryonic nuclei: The evaluation of FISH results in single embryonic nuclei requires strict criteria, as the reference population (remainder of the nuclei available for analysis) is very small or not even available for analysis in case of a subsequent embryo transfer. An additional drawback in the analysis of nuclei from preimplantation embryos is the fact that internal standards are absent, since the genomic constitution of the various cells 
within one embryo is not known at the time of analysis. Especially in the case of polypronucleate embryos, where abnormal chromosome copy numbers and chromosomal mosaicism are to be expected (Coonen et al., 1994b), interpretation of the FISH data needs to be performed with great care. Also others have shown that the occurrence of numerical aberrations and/or mosaic chromosome patterns is an important confounder in the analysis of FISH data (Lomax et al., 1994).

Efficient hybridisation should result in a number of signals as expected on the basis of the number of pronuclei seen after fertilization. It is known, however, that asynchronous or delayed pronuclear formation occurs in $25 \%$ of embryos, initially classified as monopronucleate (Staessen et al., 1993). Secondly, vacuoles are occasionally misidentified as pronuclei (Van Blerkom et al., 1987). It is therefore not always reliable to deduce chromosomal ploidy from the number of pronuclei present. Various factors may influence the ISH pattern and the subsequent interpretation of the signals. The number of hybridisation signals can be under-estimated as a result of signal fusion, caused by co-localisation of homologous DNA sequences in interphase nuclei. Even though occurring at low frequency, attention should be paid in this respect to possible differences in signal size and signal intensity within one nucleus. Apparent over-representation of chromosomes may be erroneously concluded from the occurrence of so called 'split-spots'. These are separated, but closely linked signals on both chromatids, located in the centromeric region of a chromosome (Cremer et al., 1988; Hopman et al., 1988). Again, signal size and localisation may indicate this phenomenon. When using cosmid probes, the presence of 'doublets', duplicated signals as a result of DNA replication during the cell cycle, could further complicate the interpretation of the signal copy number (Matsumura et al., 1992; Selig et al., 1992). FISH studies on human lymphocytes have shown that the percentage of apparently monosomic cells in normal individuals ranges from 5 to $10 \%$, whereas the frequency of apparently trisomic cells is lower than $1 \%$ (Eastmond and Pinkel, 1990). It is therefore unlikely that the presence of supernumerical signals is due to FISH artefacts, provided that the quality of the FISH is high. Extrapolation of these data to embryonic cells would establish a low limit for the detection of trisomy or triploidy in these cells. Detection of loss of DNA material from human blastomeres, indicated by the loss of hybridisation signals is some-what more complicated but is improbable to be due to inefficient hybridisation, given a high hybridisation efficiency of the embryonic nuclei and a low percentage of aberrant (diploid) control cells, (Coonen et al., 1994b). Nevertheless, apparent monosomy due to inefficient hybridisation can never be totally precluded, although the simultaneous application of multiple probes will drastically decrease the chance on an incorrect interpretation of the data.

\subsection{Genomic constitution of human preimplantation embryos}

The introduction of in vitro fertilization (IVF) treatment has created the possibility to investigate human gametes and zygotes. The confluence of evolving assisted reproductive technologies and the development of highly specific molecular and genetic techniques allows the investigation of embryos at the earliest stages of development for the presence of disease-related chromosomal changes. By such 
means, preimplantation diagnosis of inherited disease offers selective transfer of unaffected embryos. However, extensive knowledge on the genomic constitution of human gametes and preimplantation embryos is a prerequisite for a reliable diagnosis.

Initially, most studies on human gametes and embryos were performed by karyotyping. During ensuing years, also PCR and (F)ISH techniques were applied. Although information on the genomic constitution of human gametes and embryos obtained by (F)|SH is accumulating rapidly, it can not be discussed without relating it to the knowledge derived from other techniques. The relevant literature published to date on the investigation of preimplantation embryos by karyotyping and $(\mathrm{F}) \mathrm{ISH}$ is summarised in tables 1 and 2 , respectively.

Table 1. overview of literature using cytogenetic analysis to study the genomic constitution of human preimplantation embryos

embryo stage

$5-12$ cell meta/inter

2-8 cell meta/inter

2-8 cell meta

1-3 cell meta

2-8 cell meta

2-12 cell meta

1cell-blast meta

1-7 cell meta

oocytes, $2-8$ cell meta

various stages meta

various stages meta

8 cell meta

oocytes

oocytes

4-8 cell meta

1 cell-morula meta

oocytes

oocytes; 1 cell-blast

oocytes

2-6 cell meta

oocytes

2-8 cell meta

various stages meta

1-8 cell meta technique

karyotyping and DNA measurement karyotyping and DNA measurement karyotyping

karyotyping

karyotyping

karyotyping

karyotyping

ploidy assessment

karyotyping and ploidy assessment

karyotyping

karyotyping

karyotyping

karyotyping

karyotyping

ploidy assessment

karyotyping and ploidy assessment

karyotyping

karyotyping

ploidy assessment

ploidy asssessment

karyotyping

ploidy assessment

karyotyping

karyotyping reference

Angell et al., 1983

Angell et al., 1986

Michelmann et al., 1986

Kola et al., 1987

Plachot et al., 1987

Wramsby et al., 1987

Angell et al., 1988

Macas et a., 1988

Plachot et al., 1988

Wimmers et al.,1988

Papadopoulos etal., 1989

Ma et al., 1990

Macas et al., 1990

Angell et al., 1991

Bongso et al., 1991b

Martin-Pont et al., 1991

Selva et al., 1991

Edirisinghe et al., 1992

Gras et al., 1992

Pieters et al., 1992

Angell et al., 1993

Staessen et al., 1993

Jamieson et al., 1994

Pellestor et al., 1994 
Table 2. overview of literature using ISH to study the genomic constitution of human* preimplantation embryos

embryo stage

various stages ${ }^{1}$ meta $^{2} /$ inter $^{3}$ various stages meta/inter

2 cell-blast meta/inter

2 cell-blast meta/inter

2 cell-blast meta/inter

4-8 cell' meta/inter

1-5 cell inter

$1-8$ cell meta/inter

various stages inter

4-7 cell metalinter

1 cell-blast inter

morula-blast inter

6-8 cell inter

$1-8$ cell inter

$1-8$ cell inter

1-15 cell inter

2 cell-blast inter

1 cell-blast ${ }^{1}$ inter

2-9 cell inter

1-10 cell inter

5-12 cell inter

6-10 cell inter

$1-5$ cell inter

1.8 cell inter

1-8 cell inter technique

pretreatment

no. targets probe(s)

meth/acid ${ }^{4}$

meth/acid

meth/acid

meth/acid

meth/acid

meth/acid

meth/acid

meth/acid;protK ${ }^{7}$

meth/acid;protk

meth/acid;protk

meth/acid

ethan/acid ${ }^{10}$

meth/acid;protk

meth/acid

meth/acid

meth/acid

meth/acid;protK

HCl-Tw ${ }^{13}$;pepsin

HCl-Tw;pepsin

HCL-Tw;pepsin

HCl-Tw;pepsin

$\mathrm{HCl}$-Tw;pepsin

HCl-Tw;pepsin

meth/acid

meth/acid

\begin{tabular}{ll} 
single target & $Y$ \\
single target & $Y$ \\
single target & $Y$ \\
single target & $Y$ \\
single target & $Y$ \\
single target & $3 ; X$ \\
single target & $Y$ \\
single target & $1 ; Y$ \\
single target & $X ; Y$ \\
double target & $X, Y$ \\
double target & $X, Y$ \\
single target & $X ; Y ; 18$ \\
double target & $X, Y$ \\
triple target & $X, Y, 8$ \\
double target & $X, Y$ \\
multi target & $X, Y, 18,13 / 21$ \\
single target & 18 \\
double target & $X, Y$ \\
double target & $X, Y$ \\
triple target & $11^{\mathrm{P}}, 11^{\mathrm{c}}, 11^{\natural}$ \\
double target & $\mathrm{X}, \mathrm{Y}$ \\
double target & $\mathrm{X}, \mathrm{Y} ; 1,17$ \\
double target & $\mathrm{X}, \mathrm{Y}$ \\
triple target & $\mathrm{X}, \mathrm{Y}, 18$ \\
triple target & $\mathrm{X}, \mathrm{Y}, 18$ \\
& \\
\hline
\end{tabular}

ligand/label

efficiency"

reference

${ }^{3} \mathrm{H}$

${ }^{3} \mathrm{H}$

${ }^{3} \mathrm{H}$

${ }^{3} \mathrm{H} /$ bio $^{6}$

bio

bio

bio

sulfone

bio

bio/dig ${ }^{8}$

bio/dig

bio

bio/dig

fluorochrome

fluorochrome

dig/fluorochrome

bio

bio/dig

bio/dig

bio/dig/fluorochrome

fluorochrome

fluorochrome

fluorochrome

fluorochrome

fluorochrome not given Jones et al., 1987

not given Jones et al., 1987

$n c^{5} \quad$ West et al., 1987

nc West et al., 1988

nc Penketh et al., 1989

not given Grifo et al., 1990

not given Grifo et al., 1990

not given Pieters et al., 1990

nc

$83 \%^{9}$

not given

not given

$95 \%{ }^{11}$

$88 \%^{12}$

$99 \%$

$99 \%$

$95 \%$

$95 \%$

$93 \% \%^{12}$

$60 \%{ }^{14}$

$93 \%{ }^{12}$

$92 \%^{12}$

$83 \%^{12}$

$95 \%{ }^{12}$

$87 \%{ }^{12}$
Griffin et al., 1991

Griffin et al. 1992

Balakier et al., 1993

Benkhalifa etal., 1993

Delhanty et al., 1993

Munné et al.,1993a

Munné et al., 1993b

Munné et al., 1993c

Schrurs et al., 1993

Coonen et al., 1994a

Coonen et al., 1994b

Coonen et al., 1994c

Harper et al., 1994a

Harper et al., 1994b

Harper et al., 1994c

Munné et al., $1994 a$

Munné et al., 1994b

Legend to the table;" unless indicated otherwise; "* efficiency per sucessfully spread nucleus; ${ }^{1}$ mouse embryos; ${ }^{2}$ metaphase; ${ }^{3}$ interphase;

${ }^{4}$ methanol/acetic acid $3: 1 ;{ }^{5}$ not calculable on basis of only $\mathrm{Y}$ or $\mathrm{X}$-specific probe; ${ }^{6}$ biotin; ${ }^{7}$ proteinase $\mathrm{K} ;{ }^{8}$ digoxigenin; ${ }^{9}$ efficiency for interphase nuclei; ${ }^{10}$ ethanol/acetic acid $2: 1 ;{ }^{11}$ efficiency per embryo; ${ }^{12}$ efficiency per nucleus, from fixing upto and including hybridisation; ${ }^{13} 0.01 \mathrm{~N} H C l / 0.1 \%$ Tween 20; ${ }^{14}$ efficiency per nucleus for single copy probes 

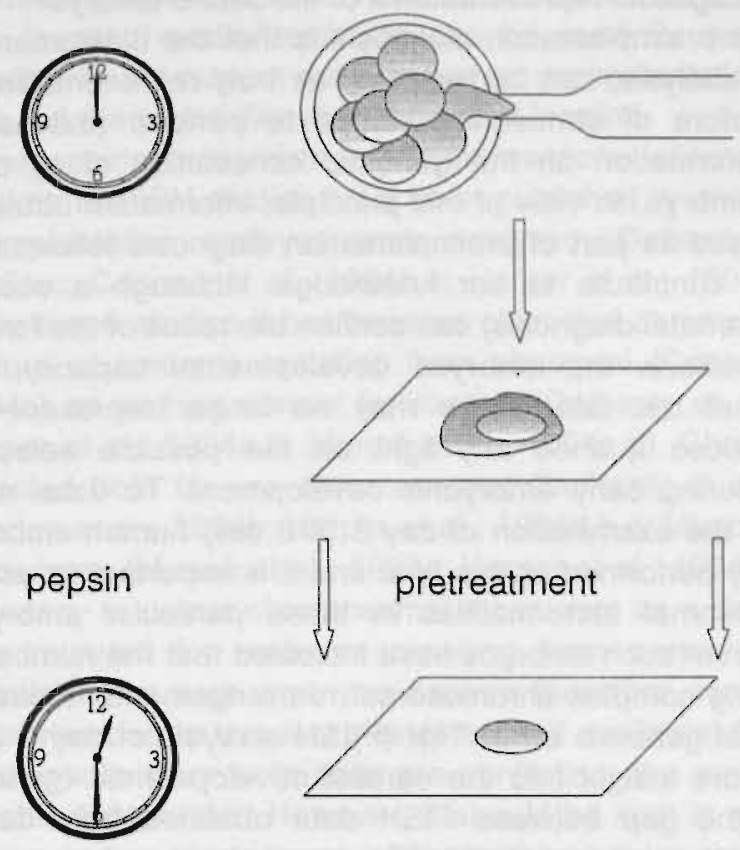

$\left\{\begin{array}{l}\text { denaturation } \\ \text { and } \\ \text { hybridisation }\end{array}\right.$

[3 wash procedure ] $\sqrt{1}$

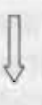

blastomere biopsy day 3 embryo

spreading

$\mathrm{HCl}$-Tween20 or

fixation

methanol:acetic acid

\section{RNAse}

proteinase $\mathrm{K}$

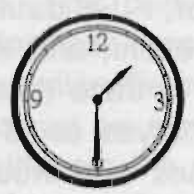

$\int \begin{aligned} & \text { immunocytochemical } \\ & \text { detection }\end{aligned}$

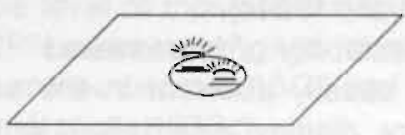

wash procedure
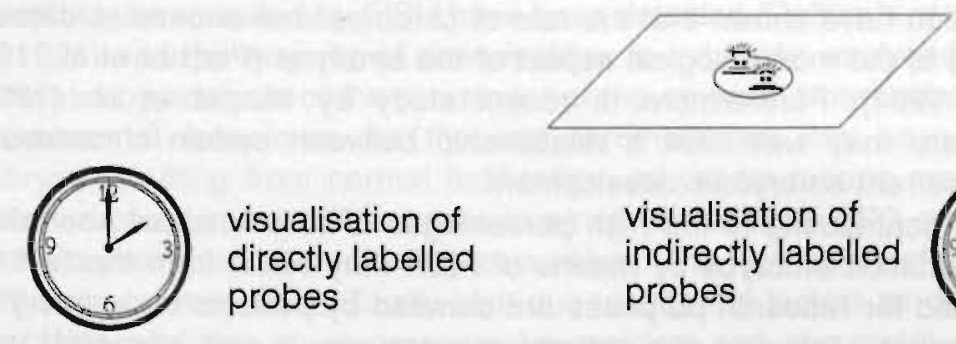

visualisation of directly labelled probes

visualisation of indirectly labelled probes

figure 1. outline of hybridisation protocols: After biopsy, blastomeres are spread on a glass slide and pretreated with a proteolytic enzyme. Nuclear and probe DNA are denatured and slides are left to hybridise. After a washing procedure and, if necessary, an immunocytochemical detection of formed hybrids, slides can be examined. 
Are blastomeres analysed for diagnosis representatitive of the whole embryo?

The most crucial assumption in preimplantation diagnosis is that the blastomere(s) removed from the embryo for analysis, can be regarded as truly representative of the whole embryo. It is therefore of utmost importance to perform (extensive) feasibility studies to collect information on the genomic constitution of all cells present in one and the same embryo. In view of this principle, information obtained from a few blastomeres, analysed as part of preimplantation diagnosis followed by embryo transfer, does hardly contribute to our knowledge. Although a second analysis at a later stage (e.g. prenatal diagnosis) can confirm the result of the former and an ongoing pregnancy reflects the embryos developmental capacity, the embryonic material analysed at this later stage may no longer represent the preimplantation embryo, nor does it shed any light on the possible selection mechanisms that take place during early embryonic development. To date, most FISH studies have focused on the examination of day 3 (4-8 cell) human embryos as the embryo biopsy is usually performed at this time and it is important to ascertain the incidence of chromosomal abnormalities in these particular embryos. However, FISH data obtained from such embryos have indicated that the number of cells present, and each showing complex chromosomal rearrangements, makes it difficult to trace (back) the initial genomic error. The (F)ISH analysis of day 2 (2-4 cell) embryos could provide more insight into the earliest developmental (genetic) processes and would fill up the gap between FISH data obtained from day 3 embryos and karyotyping data obtained from (un)fertilized oocytes.

The need for analysis of all blastomeres to warrant a complete understanding of early developmental processes imposes upon the procedures for embryo spreading and hybridisation. It has recently been shown that embryo spreading with $0.01 \mathrm{~N}$ $\mathrm{HCL} / 0.1 \%$ Tween 20 (Coonen et al., 1994a) in combination with FISH using (directly labelled) DNA probes is a very efficient approach (Coonen et al., 1994b; Harper et al., 1994a,b,c) and is sensitive enough to permit the detection of unique DNA sequences in embryonic nuclei (Coonen et al., 1994c).

Extemal factors that may cause genomic instability of blastomeres

Embryos used for research analysis are usually aberrant in the sense that they exhibit morphological abnormalities and/or display retardation in cleavage after fertilization. Studies on the morphology of human embryos in relation to their genomic constitution have shown that the rate of chromosomal anomalies detected is strongly related to the morphological aspect of the embryos (Plachot et al., 1988; Pellestor et al., 1994). Furthermore, a recent study by Munné et al. (1993c) indicated that there may well exist a relationship between certain chromosomal anomalies and aberrant embryonic development.

Additional factors contributing to the high percentages of chromosomal aberrations found in preimplantation embryos by means of FISH may result from the fact that most embryos used for research purposes are donated by patients undergoing IVF for infertility treatment. Moreover, the patients average age is well advanced when compared to the maternal age in the general population. Although there exists no consistency in data available from the literature concerning chromosomal abnormalities in relation to maternal age (reviewed by Zenzes and Casper,1992; Angell et al., 1993), studies by Plachot et al. (1988) and Macas et al. (1990) support the hypothesis that aneuploidy shows an increased incidence in oocytes of older women. 
Transfer and/or cryopreservation of the best embryos obtained after IVF implies that only 'second quality' embryos can be used for research. It is as yet not known whether or not current data on human preimplantation embryos are biassed by that fact, but the possibility should be kept in mind.

\section{Chromosomal mosaicism in human preimplantation embryos}

To date few ISH studies have been published in which virtually all cells from human preimplantation embryos were analysed (Delhanty et al., 1993; Munné et al., 1993b,c; Coonen et al., 1994b,c; Harper et al., 1994a,b,c; Munné et al., 1994a,b). From these studies it has become clear that chromosomal mosaicism is a common feature of embryos resulting from abnormal (Coonen et al.,1994b; Harper et al., 1994c) as well as normal fertilization (Delhanty et al., 1993; Munné et al., 1993c; Harper et al., 1994a,b; Munné et al., 1994a,b). Chromosomal mosaicism has been detected both for sex chromosomes (Delhanty et al., 1993; Munné et al., 1993c; Coonen et al., 1994b; Harper et al., 1994a,b,c; Munné et al., 1994a,b) as well as for autosomes (Munné et al., 1993c; Harper et al., 1994b; Munné et al., 1994a,b).

An assay to detect chromosomal mosaicism as a decisive parameter for transfer is only relevant for embryos resulting from normal fertilization. The detection of mosaicism in such embryos causes therefore concern and for that reason it is recommended to use two blastomeres (if available) for preimplantation diagnosis. In case results from both cells are conflicting, the embryo should not be considered suitable for transfer. However, it should be kept in mind that, although the analysis of one or two blastomeres of the embryo under consideration for transfer may not reveal any mosaicism, chromosomal heterogeneity in the remaining cells can never be totally excluded. Though initial studies have been performed, we feel that the genomic constitution of embryos resulting from normal fertilization has as yet not been studied sufficiently to conclude that the one or two blasto-meres removed from the embryo for analysis are truly representative of the whole embryo.

The few studies that have been performed on 2PN embryos for research purposes indicate that the level of mosaicism detected is high, ranging from $43 \%$ (autosomes 1 and 17) in 2PN embryos of good morphology (Harper et al., 1993b) to $70 \%$ (sex chromosomes and autosomes $13 / 21$ and 18) in abnormally developing monospermic embryos (Munné et al., 1993c).

Also during preimplantation sex determination chromosomal mosaicism and aneuploidy as revealed by FISH have been detected (Delhanty et al., 1993; Griffin et al., 1994) and the majority of abnormalities found in the analysed blastomeres was confirmed by analysis of the remainder of the embryo. Notwithstanding the fact that chromosomal mosaicism for the sex chromosomes has been demonstrated in embryos resulting from normal fertilization, as yet no reports are known about the presence of a female $(X X)$ nucleus in an otherwise male $(X Y)$ embryo, which could lead to a preimplantation misdiagnosis of sex. The high levels of mosaicism found in $2 \mathrm{PN}$ embryos may be artificially high due to external factors as described above.

Most data available on chromosomal mosaicism and aneuploidy in preimplantation embryos are derived from karyotyping studies of oocytes and preimplantation embryos (for references see table 1). However, the quality of chromosomes obtained from embryonic cells is usually very poor and chromosome plates are seldomly obtained from more than a few cells per embryo. The incomplete data obtained by karyotyping can therefore not be used as a standard for comparison with the data 
obtained by ISH. Although information provided by karyotyping studies is fragmentary as far as the number of cells investigated is considered, it does give a detailed view of the chromosomal constitution of those blastomeres that could be succesfully analysed. From these studies it has become clear that nuclei of preimplantation embryos, arising from tripronuclear zygotes, display a variety of chromosomal complements (Angell et al., 1986; Michelmann et al., 1986; Kola et al., 1987; Plachot et al., 1989; Pieters et al., 1992). They include 1) complete triploidy in all cells after regular division, 2) gross abnormalities in all cells due to chaotic chromosome movement after multipolar spindle division, 3) cell subpopulations with either a haploid or a diploid chromosomal content because of extrusion of a haploid nucleus during the first cleavage division, and 4) cell subpopulations with a diploid or a triploid chromosomal content as a result of extrusion of a haploid nucleus during the first cleavage division and subsequent incorporation in one of the two nuclei. FISH studies performed on nuclei of embryos resulting from abnormal fertilisation revealed mostly mosaic chromosome complements (Coonen et al., 1994b; Harper et al., 1994c).

The incidence of chromosomal anomalies in spontaneous abortions or live births after IVF is not as high as would be expected on basis of the level of chromosomal abnormalities found in preimplantation embryos. There are several explanations for this phenomenon. Firstly, chromosomal aberrations could lead to a failure of the embryo to implant, thus not leading to a viable pregnancy. Secondly, chromosomal aberrations that do not affect the preimplantation embryo, could be lethal in early postimplantation developmental stages. Thirdly, if few chromosomally abnormal cells are present in an otherwise normal embryo, they may develop at a slower rate than the normal cells or may be even excluded from further cell division in later embryonic development. Finally, selection mechanisms could occur to influence the fate of embryonic cells upon partition of the inner cell mass and the embryo proper during blastocyst formation (James and West., 1994).

Anucleate and multinucleate blastomeres in preimplantation embryos

Apart from the occurrence of chromosomal mosaicism in human preimplantation embryos, the presence of multinucleated or anucleated blastomeres could hamper a reliable preimplantation diagnosis based on FISH. Blasto-meres with an abnormal number of nuclei are readily found in preimplanta-tion embryos. About $17 \%$ of all 2 to 4 cell embryos resulting from normal fertilization contain at least one binucleate blastomere, increasing to $65 \%$ at the 9 to 16 cell stage (Hardy et al., 1993). Photocytometric measurement of the total cellular DNA content of multinucleated human blastomeres re-vealed that they contain DNA levels consistent with a diploid DNA content (Winston et al., 1993). Munné et al. (1993b) reported the presence of multinucleated human blastomeres in about one-third of human embryos arrested following cleavage in vitro. FISH analysis of these blastomeres revealed that, although in $95 \%$ of the embryos in which multinucleated blastomeres were analysed the sex of these blastomeres corresponded with that of the entire embryo, the number of sex chromosomes per multinu-cleated blastomere and their distribution varied greatly among the different nuclei, thereby indicating their unsuitability for aneuploidy diagnosis at the preimplantation stage. The incidence of anucleate blastomeres in embryos resulting from normal fertilization has also been reported high, especially in embryos of poor morphology (Hardy et al., 1993). In case that an 
anucleate blastomere is removed from the embryo for analysis, no information will be obtained on the genomic constitution of the embryo and another blastomere will need to be removed and subsequently analysed. It is therefore extremely important to be sure that a mononucleated cell is used for analysis. The spreading method using $\mathrm{HCl} /$ Tween 20 , developed for embryonic nuclei to be analysed by FISH (Coonen et al., 1994a), allows a continuous survey of the blastomere and provides certainty about the presence and number of nuclei.

\subsection{Objectives of this thesis}

The aim of the underlying study was:

To improve the efficiency and reproducibility of standard ISH procedures on gametes and embryonic cells

To improve the sensitivity of the developed ISH procedures to enable implementation of more advanced ISH technologies, in particular the use of DNA probes specific for unique sequences, for the genetic analysis of gametes and preimplantation embryos

To condense the ISH procedure in such a way that preimplantation diagnosis can be performed within one day

To gain insight into the degree of genomic heterogeneity displayed by human embryos, applying newly developed ISH procedures. This would provide information whether blastomeres, removed from the embryo for preimplantation diagnosis, reflect the genomic make-up of the embryo in general 


\subsection{References}

Angell RR, Aitken RJ, van Look PFA, Lumsden MA \& Templeton AA (1983) Chromosome abnormalities in human embryos after in vitro fertilization. Nature 303:336-338

Angell RR, Templeton AA \& Messinis IE (1986) Consequences of polyspermy in man. Cytogen Cell Genet 42:1-7

Angell RR, Sumner AT, West JD, Thatcher SS, Glasier AF \& Baird DT (1987)Post-fertilizati on polyploidy in human preimplantation embryos fertilized in- vitro. Hum Reprod 2:721-727

Angell RR (1988) Chromosome anomalies in early human embryos. J Reprod Fertil Suppl 36:73-81

Angell RR, Ledger W, Yong EL, Harkness L \& Baird DT (1991) Cytogenetic analysis of unfertilized oocytes. Hum Reprod 6:568-573

Angell RR, Xian J, \& Keith J (1993) Chromosomal anomalies in human oocytes in relation to age. Hum Reprod 8:1047-1054

Angell RR (1994) Possible pitfalls in preimplantation diagnosis of chromosomal disorders based on polar body analysis. Hum Reprod 9:181-182

Balakier H, Squire J \& Casper RF (1993) Characterization of abnormal one pronuclear human oocyets by morphology, cytogenetics and in-situ hybridization. Hum Reprod 8 : $402-408$

Benkhalifa M, Janny L, Vye P, Malet P, Boucher D \& Menezo $Y$ (1993) Assessment of polyploidy in human morulae and blastocysts using co-culture and fluorescent in-situ hybridization. Hum Reprod 8:895-902

Bongso A, Ng SC, Fong ChY \& Ratnam S (1991a) Cocultures: a new lead in embryo quality improvement for assisted reproduction. Fertil Steril 56:179-191

Bongso A, Ng SC, Lim J, Fong ChY \& Ratnam S (1991b) Preimplantation genetics: chromosomes of fragmented human embryos. Fertil Steril 56:66-70

Brambati B (1993) Genetic disorders: methods of avoiding the birth of an affected child. Hum Reprod Update 11:1983-2000

Braude PR, Bolton VN \& Moore, S (1988) Human gene expression first occurs between the four- and eight-cell stages of preimplantation development. Nature 332:459-461

Braude PR, Monk M, Pickering SJ, Cant A \& Johnson MH (1989) Measurement of HPRT activity in the human unfertilized oocyte and pre-embryo. Prenatal Diagnosis 9:839-850

Buster JE, Busillo M, Rodi IA, Cohen SW, Hamilton M, Simon JA, Thorneycroft IH \& Marshall SR (1985) Biologic and morphologic development of donated human ova recovered by non-surgical uterine lavage. Am J Obstet Gynecol 153:211-217

Carson SA, Smith AL, Scoggan JL \& Buster JE (1991) Superovulation fails to increase human blastomere yield after uterine lavage. Prenat Diagn 11:513-522

Chong SS, Cota J, Hardikar SD, Handyside AH \& Hughes MR (1993) Preimplantation diagnosis of $X$-linked disease: reliable and rapid sex determination of single human cells by restriction site analysis of simultaneously amplified ZFX and ZFY sequences. Hum Mol Genet 2 1183-1185 
Coonen E, Dumoulin JCM, Ramaekers FCS \& Hopman AHN (1994a) Optimal preparation of preimplantation embryo interphase nuclei for analysis by fluorescent in situ hybridisation. Hum Reprod 3:533-537

Coonen E, Harper JC, Ramaekers FCS, Delhanty JDA, Hopman AHN, Geraedts JPM \& Handyside AH (1994b) Presence of chromosomal mosaicism in abnormal preimplantation embryos detected by fluorescent in situ hybridisation. Human Genetics 94:609-615

Coonen E, Martini E, deDie-Smulders CEM, Ramaekers FCS, Geraedts JPM \& Hopman AHN (1994c) FISH using region-specific DNA probes for preimplantation diagnosis. Hum Reprod 9 suppl 4:30

Coutelle C, Williams C, Handyside AH, Hardy K, Winston RML \& Williamson R (1989) Genetic analysis of DNA from single human oocytes: a model for preimplantation diagnosis of cystic fibrosis. Brit Med J 299:22-24

Cremer T, Tesin D, Hopman AHN \& Manuelidis L (1988) Rapid interphase and metaphase assessment of specific chromosomal changes in neuroectodermal tumor cells by in situ hybridization with chemically modified DNA probes. Exp Cell Res $178: 199-220$

Dauwerse JG, Wiegant J, Raap AK, Breuning MH \& Ommen van GJB (1992) Multiple colors by fluorescence in situ hybridization using ratio-labelled DNA probes create a molecular karyotype. Hum Mol Gen 1:593-598

Delhanty JDA, Griffin DK, Handyside AH, Harper JC, Atkinson GHG, Pieters MHEC \& Winston RML (1993) Detection of aneuploidy and chromosomal mosaicism in human embryos during preimplantation sex determination by fluorescent in situ hybridisation, (FISH). Hum Mol Genet 2:1183-1185

Devilee P, Thierry RF, Kievits T, Rukmini K, Hopman AHN \& Huntington W (1988) Detection of chromosome aneuploidy in interphase nuclei from human primary breast tumors using chromosome-specific repetitive DNA probes.Cancer Res 48:5825-5830

Dokras A, Sargent IL, Ross C, Gardner RL \& Barlow DH (1990) Trophectoderm biopsy in human blastocysts. Hum Reprod 5:821-825

Eastmond DA \& Pinkel D (1991) Detection of aneuploidy and aneuploidy-inducing agents in human lymphocytes using fluorescence in situ hybridization with chromosome-specific DNA probes. Mutat Res 234:303-318

Edirisinghe WR, Murch AR \& Yovich JL (1992) Cytogenetic analysis of human oocytes and embryos in an in-vitro fertilization programme. Hum Reprod 7:230-236

Edwards RG \& Hollands P (1988) New advances in human embryology: implications of the preimplantation diagnosis of genetic disease. Hum Reprod 3: 549-556

Gall JG \& Pardue ML (1969) Formation and detection of RNA-DNA hybrid molecule in cytological preparations. Proc Natl Acad Sci USA 63:378-383

Gras L, McBain J, Trounson A \& Kola I (1992) The incidence of chromosomal aneuploidy in stimulated and unstimulated (natural) uninseminated human oocytes. Hum Reprod 7:13961401

Griffin DK, Handyside AH, Penketh RJ, Winston RM \& Delhanty JD (1991) Fluorescent insitu hybridization to interphase nuclei of human preimplantation embryos with $X$ and $Y$ chromosome specific probes. Hum Reprod 6:101-105 
Griffin DK, Wilton LJ, Handyside AH, Winston RML \& Delhanty JDA (1992) Dual fluorescent in situ hybridisation for simultaneous detection of $X$ and $Y$ chromosome-specific probes for the sexing of human preimplantation embryonic nuclei. Hum Genet 89:18-22

Griffin DK, Handyside AH, Harper JC, Wilton LJ, Atkinson G, Soussis I, Wells D, Kontogianni E, Tarin J, Geber S, Ao A, Winston RML \& Delhanty JDA (1994) Clinical experience with preimplantation diagnosis of sex by dual fluorescent in-situ hybridisation. $J$ Ass Reprod Gen in press

Grifo JA, Boyle A, Fischer E, Lavy G, DeCherney AH, Ward DC \& Sanyal MK (1990) Preembryo biopsy and analysis of blastomeres by in situ hybridization. Am J Obstet Gynecol 163:2013-2019

Grifo JA, Boyle A, Tang YX \& Ward DC (1992a) Preimplantation genetic diagnosis. In situ hybridization as a tool for analysis. Arch Pathol Lab Med 116:393-397

Grifo JA, Tang YX, Cohen J, Gilbert F, Sanyal MK \& Rosenwaks Z (1992b) Pregnancy after embryo biopsy and coamplification of DNA from $X$ and $Y$ chromosomes.J Am Med Assoc 6:727-729

Handyside AH, Pattinson JK, Penketh RJ, Delhanty JD, Winston RM \& Tuddenham EG (1989) Biopsy of human preimplantation embryos and sexing by DNA amplification. Lancet 1:347-349

Handyside AH, Kontogianni EH, Hardy K \& Winston RML (1990) Pregnancies from biopsied human pre-implantation embryos sexed by $Y$-specific DNA amplification. Nature 344:768770

Handyside AH, Lesko JG, Tarin JJ, Winston RML \& Hughes MR (1992) Birth of a normal girl after in vitro fertilization and preimplantation diagnostic testing for cystic fibrosis. $N$ Engl $J$ Med 327:905-909

Handyside AH \& Delhanty JDA (1993) Cleavage stage biopsy of human embryos and diagnosis of $X$-linked recessive disease. In Preconception and preimplantation diagnosis of human genetic disease. RG Edwards (ed) Cambridge, Cambridge University Press, pp239-270

Hardy K, Martin KL, Leese HJ, Winston RML \& Handyside AH (1990) Human preimplantation development is not adversely affected by biopsy at the 8-cell stage. Hum Reprod 5:708-714

Hardy K (1991) Development of the human blastocysts in vitro. In: Bavister B (ed) Preimplantation embryo development. Springer-Verlag. New York pp

Hardy K, Winston RML \& Handyside AH (1993) Binucleate blastomeres in preimplantation human embryos in vitro: failure of cytokinesis during early cleavage. J Reprod Fertil 98:549-558

Harper JC, Coonen E, Ramaekers FCS, Delhanty JDA, Handyside AH, Winston RML \& Hopman AHN (1994a) Identification of the sex of human preimplantation embryos in two hours using an improved spreading method and fluorescent in-situ hybridization (FISH) using directly labelled probes. Hum Reprod 4:721-724

Harper JC, Coonen E, Handyside AH, Winston RML, Hopman AHN\& Delhanty JDA (1994b) Detection of sex chromosome and autosome mosaicism in normally fertilised preimplantation human embryos (Prenatal Diagnosis, in press)

Harper JC, Robinson F, Duffy S, Griffin DK, Handyside AH, Delhanty JDA \& Winston RML (1994c) Detection of fertilisation in embryos with accelerated cleavage by fluorescent in situ hybridisation (FISH) (submitted) 
Hassold T, Hunt PA \& Sherman S (1993) Trisomy in humans: incidence, origin and etiology. Curr Opin Genet Dev 3:398-403

Holding C \& Monk M (1989) Diagnosis of beta-thalassaemia by DNA amplification in single blastomeres from mouse preimplantation embryos. Lancet ii :532-535

Hopman AHN, Ramaekers FCS, Raap AK, Beck JLM, Devilee P. Ploeg van der M \& Vooijs GP (1988) In situ hybridization as a tool to study numerical chromosome aberrations in solid bladder tumors. Histochemistry 89:307-316

James RM \& West JD (1994) A chimaeric animal model for confined placental mosaicism. Hum Genet 93:603-604

Jamieson ME, Coutts JRT \& Connor JM (1994) The chromosome constitution of human preimplantation embryos fertilized in vitro. Hum Reprod 9:709-715

John H, Bimstiel ML \& Jones KW (1969) RNA-DNA hybrids at the cytological level. Nature 223:578-582

Jones KW, Singh L \& Edwards RG (1987) The use of probes for the $Y$ chromosome in preimplantation embryo cells. Hum Reprod 2:439-445

Kola I, Trounson A, Dawson G \& Rogers P (1987) Tripronuclear human oocytes: altered cleavage patterns and subsequent karyotypic analysis of embryos. Biol Reprod 37:395401

Kristjansson K, Chong SS, Van den Veyver IB, Subramanian S, Snabes MC \& Hughes MR (1994) Peimplantation single cell analyses of dystrophin gene deletions using whole genome amplification. Nat Gen 6:19-23

Kwok S \& Higuchi R (1989) Avoiding false positives with PCR. Nature 339:237-238

Li A, Gyllensten UB, Cui X, Saiki RK, Erlich HA \& Amheim M (1988) Amplification and analysis of DNA sequences in single human sperm and diploid cells. Nature 335:414-419

Lichter P, Boyle AL, Cremer T\& Ward DC (1991) Analysis of genes and chromosomes by nonisotopic in situ hybridization. GATA 8:24-35

Liu J, Lissens W, Devroey P, Van Steirteghem AC \& Liebaers I (1992) Efficiency and accuracy of polymerase-chain-reaction assay for cystic fibrosis allele delta F508 in single cell. Lancet 339:1190-1192

Liu J, Lissens W, Devroey P, Liebaers \& Van Steirteghem AC (1993) Efficiency of polymerase chain reaction assay for cystic fibrosis in single human blastomeres according to the presence or absence of nuclei. Fertil Steril 59:815-819

Liu J, Lissens W, Devroey P, Steirteghem AC \& Liebaers I (1994) Amplification of X- and Ychromosome-specific regions from single human blastomeres by polymerase chain reaction for sexing of preimplantation embryos. Hum Reprod:716-720

Lomax BL, Kalousek DK, Kuchinka BD, Barrett IJ, Harrison KJ \& Safavi H (1994) The utilization of interphase cytogenetic analysis for the detection of mosaicism. Hum Genet 93:243-247

Ma S, Kalousek DK, Zouves C, Yuen BH, Gomel V \& Moon YS (1990) The chromosomal complements of cleaved human embryos resulting from in vitro fertilization. $J$ In Vitro Fert Embryo Transf 7:16-21 
Macas E, Suchanek E, Grizelj V, Puharic I \& Simunic V (1988) Chromosomal preparations of human triploid zygotes and embryos fertilized in vitro. Eur J Obstet Gynecol Reprod Biol 29:299-304

Macas E, FloersheimY, Hotz E, Imthurn B, Keller PJ \& Walt H (1990) Abnormal chromoso mal arrangements in human oocytes. Hum Reprod 5:703-707

Manuelidis L, Langer-Safer PR \& Ward DC (1982) High-resolution mapping of satellite DNA using biotin-labeled DNA probes. J Cell Biol 95 619-625

Martin-Pont B, Selva J, Bergere M, Fillion C, Hugues JN, TamboiseA \&Tamboise E (1991) Chromosome analysis of multipronuclear human oocytes after in vitro fertilization. Prenat Diagn 11:501-507

Matsumura K, Kallioniemi A, Kallioniemi O, Chen L, Smith HS, Pinkel D, Gray J \& Waldman FM (1992) Deletion of chromosome 17p loci in breast cancer cells detected by fluorescen ce in situ hybridization Cancer Res 52:3474-3477

Mettler L \& Michelmann,H.W. (1985) Chromosome studies of early human embryos: proof of fertilization in uncleaved human oocytes. Ann NY Acad Sci 442:458-465

Michelmann HW, Bonhoff A \& Mettler L (1986) Chromosome analysis in polyploid human embryos. Hum Reprod 1:243-246

Monk M, Handyside AH, Hardy K, \& Wittingham D (1987) Preimplantation diagnosis of deficiency of hypoxanthine phosphoribosyl transferase in a mouse model for Lesch-Nyhan syndrome. Lancet ii:423-425

Morsy M, Takeuchi K, Kaufmann R, Veeck L, Hodgen GD \& Beebe SJ (1992) Preclinical models for human pre-embryo biopsy and genetic diagnosis. II. Polemerase chain reaction amplification of deoxribinucleic acid from single lymfoblasts and blastomeres with mutation detection. Fertil Steril 57:431-438

Muggleton-Harris AL, Glazier AM \& Pickering SJ (1993) Biopsy of the human blastocyst and polymerase chain reaction (PCR) amplification of the B-globin gene and a dinucleotide repeat motif from 2-6 trophevtoderm cells. Hum Reprod 8:2197-2205

Munné S, Weier UH, Stein J, Grifo J \& Cohen J (1993a) A fast and efficient method for simultaneous $X$ and $Y$ in situ hybridization of human blastomeres. J Assist Reprod Genet $10: 82-90$

Munné S \& Cohen J (1993b) Unsuitability of multinucleated human blastomeres for preimplantation genetic diagnosis. Hum Reprod 8:1120-1125

Munné S, Lee A, Rosenwaks Z, Grifo J \& Cohen J (1993c) Diagnosis of major aneuploidies in human preimplantation embryos. Hum Reprod 8:2185-2191

Munné S, Alikani M \& Cohen J (1994a) Monospermic polyploidy and atypical embryo morphology. Hum Reprod 9:506-510

Munné S, Grifo J \& Weier H-UG (1994b) Chromosome abnormalities in human arrested preimplantation embryos: a multiple-probe FISH study. Am J Hum Gen 55:150-159

Papadopoulos G, Templeton AA, Fisk N \& Randall J (1989) The frequency of chromosome anomalies in human preimplantation embryos after invitro fertilization. Hum Reprod 4:91-98

Pellestor F, Dufour M-C, Arnal F \& Humeau C (1994) Direct assessment of the rate of chromosomal abnormalities in grade IV human embryos produced by in-vitro fertilization procedure. Hum Reprod 9:293-302 
Penketh RJ, Delhanty JD, van-den-Berghe JA, Finklestone EM, Handyside AH, Malcom S \& Winston RM (1989) Rapid sexing of human embryos by non-radioactive in situ hybridization: potential for preimplantation diagnosis of X-linked disorders. Prenat Diagn 9:489-499

Pickering SJ, McConnell JM, Johnson MH \& Braude PR (1992) Reliability of detection by polymerase chain reaction of the sickle cell-containing region of the beta-globin gene in single human blastomeres. Hum Reprod 7:630-636

Pieters MHEC, Geraedts JPM, Meyer H, Dumoulin JC, Evers JL, Jongbloed RJ, Nederlof PM \& van-der-Flier S (1990) Human gametes and zygotes studied by nonradioactive in situ hybridization. Cytogent Cell Genet 53:15-19

Pieters MHEC, Dumoulin JD, Ignoul-Vanvuchelen RC, Bras M, Evers JL \& Geraedts JPM (1992) Triploidy after in vitro fertilization: cytogenetic analysis of human zygotes and embryos. J Assist Reprod Genet 9:68-76

Plachot M, Junca A-M, Mandelbaum J, de Grouchy J, Salat-Baroux J \& Cohen J (1987) Chromosome investigations in early life. II. Human preimplantation embryos. Hum Reprod 2:29-35

Plachot M, de-Grouchy J, Junca AM, Mandelbaum J, Salat-Baroux J \& Cohen J (1988) Chromosome analysis of human oocytes and embryos: does delayed fertilization increase chromosome imbalance? Hum Reprod 3:125-127

Plachot M, Mandelbaum J, Junca A-M, de Grouchy J, Salat-Baroux J \& Cohen J (1989) Cytogenetic analysis and developmental capacity of normal and abnormal embryos after IVF. Hum Reprod 4 suppl:99-103

Plachot M \& Crozet N (1992) Fertilization abnormalities in human in-vitro fertilization. Hum Reprod 7 suppl 1:89-94

Sheardown SA, Findlay I, Turner A, Greaves D, Bolton VN, Mitchell M, Layton DM \& Muggleton-Harris AL (1992) Preimplantation diagnosis of a human B-globin transgene in biopsied trophectoderm celis and blastomeres of the mouse embryo. Hum Reprod 7:1297-1303

Schrurs BM, Winston RM \& Handyside AH (1993) Preimplantation diagnosis of aneuploidy using fluorescent in-situ hybridization: evaluation using a chromosome 18-specific probe. Hum Reprod 8:296-301

Selig S, Okumura K, Ward DC \&Cedar H (1992) Delineation of DNA replication time zones by fluoresence in situ hybridization. EMBO J 11:1217-1225

Selva J, Martin-Pont B Hugues JN, Rince P, Fillion C, Herve F, Tamboise A \& Tamboise E (1991) Cytogenetic study of human oocytes uncleaved after in-vitro fertilization. Hum Reprod 6:709-713

Sermon K, Nijs M, Lissens W, van Steirteghem AC \& Liebaers I (1991) B-N-acetylhexosa minidase activity in mouse oocytes and preimplantation embryos. Hum Reprod 6:280-283

Sermon K, Lissens W, Tarlatzis B, Braude PR, Devroey P, van Steirteghem AC \& Liebaers I (1992) B-N-acetylhexosa minidase activity in human oocytes and preimplantation embryos. Hum Reprod 7:1278-1280

Staessen C, Janssenswillen C, Devroey P \& Van Steirteghem AC (1993) Cytogenetic and morphological observations of single pronucleated human oocytes after in-vitro fertilization. Hum Reprod 8:221-223 
Strom CM, Verlinsky Y, Milayeva S, Evsikov S, Cieslak J, Lifchez A, ValleJ,Moise J, Ginsberg N \& Applebaum M (1990) Preconception genetic diagnosis of cystic fibrosis. Lancet 336:306-307

Strom CM, Rechitsky S \& Verlinsky Y (1991) Reliability of gender determination using the polymerase chain reaction (PCR) for single cells. J In Vitro Fert Embryo Transfer 8:225-229

Tarin JJ, Conaghan J, Winston RML \& Handyside AH (1992) Human embryo biopsy on the 2nd day after insemination for preimplantation diagnosis: removal of a quarter of embryo retards cleavage. Fertil Steril 5:970-976

Tarin JJ \& Handyside AH (1993) Embryo biopsy strategies for preimplantation diagnosis. Fertil Steril 59:943-952

Tarkowski AK (1966) An air drying method for chromosome preparations from mouse eggs. Cytogenetics 5:0394-400

Tkachuk DC, Pinkel D, Kuo W-L, Weier H-U \& Gray JW (1991) Clinical applications of fluorescence in situ hybridization. GATA 8:67-74

Van Blerkom J, Bell H \& Henry G (1987) The occurrence, recognition and development of pseudo-multipronuclear eggs after in-vitro fertilization of human oocytes. Hum Reprod 2:217-225

Varawalla NY, Dokras A, Old JM, Sargent IL \& Barlow DH (1991) An approach to preimplan tation diagnosis of beta-thalassaemia. Prenat Diagn 11:775-785

Verlinsky Y, Rechitsky S, Evsikov S, White M, Cieslak J, Lifchez A, Valle J, Moise J \& Strom $\mathrm{CM}$ (1992) Preconception and preimplantation diagnosis for cystic fibrosis. Prenat Diagn 12:103-110

West JD, Angell RR, Thatcher SS, Gosden JR, Hastie ND, Glasier AF \& Baird D (1987) Sexing the human pre-embryo by DNA-DNA in-situ hybridisation. Lancet 2:1345-1347

West JD Gosden JR, Angell RR, West KM, Glasier AF, Thatcher SS \& Baird DT (1988) Sexing whole human pre-embryos by in-situ hybridization with a Y-chromosome specific DNA probe. Hum Reprod 3:1010-1019

West JD, West KM \& Aitken RJ (1989) Detection of Y-bearing spermatozoa by DNA-DNA in situ hybridisation. Mol Reprod Dev 1:201-207

Wimmers MS \& Van-der-Merwe JV (1988) Chromosome studies on early human embryos fertilized in vitro. Hum Reprod 3:894-900

Winston NJ, Johnson MH \& Braude PR (1993) Assessment of the cellular DNA content of whole mounted mouse and human oocytes and blastomeres containing single or multiple nuclei. Zygote 1:17-25

Wramsby H, Fredga K \& Liedholm P (1987) Ploidy in human cleavage stage embryos after fertilization in vitro. Hum Reprod 2:233-236

Zenzes MT \& Casper RF (1992) Cytogenetics of human oocytes, zygotes, and embryos after in vitro fertilization. Hum Genet 88:367-375 


\title{
Nonisotopic in situ hybridisation as a method for nondisjunction studies in human spermatozoa
}

\author{
Edith Coonen, Math HEC Pieters, John CM Dumoulin, Henk Meyer, \\ Johannes LH Evers, Frans CS Ramaekers \& Joep PM Geraedts
}

Molecular Reproduction and Development, 28:18-22 1991

Human spermatozoa were studied with a nonradioactive in situ hybridisation method. Using a chemically modified DNA probe and immunocytochemical reactions for visualization, it was possible to obtain hybridisation signals in 31 of 32 semen samples. Positive hybridisation reactions, depending on cell accessibility, varied from $40 \%$ to over $90 \%$ for the different samples. Using a chromosome 1-specific DNA probe, disomy for this chromosome was found in $0.67 \%$ of all accessible sperm cells.

\subsection{Introduction}

Since its first introduction in 1969 (Gall and Pardue, 1969; John et al., 1969), the in situ hybridisation (ISH) technique has been used to localize specific (i.e., target) DNA sequences in interphase and metaphase nuclei from many different cell types. Because of the poor microscopic resolution and the long exposure time needed, radiolabelled probes were replaced by biotinylated probes (Langer et al., 1981) and autoradiography by fluorescence visualization of the formed (DNA-DNA) hybrids (Manuelidis et al., 1982). Aneuploidy studies of human spermatozoa have been performed in different ways, but only few ISH results have been described. Negative ISH (Joseph et al., 1984) might have resulted from nonaccessibility of the spermatozoa, which is influenced by nucleus condensation and disulphide links between nucleoprotein chains in nuclear chromatin (Bedford et al., 1972). From both studies mentioned above, treatment with dithiotreitol (DTT) proved to be necessary.

Successful attempts of ISH on ejaculated spermatozoa were reported by Burns et al. (1985) and Jones et al. (1987), who studied in situ hybridisation with $Y$ chromosome-specific probes in somatic cells and preimplantation embryonic cells, respectively. 
The present paper summarizes the results of a nonisotopic ISH method that was carried out on semen samples from a series of normal partners of in vitro fertilization (IVF) patients. Although there is considerable heterogeneity between and within semen samples the method used gives reproducible nonradioactive ISH results (Pieters et al., 1990).

\subsection{Materials \& methods}

Material used for this study was obtained from a series of 32 normal healthy men who participated in an IVF program for non-male indications. Spermatozoa were washed three times in PBS and the remaining sperm pellet was fixed in a small volume of methanol:glacial acetic acid (3:1). Sperm cells were diluted until the concentration was approximately 150 cells per microscopic field of view (magnification $x 400$ ). Following final dilution in fixative the sperm cell suspension was dropped onto clean dry slides and air dried.

\section{Labelling of DNA probes and visualization of the specific hybrids}

Labelling of DNA probes was performed with the Chemiprobe kit (FMC BioProducts, Amstelstad bv. Zwanenburg). This procedure is based on a transamination reaction resulting in a sulfone group on the cytosine moieties (Budowsky et al., 1972). To visualize the labelled (DNA-DNA) hybrids, a specific mouse monoclonal antiserum was used. This was followed by a second immunocytochemical reaction with an immunoglobulin conjugate (antimouse IgG fluorescein isothyocyanate, Sigma) giving a bright fluorescence spot at the site of the primary immune reaction.

\section{Pre-hybridisation treatment}

Slides were washed in 2 XSSC to remove the remainders of fixative, dehydrated through an ethanol series $(70 \%-90 \%-100 \%)$ and air dried. To make sperm nuclei accessible to the probes slides were incubated for 5-20 $\mathrm{min}$ in $25 \mathrm{mM}$ DTT in $0.1 \%$ trypsin (Difco). After incubation with DTT, slides were washed twice in $2 \times S S C$ and again dehydrated through an ethanol series and air dried (Jones et al., 1987).

\section{Hybridisation}

For the experiments described in this paper, the DNA probe pUC 1.77, specific for the centromeric region of chromosome 1 , was used. The probe represents a $1.77 \mathrm{~kb}$ cloned EcoRI fragment of human satellite III DNA (Cooke and Hindley, 1979) and was a generous gift of Howard Cooke. Before denaturation $5 \mu$ l of labelled probe ( 5 $\mathrm{ng} / \mu \mathrm{l}$ in a hybridisation mixture of $60 \%$ formamide in $2 \times S S C$ ) was applied to the slide and covered with a $18 \times 18 \mathrm{~mm}$ coverslip. Probe and target DNA on the slides were denatured simultaneously for $5 \mathrm{~min}$ on a $80^{\circ} \mathrm{C}$ hot plate, after which the slides were transferred immediately to a $37^{\circ} \mathrm{C}$ moist chamber for overnight hybridisation. 


\section{Posthybridisation treatment}

Posthybridisation treatment and visualization of the target DNAs was performed as described previously (Pieters et al., 1990). Counterstaining of cells was performed with propidium iodide ( $\mathrm{Pl} ; 1 \mu \mathrm{g} / \mathrm{ml})$.

\section{Microscopic examination}

The slides were examined with a Leitz fluorescence microscope (magnification $\mathrm{x}$ 1.000).Positive hybridisation signals appeared as yellow-green spots, whereas the rest of the spermatozoa appeared red. To establish the percentage of positive cells 1.000 sperms were scored after at random selection. To obtain information on disomic and diploid cells, 1.000 positive sperm were screened for the presence of more than one hybridisation spot. Sperm heads showing clear size differences were assumed to be diploid.

\subsection{Results}

Slide preparations from ejaculated human spermatozoa of 32 healthy men with normal semen parameters (table 1) were investigated.

Table 1. Semen parameters of 32 investigated men

\begin{tabular}{lll}
\hline Parameter & Mean & Range \\
\hline & & \\
Volume $(\mathrm{ml})$ & 4.1 & $0.8-9.5$ \\
Conc. $\left(\times 10^{6} / \mathrm{ml}\right)$ & 114 & $20-300$ \\
Percent motile & 45 & $30-75$ \\
MNSD & 38.7 & $7.2-145.6$
\end{tabular}

a MSD motile normal sperm density (Glazener et al., 1987)

Duration of DTT treatment appeared to be an important factor for successful in situ hybridisation and had to be determined for each individual. On every semen sample a time series (5-10-15 min.) was performed, and, on the basis of the visible result (figure 1), the best DTT time was chosen. Optimization of the treatment duration was obtained by a second time series starting with the DTT time from the first series plus or minus 1,2 , and $3 \mathrm{~min}$. In one case a DTT time of 19 minutes appeared to be optimal. Results are summarized in figure 2 . Omission of pretreatment left the spermheads morphologically unaltered, and no fluorescence signal (as a reflection of a successful ISH) could be observed. Overtreatment with DTT caused lysis of spermatozoa, and after ISH only fluorescence grains could be observed, which were scattered all over the morphologically indistinct sperm heads. Therefore, the optimal DTT time was a compromise between the number of unaltered cells (undertreat- 
ment) and the number of destroyed spermatozoa (overtreatment). Only DTT treatment between 6 and 19 min gave analyzable results (figure 3a). One of the 32 cases investigated showed no positive signs of hybridisation (table 2).

Table 2. ISH scores of 32 men investigated

\begin{tabular}{|c|c|c|c|}
\hline \multirow[b]{2}{*}{ Subject } & \multirow[b]{2}{*}{$\begin{array}{l}\text { Percentage of } \\
\text { positive cells }\end{array}$} & \multicolumn{2}{|c|}{ Aneuploidy(\%) } \\
\hline & & Disomy & Diploidy \\
\hline $\begin{array}{l}01 \\
02 \\
03 \\
04 \\
05 \\
06 \\
07 \\
08 \\
09 \\
10 \\
11 \\
12\end{array}$ & $\begin{array}{l}63 \\
63 \\
61 \\
59 \\
76 \\
89 \\
64 \\
71 \\
65 \\
59 \\
64 \\
39\end{array}$ & $\begin{array}{l}1.0 \\
0.6 \\
0.9 \\
0.9 \\
0.6 \\
0.9 \\
0.8 \\
0.6 \\
0.4 \\
0.5 \\
0.4 \\
0.9\end{array}$ & $\begin{array}{l}0.3 \\
0.3 \\
0.3 \\
0.2 \\
0.3 \\
0.3 \\
0.3 \\
0.6 \\
0.2 \\
0.2 \\
0.6 \\
0.3\end{array}$ \\
\hline $\begin{array}{l}14 \\
15 \\
16 \\
17 \\
18 \\
19 \\
20 \\
21 \\
22 \\
23 \\
24 \\
25 \\
26 \\
27 \\
28 \\
29 \\
30 \\
31 \\
32\end{array}$ & $\begin{array}{l}64 \\
73 \\
60 \\
57 \\
62 \\
64 \\
80 \\
70 \\
65 \\
62 \\
76 \\
57 \\
60 \\
70 \\
55 \\
67 \\
56 \\
52 \\
64\end{array}$ & $\begin{array}{l}0.2 \\
0.6 \\
0.3 \\
0.8 \\
0.3 \\
0.6 \\
0.8 \\
0.8 \\
1.3 \\
0.2 \\
1.2 \\
0.8 \\
0.5 \\
0.6 \\
0.5 \\
0.9 \\
0.9 \\
0.5 \\
0.6\end{array}$ & $\begin{array}{l}0.2 \\
0.2 \\
0.3 \\
0.5 \\
0.6 \\
0.6 \\
0.4 \\
0.0 \\
0.0 \\
0.5 \\
0.3 \\
0.3 \\
0.5 \\
0.2 \\
0.3 \\
0.3 \\
0.6 \\
0.3 \\
0.3\end{array}$ \\
\hline Average & 64 & 0.67 & 0.33 \\
\hline
\end{tabular}

- No ISH could be achieved 

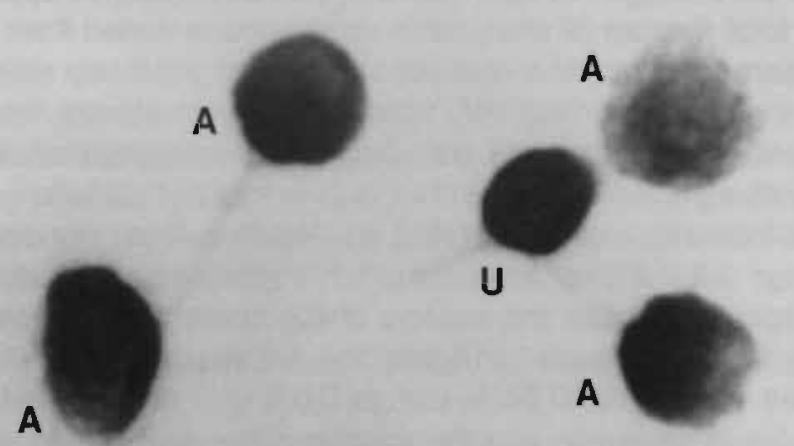

U

A

\section{A}

o

Figure 1. Morphology of spermatozoa after DTT treatment. A; accessible $\mathrm{U}$; undertreatment $\mathbf{O}$; overtreatment

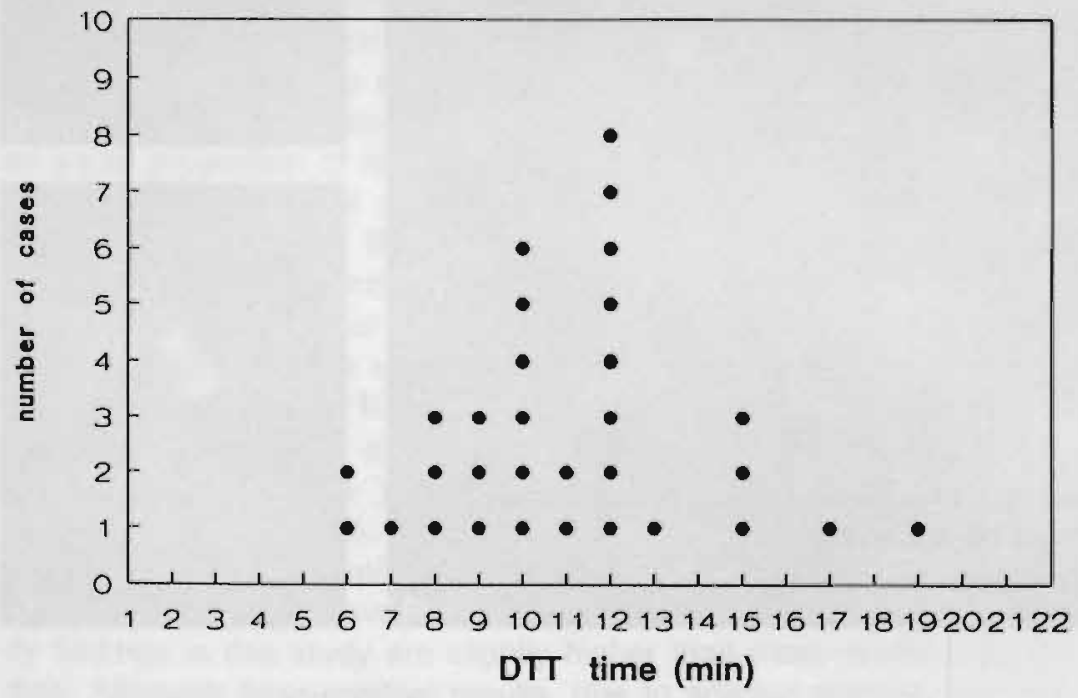

Figure 2. Distribution of DTT time among cases (") 
The percentages of spermatozoa with fluorescence spots calculated on the basis of the total number of analyzable spermatozoa varied from $40 \%$ to $90 \%$ for the different semen samples. The real percentages of positively stained spermatozoa in relation to the total number of accessible spermatozoa are underestimated because spermatozoa that were morphologically unaltered or destroyed were regarded as negatively stained. More than one in situ hybridisation signal of roughly equal size and intensity was interpreted as resulting from nondisjunction. A mean of $0.67 \%$ (range $0.2-1.3 \%$ ) of all successfully hybridised spermatozoa showed two fluorescence spots, whereas the volume of the sperm head appeared normal, indicating disomy for chromosome 1 (figure $3 b$ ). No spermatozoa with more than two spots were found. A mean of $0.33 \%$ (range $0.0-0.6 \%$ ) of all spermatozoa counted showed two fluorescence spots, and the volume of the spermhead was clearly increased, probably indicating diploid sperm cells (figure $3 \mathrm{c}$ ).

To detect intra-individual differences, the homogeneity of the results was evaluated with the $x^{2}$ method. For the percentages of positive cells and disomy and diploidy cells, the respective means were used as expectations. The summated $x^{2}$ values were $39.0,3.3$, and 2.4 respectively $(\mathrm{df}=30$ ). This means that the data can be regarded as homogeneous.
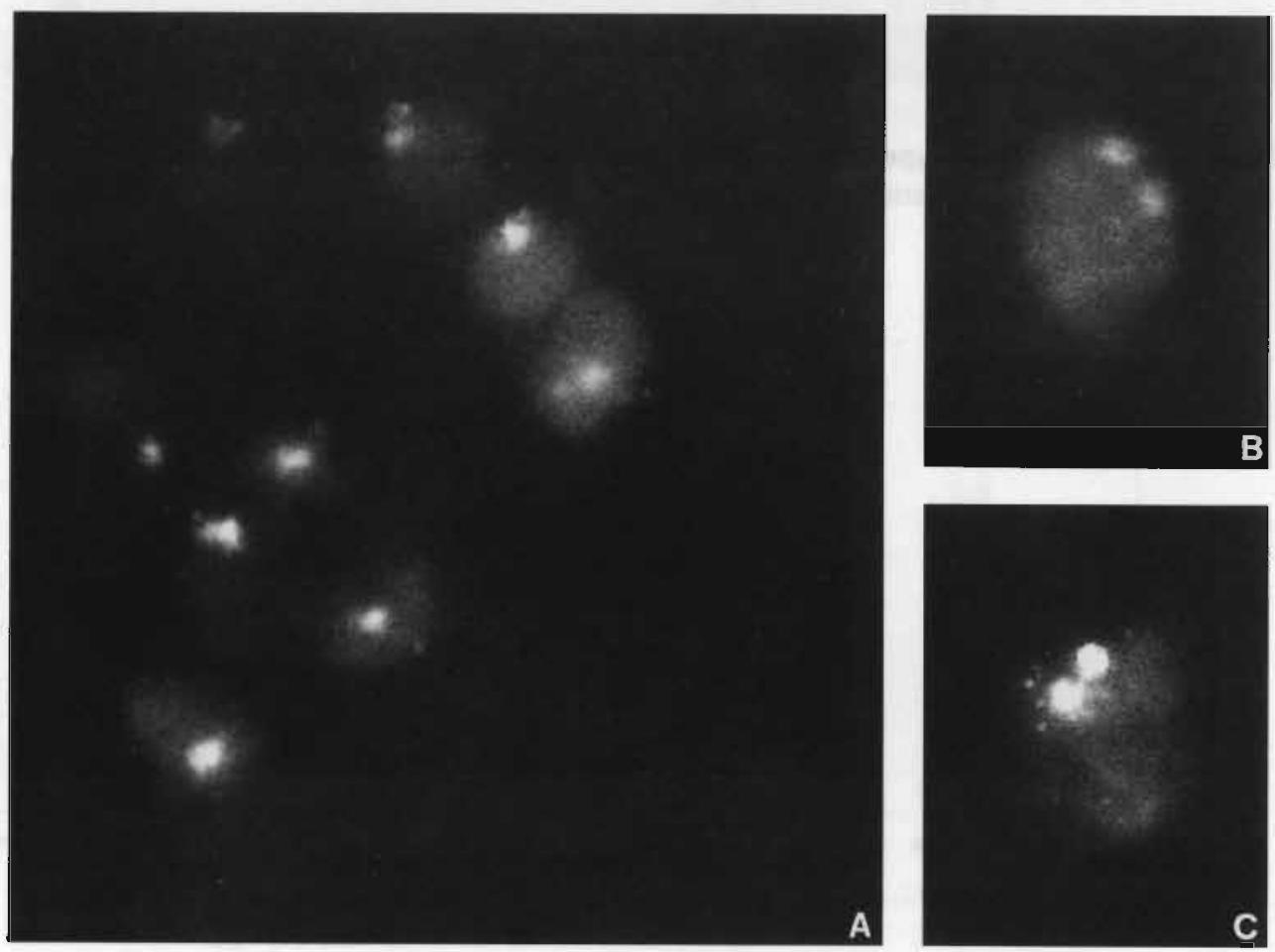

Figure 3. Human spermatozoa after in situ hybridisation with pUC 1.77. a; one fluorescence spot in every sperm cell b; two spots in a normal sperm, indicating disomy $c$; two spots in a large sperm cell, indicating diploidy 


\subsection{Discussion}

The total procedure takes only about $24 \mathrm{hr}$ whereas an autoradiographical method can take between 1 week and 3 months (Joseph et al., 1984). Therefore, the nonisotopic ISH method presented here provides a reasonable alternative to overcome one of the major disadvantages of autoradiographical detection. Furthermore, it is of great advantage that the use of radioisotopes is prevented. Only recently was it possible to perform ISH on ejaculated spermatozoa (Guttenbach and Schmid, 1990). Previous attempts were unsuccessful, probably because of the difficulty of making the sperm cells accessible for the DNA probes without destroying them completely. Bedford et al. (1972) stated that, while in the epididymis, human spermatozoa undergo chemical changes in the nucleus and surface membrane. The stabilization of the nuclear chromatin by establishment of -S-S- crosslinks between the nucleoprotein chains influences the accessibility. By treating the spermatozoa with DTT, the covalent disulphide links in the nuclear chromatin are reduced, providing a way for the DNA probes to contact the target DNA. Using the chromosome 1-specific probe, fluorescence signals could be generated in $40-90 \%$ of the counted spermatozoa. The variation in relative frequency of positively stained spermatozoa can be explained by the fact that sperm nuclei in the human ejaculate are at different stages of maturation and stability, which is reflected in a variable accessibility of the cells to the DNA probes. In cases of a low percentage of positively stained sperm cells, increasing the DTT treatment time did not result in a higher percentage of accessible sperm cells. The optimal time appeared to be variable, probably due to the biological heterogeneity of the ejaculated sperm samples. We have no explanation for the one case that remained negative. False negative results might be caused by an undertreatment (less than $6 \mathrm{~min}$.) or an overtreatment (more than $19 \mathrm{~min}$.) of the spermatozoa with DTT prior to hybridisa-tion. Under- or overtreatment in the negative case is unlikely since the sperm cells showed the same morphological features as those on the preparations with positive results. The proportion of nullisomic spermatozoa cannot be established directly, since the majority of cells will show no hybridisation for methodological reasons. However, it might be assumed that there is an equal proportion of nullisomic and disomic sperms. No relation could be found between the individual optimal DTT treatment time and the semen parameters summarized in table 1. Blocking aspecific immune reactions proved to be important in preventing false-positive results. Since it is possible to discriminate between spermatozoa with one or two (and more) spots, an indication is given of the percentage of aneuploidy in a semen sample. Two chromosome 1-specific spots (disomy) were observed in $0.67 \%$ of the sperm cells, which is about twice as high as was reported by Joseph et al. (1984) for chromosome $1(0.35 \%)$ and Guttenbach and Schmid $(1990)$ for the Y-chromosome $(0.27 \%)$. The mean percentage of diploid sperm cells was $0.33 \%$. This was based on the assumption that it is possible to establish the ploidy level from the head size, as indicated by Joseph et al. (1984). Individual aneuploidy levels did not differ significantly from the mean. The aneuploidy findings in this study are slightly higher than most results reported in other studies. Although false-positive results, due to artefact staining, can not be excluded, an explanation could be the unselected sperm cell analysis. Different investigations of human spermatozoa have revealed aneuploidy for chromosome 1 from $2 \%$ with 
less specific staining of heterochromatin (Geraedts and Pearson, 1973) to less than $0.1 \%$ in sperm penetrated zona-free hamster oocytes (Brandriff et al., 1986; Martin and Rademaker, 1990). Chromosome 1 disomic sperm are capable of oocyte penetration in vitro (Watt et al., 1987). It remains to be determined whether all aneuploid sperm cells are able to fertilize in vitro as well as in vivo.

Acknowledgements: The authors wish to thank Marijke Bras, Roselie Jongbloed and Wiel Debie for their technical assistance and Francis van der Lubbe for her excellent photography. This investigation has been supported by the foundation for Medical and Health Research Medigon (grant no. 900.504.067)

\subsection{Addendum}

In the last few years, several reports have described the use of the (F)ISH technique for analysis of the genomic constitution of human spermatozoa (Guttenbach et al., 1991; Han et al., 1992; Wyrobek et al., 1992; Han et al., 1993; Holmes et al., 1993; Martin et al., 1993; Robbins et al., 1993; Bischoff et al., 1994; Guttenbach et al., 1994; Miharu et al., 1994). On basis of these data, there seems not to be consensus on whether or not each chromosome has an equal probability for nondisjunction during spermatogenesis. This is also reflected by the various percentages of aneuploidy reported by these authors for individual chromosomes. However, even for the same chromosome studied by different groups, a fairly wide range in aneuploidy is found.

Sources of methodological variation among different studies include decondensation of the sperm DNA to increase probe accessibility, differences in hybridisation efficiency, inclusion of diploid cells in disomy rates, and the use of distinct evaluation criteria of scoring criteria (Miharu et al., 1994). Moreover, analysis is often performed on semen from only one or few donors of which it can not be excluded that they are predisposed to a higher or lower frequency of non-disjunction. Also, external factors, such as environmental pollution, exposure to chemicals or social behaviour may influence the aneuploidy ratios. Although the discrepancy in results can be partly explained, the sample to sample variation of the different methods used calls for a standard protocol, that can be routinely applied to any given sample.

With the rapid development of the (F)ISH technique, more complex applications to study spermatozoa have come within reach. At first, only single target (F)ISH was availably to investigate sperm cells. However, the use of such an approach single probe is limited in its application to study aneuploidy, especially with regard to the discrimination between diploid and disomic sperms. During ensuing years, multilabel hybridisation procedures were developed, providing an internal control for the accurate interpretation of (F)ISH signals. Recently, Martini et al. $(1994,1995)$ described a new approach for ISH in spermatozoa, making use of permanent enzymesubstrate precipitates to visualise the ISH signals, combined with a morphological staining to outline the whole spermatozoon, including the tail. By such means, it is possible to discriminate between disomic-, diploid-and abnormal spermatozoa and to recognize somatic cells present in the ejaculate, hence making an accurate estimation of chromosomal aneuploidy in spermatozoa possible. 
The frequency of chromosome abnormalities in human spermatozoa is estimated to be $10 \%$, with aneuploidy representing $3-4 \%$ (Martin et al., 1993). As the DNA of spermatozoa represents half the genome of a potential embryo, the application of a reliable and sensitive (F)ISH method to study such genomic abnormalities is of clear clinical relevance to human preimplantation diagnosis.

\subsection{References}

Bedford JM, Cooper GW \& Calvin HI (1972) Post meiotic changes in the nucleus and membranes of mammalian spermatozoa, in: Beatty RA, Glueck sohn- Waelsch S (eds): The genetics of the spermatozoan pp 69-89 (Edinburgh, NewYork)

Bischoff FZ, Nguyen DD, Burt KJ \& Shaffer, L.G. (1994) Estimates of aneuploidy using multicolor fluorescence in situ hybridization on human sperm. Cytogenet Cell Genet 66:237-243

Brandriff B, Gordon L, Ashworth LK, Watchmaker G \& Carrano AV (1986) Detection of chromosomal abnormalities in human sperm. In Ramel C, Lambert B, Magnisson J (eds): Genetic Toxicology of Environmental Chemicals Part B: Genetic Effects and Applied Mutagenesis New York: Alan R. Liss, Inc.. p 469

Budowsky EI, Sverdlov ED \& Monastyrskaya GS (1972) New method of selective and rapid modification of the cytidine residues. FEBS letters 25:201-204

Burns J, Chan VTW, Jonasson JA, Fleming KA, Taylor S \& McGee JO'D (1985) Sensitive system for visualising biotinylated DNA probes hybridised in situ: rapid sex determination of intact cells. J Clin Pathol 38:1085-1092

Cooke HJ \& Hindley J (1979) Cloning of human satellite III DNA: different components are on different chromosomes. Nucl Acids Res 6:3177-3197

Coonen E, Pieters MHEC, Dumoulin JC, Meyer H, Evers JL, Ramaekers FCS \& Geraedts JPM (1991) Nonisotopic in situ hybridization as a method for nondisjunction studies in human spermatozoa. Mol Reprod Dev 28:18-22

Gall JG \& Pardue ML (1969) Formation and detection of RNA-DNA hybrid molecules in cytological preparations. Proc Natl Acad Sci USA 63:378-383

Geraedts JPM \& Pearson PL (1973) Specific staining of the human chromosome No. 1 chromosome in spermatozoa. Humangenetik 20:171-173

Glazener CMA, Kelly NJ, Jane M, Weir A, David JSE, Cornes JS \& Hull MGR (1987) The diagnosis of male infertility-prospective time-specific study of conception rates related to seminal analysis and post-coital sperm-mucus penetration and survival in otherwise unexplained infertility. Hum Reprod 2:665-671

Guttenbach M \& Schmid M (1990) Determination of $Y$ chromosome aneuploidy in human sperm nuclei by nonradioactive in situ hybridisation. Am J Hum Genet 46:553-558 
Guttenbach M \& Schmid M (1991) Non-isotopic detection of chromosome 1 in human meiosis and demonstration of disomic sperm nuclei. Hum Genet 87:261-265

Guttenbach M, Schakowski R \& Schmid M (1994) Incidence of chromosome 18 disomy in human sperm nuclei as detected by nonisotopic in situ hybridization. Hum Genet93:421-423

Han TL, Webb GC, Flaherty SP, Correll A, Matthews CD \& Ford JH (1992) Detection of 17and $\mathrm{X}$-bearing human spermatozoa using fluorescence in situ hybridization. Mol Reprod Dev 33:189-194

Han TL, Ford JH, Webb GC, Flaherty SP, Correll A \& Matthews CD (1993) Simultaneous detection of $\mathrm{X}$ - and $\mathrm{Y}$-bearing human sperm by double fluorescence in situ hybridization. Mol Reprod Dev 34:308-313

Holmes JM \& Martin RH (1993) Aneuploidy detection in human sperm nuclei using fluore scence in situ hybridization. Hum Genet 91:20-24

John H, Bimstiel ML \& Jones KW (1969) RNA-DNA hybrids at the cytological level. Nature 223:578-582

Jones KW, Singh L \& Edwards RG (1987) The use of probes for the $Y$ chromosome in preimplantation embryo cells. Hum Reprod 2:439-445

Joseph AM, Gosden JR \& Chandley AC (1984) Estimation of aneuploidy levels in human spermatozoa using chromosome specific probes and in situ hybridization. Hum Genet 66:234-238

Langer PR, Waldrop AA \& Ward DC (1981) Enzymatic synthesis of biotin-labeled polynucle otides: novel nucleic acid affinity probes. Proc Natl Acad Sci USA 78:6633-6637

Manuelidis L, Langer-Safer PR \& Ward DC (1982) High-resolution mapping of satellite DNA using biotin-labeled DNA probes. J Cell Biol 95:619-625

Martin RH \& Rademaker A (1990) The frequency of aneuploidy among individual chromoso mes in 6821 human sperm chromosome complements. Cytogenet Cell Genet 53:103-107

Martin RH, Ko E \& Chan K (1993) Detection of aneuploidy in human interphase spermato zoa by fluorescence in situ hybridization (FISH). Cytogenet Cell Genet 64:23-26

Martini E, Speel E-JM, Coonen E, Ramaekers FCS, Geraedts JPM \& Hopman AHN (1994) New methodologies for ISH on chromosomal DNA in human spermatozoa. Hum Reprod 9 suppl 4:30

Martini E, Speel E-J M, Geraedts JPM, Ramaekers FCS \& Hopman AHN (1994) Multicolor brightfield microscopical detection of numerical aberrations in morphologically intact human sperm by means of in situ hybridization. (Human Reprod, in press)

Miharu N, Best RG \& Young, SR (1994) Numerical chromosome abnormalities in spermato zoa of fertile and infertile men detected by fluorescence in situ hybridization. Hum Genet 5:502-506 
Pieters MHEC, Geraedts JPM, Meyer H, Dumoulin JCM, Evers JLH, Jongbloed RJE, Nederlof PM \& van der Flier S (1990) Human gametes and zygotes studied by nonradioactive in situ hybridization. Cytogenet Cell Genet 53:15-19

Robbins WA, Segraves R, Pinkel D \& Wyrobek AJ (1993) Detection of aneuploid human sperm by fluorescence in sity hybridization: evidence for a donor difference in frequency of sperm disomic for chromosomes 1 and Y. Am J Hum Genet 52:799-807

Watt JL, Templeton AA, Messinis I, Bell L, Cunningham P \& Ducan RO (1987) Trisomy 1 in an eight cell human pre-embryo. J Med Genet 24:60-64

Wyrobeck AJ, Alhborn T, Balhorn R, Stanker L \& Pinkel D (1990) Fluorescence in situ hybridization to $Y$ chromosomes in decondensed human sperm nuclei. Mol Reprod Dev 27:200-208

Wyrobeck AJ, Weier H-U, Robbins W, Mehraein Y \& Pinkel D (1992) Detection of sexchromosomal aneuploidies in human sperm using two-color fluorescence in situ hybridizati on. Environ Mol Mutagen 19 Suppl 20:72 



\title{
Optimal preparation of preimplantation embryo interphase nuclei for analysis by fluorescence in situ hybridisation
}

\author{
Edith Coonen, John CM Dumoulin, Frans CS Ramaekers \\ \& Anton HN Hopman
}

Human Reproduction, 3:533-537 1994

\begin{abstract}
A new method was developed to prepare and isolate interphase nuclei from murine preimplantation embryos for analysis by fluorescence in situ hybridisation. Embryos were washed with Phosphate Buffered Saline and disaggregated in a small drop of bi-destilled water containing $\mathrm{HCl}$ and Tween20. During the disaggregation procedure embryos were watched continuously with an inverted micros-cope. Embryonic nuclei were digested with pepsin to make them accessible for hybridisation to the probes and to remove remnants of cytoplasm. Nuclear and probe DNA were denatured simultaneously and hybridisation was done overnight, followed by immunocytochemical detection of the probes. Using this method we were able to perform successful in situ hybridisation on all preimplantation stages of the mouse embryo (pronuclei, 2cell, 4-cell, morula and blastocyst). Probes for the $X$ and $Y$ chromosomes were applied for sex determination. From the results described in this paper we conclude that the preparation and isolation of interphase nuclei from murine embryos with acid and Tween 20 offers high reproducibility, good morphology of the cells and a high hybridisation efficiency.
\end{abstract}

\subsection{Introduction}

Advanced molecular genetic techniques, such as the polymerase chain reaction (PCR) and the in situ hybridisation (ISH) technique have found wide application in biomedical research and have offered the opportunity to study embryonic material for preimplantation diagnosis (Jones et al., 1987; West et al., 1987; Handyside et al., 1989; Grifo et al., 1990; Griffin et al., 1992). In one of the first reports Jones et al. (1987) succeeded in performing radioactive ISH with chromosome $\mathrm{Y}$-specific probes in human and murine blastocyst cells. West et al. (1987) reported the identification of male human pre-embryos with ISH using radioactively labelled probes for the $Y$ 
chromosome. Handyside et al. (1989) first applied PCR for sex determination of biopsied cells from human embryos (6-10 cells) using primers specific for the repeats on the long arm of chromosome $Y$. The outcome of the PCR procedure was compared to results obtained with ISH using a biotinylated probe for the $Y$ chromosome. Grifo et al. (1990), who performed single label fluorescence hybridisation on biopsied blastomeres from mouse embryos (4-8 cells) using probes for chromosome $X$ and chromosome 3 , also reported hybridisa-tion on a human 3-cell embryo with a $Y$-specific probe. The risk of misinterpretations with respect to the presence or absence of a $Y$ chromosome was partly overcome by Griffin et al. (1992), who performed ISH using $X$ and $Y$ dual label on single cells, originating from disaggregated 4-7 cell human embryos.

All studies mentioned above used methanol/acetic acid (3:1) fixed cells, which were often subjected to hypotonic swelling before fixation. This procedure suffers from frequent loss of cells and/or loss of cell morphology, thus decreasing reliability and reproducibility. In the case of preimplantation diagnosis, where the availability of material is limited and the reliability of the results should be as high as possible, this is a great disadvantage.

Here we present an alternative method to prepare and isolate interphase nuclei from preimplantation embryos. This new method offers high reproducibility, good morphology of cells and a high hybridisation efficiency.

\subsection{Materials \& methods}

\section{Embryos}

Murine embryos were obtained as described by Dumoulin et al. (1992). Briefly, oocytes of superovulated (C57BL/6 $\times$ DBA/2) F , hybrid female mice (Charles River Wiga, Sulzfeld, Germany) were fertilized in vitro with spermatozoa of CD1 male mice (Charles River Wiga). After appropriate culture periods in T6 medium (Quinn et al., $1985)$ the various developmental stages could be harvested; 1 cell zygotes containing 2 pronuclei after 10 to 12 hours, 2 cell embryos after 24 hours, 4 cell embryos after 2 days, morulae ( 8 or more cells) after 3 days and blastocysts after 5 days of culture, following the fertilization.

\section{Pretreatment}

Two different pretreatment methods were applied in order to test their effect on the efficiency of ISH in mouse embryonic nuclei:

1) Embryos were taken out from the T6 culture medium and incubated for 3-5 mins in distilled water, containing $500 \mathrm{IU} / \mathrm{ml}$ pronase E (Sigma, St Louis, USA) to remove the zona pellucida. Just before complete proteolysis of the zona pellucida embryos were returned to T6 medium. Embryos were then transferred with a minimal amount of T6 medium to a $10 \mu \mathrm{l}$ drop of PBS on a clean microscope slide. After about 5 mins the Phosphate Buffered Saline (PBS) was carefully removed and embryos were subsequently fixed with several drops of methanol:acetic acid (3:1). 
Slides were air dried,washed with PBS and dehydrated through an ascending ethanol series.

2) Embryos were removed from the T6 culture medium and washed in several changes of PBS for 5 to 10 minutes. After washing they were transferred with a minimal amount of PBS, using a small glass pipet, to a microdrop (1-2 $\mu$ l) of $0.01 \mathrm{~N}$ $\mathrm{HCl} / 0.1 \%$ Tween 20 in bidestilled water. During the whole procedure embryos were watched constantly using an inverted microscope. After 30 seconds to 2 minutes the zona pellucida began to desintegrate, followed by the cell membrane and the cytoplasm of the cells. Upon further digestion the nucleus, which was not affected, became clearly visible. Once all of the cytoplasm was removed the individual nuclei remained attached to the glass slides. Slides were air dried, washed with PBS and dehydrated through an ascending ethanol series.

\section{Mouse DNA probes}

Probe $X$ recognizes a $4.2 \mathrm{~kb}$, repeated DNA sequence located near the centromeric region of the $X$ chromosome. The probe was a generous gift of $C$. Disteche, Seattle, USA (Disteche et al., 1985).

Probe P17 is a M34 clone (insert $2.7 \mathrm{~kb}$ ) that recognizes the entire length of the $Y$ chromosome outside of the sex determining proximal region and was a generous gift of L. Singh, Hyderabad, India (Jones et al., 1987).

Telomere probe, specific for the telomeric region of all mammalian chromosomes (Oncor, Gaithersburg, USA)

The probes were labelled by nick translation, either with biotin-11-dUTP or digoxigenin-11-dUTP, and purified on a Sephadex G50 column.

\section{ISH procedure}

Embryonic cells, that were fixed in methanol/acetic acic $(3: 1)$ or treated with $0.01 \mathrm{~N}$ $\mathrm{HCl} / 0.1 \%$ Tween 20 were incubated for 20 minutes at $37^{\circ} \mathrm{C}$ with $100 \mu \mathrm{g} / \mathrm{ml}$ pepsin (Serva, Heidelberg, Germany) in $0.01 \mathrm{~N} \mathrm{HCl}$ to make nuclei accessible for hybridisation to the probes and to remove remnants of cytoplasm. After subsequent washes in bidestilled water and PBS, followed by 15 minutes fixation in $4 \%$ paraformaldehyde/PBS at $4{ }^{\circ} \mathrm{C}$, the slides were washed again with PBS and dehydrated through an ascending ethanol series. Mouse probes were hybridized in a mix, containing $50 \%$ formamide, $0.3 \mathrm{M} \mathrm{NaCl}: 30 \mathrm{mM}$ sodium citrate, $\mathrm{pH} 7.0$ (2xSSC), $10 \%$ dextran sulphate (Pharmacia, Uppsala, Sweden), $5 \mathrm{ng} / \mu \mathrm{l}$ yeast RNA (Sigma), $5 \mathrm{ng} / \mu \mathrm{l}$ herring sperm DNA (Sigma) and $1 \mathrm{ng} / \mu \mathrm{l}$ of the labelled DNA probe. This mix was applied to the slide and sealed under a coverslip with rubber cement. Nuclear and probe DNA were denatured simultaneously for 3 minutes at $75^{\circ} \mathrm{C}$ and hybridisation was allowed to take place overnight at $37^{\circ} \mathrm{C}$. Post hybridisation washing steps were as follows: $2 \times 5$ minutes with $50 \%$ formamide/ $2 \times S S C$ at $42{ }^{\circ} \mathrm{C}, 2 \times 5$ minutes with $2 \times S S C$ at $42{ }^{\circ} \mathrm{C}$ and $2 \times 5$ minutes with $4 \times S S C / 0.05 \%$ Tween 20 at room temperature. 
The single target ISH procedure was performed using biotinylated DNA probes, immunocytochemically detected using FITC-conjugated avidin (Vector Laboratories, California, USA) diluted $1: 200$ in $5 \%$ non fat dry milk/4xSSC. If necessary, immunological amplification was performed using biotin-labelled goat anti-avidin (Vector Laboratories) diluted $1: 100$ in $5 \%$ non fat dry milk/4xSSC, followed by a second layer of FITC-conjugated avidin.

For double target ISH reactions both biotin and digoxigenin labelled probes were used. Digoxigenin was immunocytochemically detected using monoclonal anti-digoxigenin (Sigma, dilution 1:350) in 5\% normal goat serum/PBS $/ 0.05 \%$ Tween 20 , followed by incubation with TRITC-conjugated rabbit anti-mouse (Sigma, dilution 1:100) in $5 \%$ normal goat serum/PBS $/ 0.05 \%$ Tween 20 . All incubation steps for the detection of biotin were followed by washing steps in $4 \times S S C / 0.05 \%$ Tween 20 and the digoxigenin detection steps by PBS $/ 0.05 \%$ Tween 20 . After the last washing steps slides were dehydrated and finally mounted in the anti-fading medium Vectashield (Vector) containing $1,25 \mathrm{ng} / \mathrm{ml}$ DAPI to counterstain the nuclei. Use of Vectashield strongly reduced bleaching as compared to anti-fading reagents such as DABCO (Sigma) and is important for an accurate analysis in preparations with only a few, single cells. Embryos were examined using a Zeiss Axiophot microscope and photographs were taken with a Zeiss camera using Kodak Tri-X-Pan 400 ASA film. The efficiency of the in situ hybridisation and of the immunocytochemical detection procedures was tested in each experiment on interphase nuclei obtained from ethanol fixed single cell suspensions of murine spleen. Using the conditions as described above, hybridisation efficiency was optimal and association of probes to minor binding sites was limited.

\subsection{Results}

Using the methanol:acetic acid fixation method we were able to perform successful single and double target ISH with probes for the $X$ and $Y$ chromosome in mouse embryo metaphase spreads as well as in fresh mouse blastocysts. Pre-fixation of blastocysts with $4 \%$ paraformaldehyde/PBS or storage of embryos in $70 \%$ ethanol reduced the hybridisation efficiency significantly (data not shown). In our hands the methanol:acetic acid fixation method could not be succesfully applied in mouse embryos consis-ting of four cells or less. When using the standard pretreatment protocols as described in the materials and methods section, the cytoplasm and nucleoplasm of these cells seemed insensitive to digestion with proteolytic enzymes, such as pepsin or proteinase $\mathrm{K}$. After hybridisation with a telomere-specific probe and immunocytochemical detection of hybrids, cells which were still partly covered with remaining cytoplasm showed autofluorescence and there were no signals in these areas of the cell. Parts of the cell that were free from cytoplasm however, showed relatively strong signals (figure 1b). Earlier experiments had shown that hybridisation with this telomere specific probe on isolated mouse spleen cells should give a random distribution of strong signals throughout the whole nucleus (data not shown). In the case of methanol:acetic acid fixed blastocysts it was not always possible to evaluate all nuclei separately and with the same efficiency, because treatment with pepsin or proteinase $K$ could not remove all of the cytoplasm. As a 
result cells could not be separated and the remaining cytoplasm often gave rise to autofluorescence as is seen in figure 1c. After stronger proteolytic treatment (proteinase $\mathrm{K} 10-20 \mu \mathrm{g} / \mathrm{ml}$ or pepsin $1-2 \mathrm{mg} / \mathrm{ml}$ ) the majority of the nuclei was lost since they were no longer anchored in the cytoplasm, while remaining nuclei exhibited a poor morphology. Application of dithiotreitol (DTT), which proved to be necessary for efficient hybridisation on human spermatozoa (Coonen et al., 1991) or a strong denaturing reagent as guanidine-thiocyanate did not result in any apparent improvement. For this reason other approaches were explored for the preparation of interphase nuclei from mouse embryos.

Using the alternative method, designated here as the acid/tween method, we were able to perform succesfull in situ hybridisation in mouse embryos of all preimplantation stages, including those with low cell numbers. Application of the acid/tween method under the microscope allowed us to monitor the lysis of embryonic cells and to survey the proces constantly. In this way we were able to see how many nuclei emerged from the bulk of cytoplasm and could keep track of the individual nuclei resulting from one embryo. As soon as an embryo became compacted at the morula stage or the cell number was so large that cell boundaries of every individual cell could no longer be distinguished (blastocyst), accurate counting of nuclei after spreading was no longer possible because of the inevitable overlap of neigbouring nuclei. However, treated nuclei could be collected in a small drop of buffer and therefore loss of nuclei was limited. Nuclei treated in this way retained excellent morphology, in contrast to nuclei lysed by methanol-acetic acid fixation. After the nuclei were spread onto the glass slide, a proteolytic treatment with pepsin was necessary to remove the remnants of cytoplasm. This did not result in loss of nuclei. Omission of this step reduced the hybridisation efficiency significantly. After disaggregation the nuclei could be stored for several days upto two weeks and still showed efficient hybridisation. Loss of cells during the whole procedure was low (< $10 \%$ ) and the morphology of the nuclei, when counterstained with DAPI, was still excellent.

In the case of pronuclei (figure 1d,e), 2-cell embryos (figure 1f-i) and 4-cell embryos (figure $1 \mathrm{j}, \mathrm{k}$ ) all the cytoplasm was removed by the pretreatment steps and distinct, clearly outlined nuclei remained. We evaluated 8 fertilised oocytes, 162 -cell embryos and 17 4-cell embryos and were able to generate signals in nearly all $(>90 \%)$ of the nuclei that underwent the ISH procedure. For morulae (not shown) and blastocysts (figure $11, \mathrm{~m}$ ) this method enables a better spreading of nuclei, thus making evaluation of individual cells easier. While examining the FISH results of some of the blastocysts using a fluorescence microscope, we could clearly see two subpopulations within the same embryo with regard to the number of $\mathrm{X}$-specific signals per cell. This indicated that we were able to demonstrate disomy/trisomy mosaicism for the X-chromosome in blastocyst cells as is seen in figure $1 \mathrm{~m}$. 


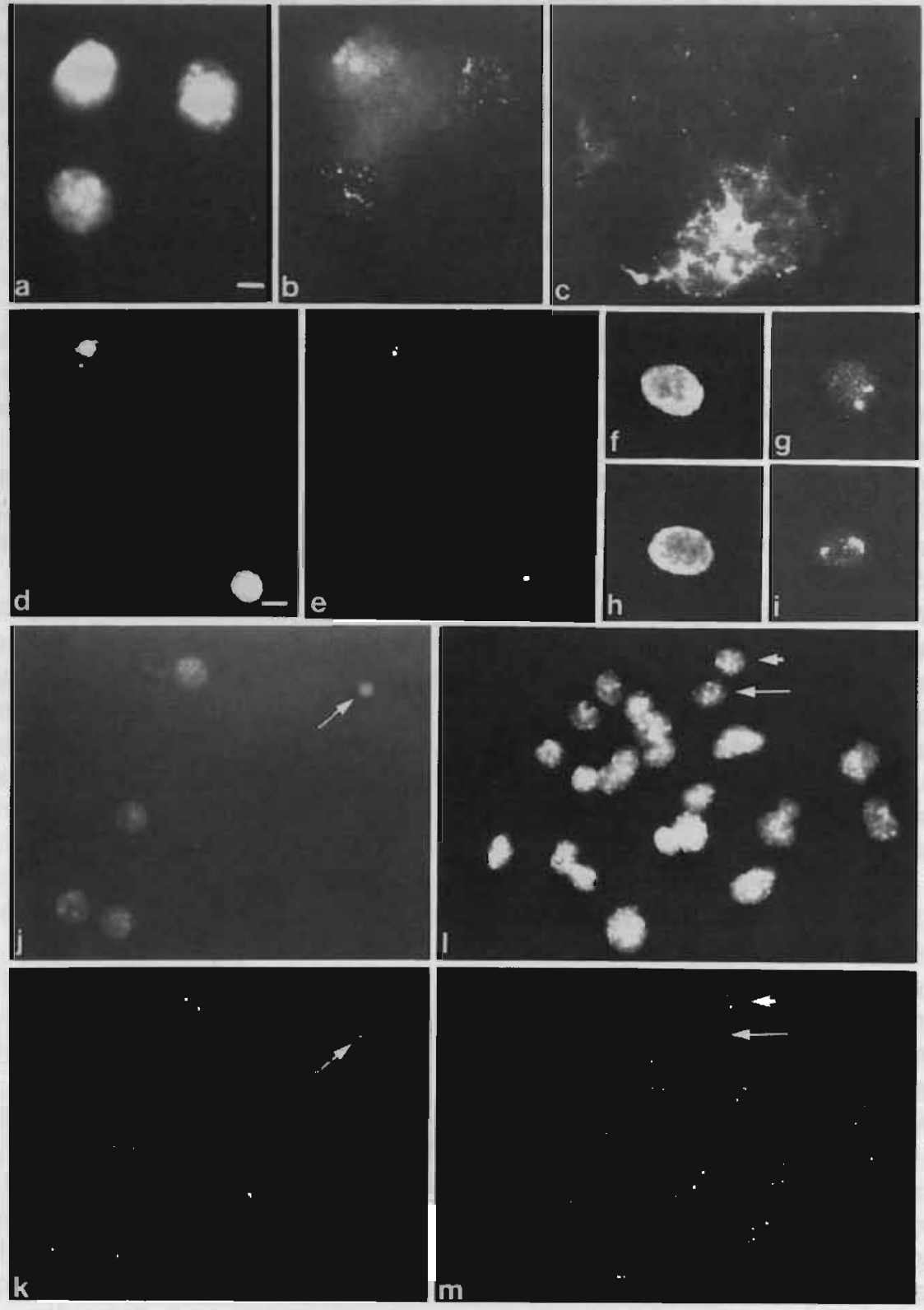

Figure 1. in situ hybridisation (ISH) of mouse preimplantation embryos at different stages of development. a,b; ISH with a telomere specific probe on a 3-cell, methanol:acetic acid fixed, embryo. A shows DAPI nuclear staining $\mathbf{c}$; methanol:acetic acid fixed blastocyst, hybridised with a probe for chromosome $X$, showing high autofluorescence of the inner cell mass $\theta, \mathbf{g}, \mathbf{i}, \mathbf{k}, \mathbf{m}$; pronuclei $(E), 2$-cell embryo $(G, I), 4$-cell embryo $(K)$ with polar body (arrow), and blastocyst ( $M$; embryo 6 from table 2 ), respectively, all hybridized with the $X$ chromosome

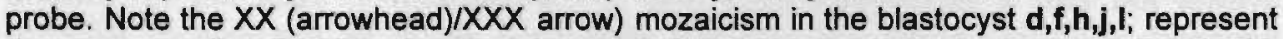
the corresponding DAPI nuclear stainings; $A, B, C, F, G, H, I$ : bar indicates $10 \mu \mathrm{m} ; \mathrm{D}, \mathrm{E}, \mathrm{J}, \mathrm{K}, \mathrm{L}, \mathrm{M}$ : bar indicates $15 \mu \mathrm{m}$ 
We examined the hybridisation efficiency of the double target FISH in early developmental stage mouse embryos by analysing a number of single, biopsied blastomeres from day 2 or day 3 embryos ( 1 or 2 cells from each embryo) with probes specific for the $X$ and $Y$ chromosome, data of which are shown in table 1.

Table 1. fluorescence in situ hybridization efficiency in single blastomeres from day 2 or day 3 mouse embryos

$\mathrm{nr}$ of embryos $\mathrm{nr}$ of nuclei $\mathrm{nr}$ of $\mathrm{XX}$ nuclei $\mathrm{nr}$ of $\mathrm{XY}$ nuclei $\mathrm{nr}$ of FISH failures

44

59

37

19

$3^{2}$

a one nucleus was not analysable because of a destroyed morphology

hybridization efficiency: $56 / 59=95 \%$

The hybridisation efficiency for both probes was $95 \%$, being equal for the $X$ and $Y$ specific probe. In all cases sibling cells revealed the same sex. Since, for practical reasons, the number of embryos (and thus the number of nuclei) investigated was limited, no statistical evaluation could be performed for the very early (1-4 cells) embryos. We statistically analysed 2 male and 6 female (as revealed by FISH) blastocysts, results of which are presented in table 2. The mean hybridisation efficiency of these embryos was virtually $100 \%$, which is higher than the percentage reported by Griffin et al. (4), who investigated single cells from human embryos. For statistical analysis we only included nuclei that showed no overlap with neighbouring nuclei.

Table 2. fluorescence in situ hybridisation efficiency in mouse blastocysts

\begin{tabular}{|c|c|c|c|c|c|c|c|}
\hline \multirow{2}{*}{ embryo } & \multirow[t]{2}{*}{$\operatorname{sex}$} & \multirow[t]{2}{*}{$\mathrm{nr}$ of nuclei } & \multicolumn{5}{|c|}{$\begin{array}{l}\mathrm{nr} \text { of nuclei with the indicated } \\
\mathrm{nr} \text { of signals for chromosome } \mathrm{X}\end{array}$} \\
\hline & & & 0 & 1 & 2 & 3 & $>3$ \\
\hline 1 & (F) & 24 & 0 & 7 & 17 & 0 & 0 \\
\hline 2 & (F) & 52 & 0 & 4 & 46 & 2 & 0 \\
\hline 3 & (M) & 70 & 0 & 68 & 2 & 0 & 0 \\
\hline 4 & (M) & 31 & 0 & 26 & 4 & 1 & 0 \\
\hline 5 & $(F)^{a}$ & 85 & 0 & 0 & 21 & 58 & 6 \\
\hline 6 & $(F)^{*}$ & 44 & 0 & 1 & 16 & 25 & 2 \\
\hline 7 & $(F)^{*}$ & 76 & 0 & 0 & 13 & 52 & 11 \\
\hline 8 & (F) & 18 & 0 & 3 & 15 & 0 & 0 \\
\hline
\end{tabular}

- the embryo exhibited a $X X / X X X$ mosaicism 
Using the acid/tween method we were also able to perform efficient in situ hybridisation of pre-fixed ( $4 \%$ araformaldehyde/PBS) and stored $\left(70 \%\right.$ ethanol, $-20^{\circ} \mathrm{C}$ ) embryos, although results were not as good as with fresh material. In this case pepsin (final concentration $100 \mu \mathrm{g} / \mathrm{ml}$ ) was added to the $0.01 \mathrm{~N} \mathrm{HCl} / 0.1 \%$ Tween 20 solution to facilitate the disaggregation of cells.

\subsection{Discussion}

We have developed a rapid and efficient spreading method for interphase nuclei from mouse preimplantation embryos to be used in in situ hybridisation procedures. The method offers several advantages as compared to the methanol:acetic acid fixation procedure that was sofar used for the preparation of such specimens.

From a practical point of view, it is a great advantage that with this acid/tween method embryonic cells can be monitored continuously during handling, allowing an exact timing of the different treatment steps. The position of the nuclei can be controled and they are well visible after the disaggregation of the embryo. This observation may be explained by the fact that embryos are not subjected to an interphase of organic and aqueous solvents in case of the acid/tween procedure. Turbulence at this stage may be a disturbing factor that occurs in the methanol:acetic acid method. For the methanol:acetic acid fixation procedure, that usually includes a hypotonic swelling step, timing is very critical and the method therefore often results in cells that can not be used for evaluation.

For small, whole mount mouse embryos (1-4 cells) the new method enables complete removal of the cytoplasm and separation of all nuclei. In our hands, the methanol:acetic acid fixation procedure, applied to these early embryos, often gave nondisaggregated clumps of nuclei, partly covered by cytoplasm. As shown in figure 1b such preparations resulted in suboptimal ISH efficiency.

For larger embryos (morulae and blastocysts) the acid/tween method provides a more efficient spreading of the individual nuclei as compared to methanol:acetic acid fixation.

A possible explanation for the better removal of cytoplasm and increased efficiency of hybridisation in the acid/tween procedure could be the fact that an increased permeability of the treated cells and solubilization of the cytoplasm is achieved by the detergent in combination with the hydrochloric acid. During the methanol:acetic acid procedure cells are in fact simultaneously permeabilized and fixed, a combination of steps that is apparently suboptimal for removal of cytoplasmic remnants, in the case of the specimens used in this study.

The fact that the acid/tween preparation method is easy to use and that it shows a high hybridisation efficiency, makes this technique widely applicable, for example for human embryo preimplantation diagnosis.

Acknowledgements: The authors wish to thank Marijke Bras and Marij van de Berg for excellent technical assistance with the IVF procedures and Monique Vallinga for excellent technical assistance with the hybridisation procedures and evaluation of the slides. Drs Joep Geraedts and Math Pieters are acknowledged for fruitfull discussions. 


\subsection{References}

Coonen E, Pieters MHEC, Dumoulin JCM, Meyer H, Evers JLH, Ramaekers FCS \& Geraedts JPM (1991) Nonisotopic in situ hybridization as a method for nondisjunction studies in human spermatozoa. Mol Reprod Dev 28:18-22

Disteche CM, Tantravahi U, Gandy S, Eisenhard M, Adler D \& Kunkel LM (1985) Isolation and characterization of two repetitive DNA fragments located near the centromere of the mouse X chromosome. Cytogenet Cell Genet 39:262-268

Dumoulin JCM, Evers JLH, Bras M, Pieters MHEC \& Geraedts JPM (1992) Positive effect of taurine om preimplantation development of mouse embryos in vitro. J Reprod Fertil 94:371-378

Griffin DK, Wilton LJ, Handyside AH, Winston RML \& Delhanty JDA (1992) Dual fluorescent in situ hybridisation for simultaneous detection $X$ and $Y$ chromosome-specific probes for the sexing of human preimplantation embryonic nuclei. Hum Genet 89:18-22

Grifo JA, Boyle A, Fisher E, Lavy G, DeChemey AH, Ward DC \& Sanyal MK (1990) Preembryo biopsy and analysis of blastomeres by in situ hybridisation. Am J Obstet Gynecol 163:2013-2019

Handyside AH, Pattinson JK, Penketh RJA, Delhanty JDA, Winston RML \& Tuddenham EGD (1989) Biopsy of human preimplantation embryos and sexing by DNA amplification. Lancet 1:347-349

Jones KW, Singh L \& Edwards RG (1987) The use of probes for the $Y$ chromosome in preimplantation embryo cells. Human Reprod 5:439-445

Quinn P, Kerin JF \& Warnes GM (1985) Improved pregnancy rate in human in vitro fertiliza tion with the use of a medium based on the composition of human tubal fluid. Fertil Steril 44:493-498

West JD, Gosden JR, Angell RR, Hastie ND, Thatcher SS, Glasier AF \& Baird DT (1987) Sexing the human pre-embryo by DNA-DNA in situ hybridisation. Lancet 2:1345-1347 

Fluorescence in situ hybridisation using cosmid probes to detect unique sequences in human embryonic cells: implications for preimplantation diagnosis

Edith Coonen, Joyce C Harper, Math HEC Pieters, Frans CS Ramaekers \& Anton HN Hopman

Submitted, 1994

In this paper we assess the feasibility of detection of unique sequences in human blastomeres with use of an improved spreading method for single embryonic cells in combination with fluorescence in situ hybridisation (FISH) based on cosmid probes. Targets of all probes used were located on chromosome 11. Efficient cell spreading and pretreatment procedures are prerequisites for reliable detection of unique sequences at the single cell level, in particular for preimplantation embryonic cells. Spreading of human blastomeres and hybridisation with cosmid probes could be performed with reasonable efficiency but results are as yet too preliminary to recommend diagnostic application.

\subsection{Introduction}

The application of the FISH technique for sex determination of single human blastomeres in preimplantation diagnosis has been well established (West et al., 1987, Grifo et al., 1990, Griffin et al., 1994). However, the standard methanol:acetic acid fixation procedure used for spreading of whole human embryos or single human blastomeres still has some disadvantages with respect to cell morphology and cell yield. Also this cell spreading procedure is laborious and requires an exact timing of the subsequent preparation steps. We have recently described a novel method to prepare single em-bryonic interphase nuclei to be analysed by FISH (Coonen et al., 1994a). This new cell spreading method offers a high reproducibility, a good morphology of embryonic nuclei and a high hybridisation efficiency. The method has been applied to preimplantation embryos resulting from both normal and abnormal fertilisation to identify chromosomal mosaicism for sex chromosomes as well as autosomes (Coonen et al, 1994b; Harper et al., 1994; Harper et al, in press). 
These studies revealed that this im-proved cell spreading method, in combination with the use of repetitive DNA probes, is a sensitive and reliable procedure that can be used for ploidy determination in preimplantation diagnosis.

So far, the application of FISH for human preimplantation diagnosis has been restricted to the detection of numerical chromosome aberrations by means of probes to repetitive DNA sequences. However, structural aberra-tions (translocations, inversions) play an important role in the vast majority of cases in which a high risk for genetic chromosome abnormalities exists. Such aberrations must in most cases be detected by the use of DNA probes for specific (non-repetitive) sequences or chromosome regions (Lichter et al., 1991; Tkachuk et al., 1991).

Here we report the use of DNA probes for unique sequences in combination with an efficient cell spreading method to prove that examination of single human blastomeres for the presence of structural aberrations is possible. We have used a triple target FISH procedure, based on a combination of two cosmid probes recognizing both arms of chromosome 11, and a repetitive DNA probe specific for the centromeric region of chromosome 11 . These chromosome targets were chosen as a model to detect partial loss or gain of chromosome arms, thus providing means to examine whether or not embryos are carrying a structural aberration. This would allow selective transfer of normal or balanced embryos.

\subsection{Materials \& methods}

\section{Human preimplantation embryos}

Embryos used in this study were obtained from patients undergoing IVF for fertility treatment at the University Hospital, Maastricht, the Netherlands or at the Hammersmith Hospital, London, UK. All patients gave written consent for the use of their embryos for research purposes. Investigation of embryos was approven by the Research Ethics Committees of University Hospital Maastricht and Royal Postgraduate Medical School, Hammersmith Hospital. Day 2 and day 3 (1-10 cell) embryos, resulting from abnormal as well as normal fertilisation, were included in these studies. The latter group consisted of embryos that showed an arrested development or aberrant cleavage rate and for those reasons were not suitable for transfer or cryopreservation. The number of embryos used for FISH with various combinations of DNA probes are shown in table 1. Due to current constraints on the use of embryos for scientific research, no embryos from patients with a previously defined genetic aberration were available.

\section{Spreading of human embryos}

The spreading of embryos or blastomeres was performed as described elsewhere (Coonen et al, 1994a; Harper et al., 1994). Briefly, whole embryos or single blastomeres were washed in phosphate buffered saline (PBS) and suspended in a solution containing $0.01 \mathrm{~N} \mathrm{HCl}$ and $0.1 \%$ Tween 20 . Nuclei that were cleared from cytoplasm were left to dry on poly-l-lysine coated slides. Slides were washed for 5 minutes in PBS and dehydrated through an ascending ethanol series. 


\section{Fluorescence In Situ Hybridisation}

The FISH procedure was performed as described previously (Coonen et al, 1994) with some minor modifications. In summary, after cell spreading and dehydration, slides were incubated for 20 minutes at $37^{\circ} \mathrm{C}$ with pepsin (Sigma, USA; $100 \mu \mathrm{g} / \mathrm{ml}$ in $0.01 \mathrm{~N} \mathrm{HCl}$ ) to increase accessibility of nuclei for hybridisation to the probes. After incubation, slides were rinsed in PBS and nuclei were fixed by incubation in $1 \%$ paraformaldehyde/PBS for 10 minutes at $4{ }^{\circ} \mathrm{C}$, again rinsed in PBS and finally dehydrated through an ascending ethanol series. Before denaturation, $10 \mu \mathrm{l}$ of hybridisation mixture ( $50 \%$ formamide/2xSSC/10\% Dextran Sulphate/tRNAVsDNA) was applied to each slide under a coverslip. Probe and nuclear DNA were denatured simultaneously for 3 minutes at $75^{\circ} \mathrm{C}$ and hybridisation was allowed to take place overnight (or at least 6 hours). We also tested separate denaturation of probe and embryonic DNA but, using the probes as described in materials and methods, this did not lead to a significant improvement of the hybridisation efficiency. Post-hybridisation washes were performed two times 5 minutes at $42^{\circ} \mathrm{C}$ with $50 \%$ formamide I2xSSC followed by two washes, 5 minutes each, at $60^{\circ} \mathrm{C}$ with $0.1 \times S S C$ and finally two times 5 minutes with $4 \times S S C / 0.05 \%$ Tween 20 at room temperature. The biotinlabelled probes were detected by incubation with Avidin-AMCA (Vector Laboratories, stad, USA; $1: 100$ in $4 \times$ SSC $/ 0.05 \%$ Tween $20 / 5 \%$ non fat dry milk) and, if necessary, the signal was amplified by subsequent incubations with biotinylated goat-anti Avidin (Vector Laboratories; 1:100 in 4xSSC/0.05\% Tween $20 / 5 \%$ non fat dry milk) and a second layer of Avidin-AMCA. All incubation steps were followed by washes with $4 \times S S C 10.05 \%$ Tween20 at room temperature. The digoxigenin-labelled probes were detected by incubations with a mouse monoclonal antibody directed against digoxin (Sigma; 1:2000 in PBS/0.05\% Tween20/5\% normal goat serum), followed by a second incubation with a TRITC-conjugated rabbit-anti mouse antibody (DAKO, Glostrup, Denmark; $1: 80$ in PBS/0.05\% Tween $20 / 5 \%$ normal goat serum). The hybridisation signal of the FITC-labelled probes was amplified, if necessary, by additional incubations with a rabbit polyclonal antibody directed against FITC (DAKO; $1: 2000$ in PBS/0.05\% Tween20/5\% normal goat serum) and a FITC-conjugated swine-anti rabbit antibody (DAKO; $1: 100$ in PBS/0.05\% Tween $20 / 5 \%$ normal goat serum). Incubations with antibodies for the detection of digoxigenin or FITC-labelled probes were followed by washes with PBS $/ 0.05 \%$ Tween20 at room temperature. After immunocytochemical staining, slides were dehydrated through an ascending ethanol series and mounted in glycerol, containing 2.3\% 1,4-diazobicyclo-(2.2.2)octane (DABCO; Sigma) to reduce photo-bleaching. For single and double target FISH, 4',6-diaminidino-2-phenylin-dole (DAPI; Sigma; 1,25 ng/ml) or propidium iodide (PI; Sigma; $0,5 \mu \mathrm{g} / \mathrm{ml}$ ) was added to the glycerol to counterstain the nuclei. Embryos were exa-mined using a Zeiss Axiophot microscope and photographs were taken by triple exposure with a Zeiss camera using Kodak Ektachrome 400 ASA film. 


\section{Human DNA probes}

Probes used in these studies were:

'cCl11-310 (cosmid probe, insert size approximately $40 \mathrm{~kb}$ ). Chromosomal localisation '11p15.1-p15.3 (Tokino et al., 1991).

'cCl11-314 (cosmid probe, insert size approximately $40 \mathrm{~kb}$ ). Chromosomal localisation '11q23.3-q24.1 (Tokino et al., 1991).

'pLC11A (plasmid probe, insert size $0.85 \mathrm{~kb}$ ). This probe recognizes a tandem repeat in the centromeric region of human chromosome 11 (Waye et al., 1987).

For multicolor FISH, probes were labelled by nick-translation with either biotin-11dUTP (Fermentas, stad, Lithuania), digoxigenin-11-dUTP (Boehringer Mannheim, Mannheim, Germany) or fluorescein-12-dUTP (Boehringer Mannheim, Mannheim, Germany) and further purified on a Sephadex G50 column (Pharmacia, Uppsala, Sweden). Probes were used at a final concentration of $4 \mathrm{ng} / \mu \mathrm{l}$ hybridisation mixture for cosmid probes, with 100 times excess of human Cot-1 DNA (BRL, USA) and 1 $\mathrm{ng} / \mu \mathrm{l}$ for centromeric probes.

\section{Control experiments}

The quality of the DNA probes and the efficiency of the probe labelling, the in situ hybridisation and the immunocytochemical detection procedures were tested on interphase nuclei obtained from ethanol fixed single cell suspensions of 5 human bladder carcinomas (Hopman et al., 1991). All probes were tested on these bladder cells (500 nuclei counted) to gain information on their hybridisation characteristics (Voorter et al, 1994). All carcinomas were diploid on basis of flow sorting and hybridisation with a number of centromere-specific probes. None of the tumors contained a numerical aberration of chromosome 11 . Using the conditions as described above, aspecific binding of probes was limited and the hybridisation efficiency of both centromeric and cosmid probes was determined.

\subsection{Results}

Using the $\mathrm{HCl} / \mathrm{T}$ ween 20 cell spreading method we were able to perform successful (multicolor) FISH with probes specific for non-repetitive sequences on both whole human embryos and biopsied single human blastomeres. Thirthy-five embryos were used in these studies (table 1), in which approximately 140 intact cells were counted, resulting in 135 nuclei after spreading ( $\pm 95 \%$ efficiency). With this method the morphology of the nuclei after FISH was good and nuclei showed, when counterstained with DAPI, the chromatin distribution characteristic of preimplantation embryo nuclei. 


\section{FISH in control cells}

The hybridisation efficiency of the different probes in the embryonic cells varied only slightly between experiments, although these variations were more pronounced as compared to the variation in FISH efficiencies seen in bladder cancer cells, used for quality control purposes. The hybridisation efficiency (presence of at least one hybridisation signal per nucleus) of the centromere-specific probe as tested on these bladder cells was $>99 \%$. In $5 \%$ of the nuclei, the number of hybridisation signals differed from the expected two copies. The majority $(60 \%)$ of these latter, aberrant cells showed only one signal for the centromere-specific probe. The presence of just one hybridisation signal does, however, not necessarily indicate monosomy, because it can result from the interphase organisation of the nucleus that occassionally causes co-localisation of identical DNA sequences (Hopman et al., 1988). This phenomenon occurs independently of the technique that is being used. Also inefficient hybridisation might lead to apparent monosomy. Using the cosmid probes, $>99 \%$ of the nuclei showed at least one hybridisation signal, but the percentage of nuclei that did not show the expected number of two signals was slightly higher than that for the centromere-specific probe, i.e. $8 \%$. Of these 'aberrant' nuclei, $75 \%$ showed only one signal for the probe used.

\section{Single target FISH in embryonic cells}

The percentage of embryonic nuclei showing hybridisation signals after FISH with the centromere-specific probe equalled that of the control cells (data not shown). Efficient hybridisation should result in the number of signals as expected on the basis of the number of pronuclei (PN) seen 16-18 hours after fertilisation. After single target FISH with the cosmid probes (table 1), 12 out of 14 nuclei examined showed at least one hybridisation signal.

\section{Double target FISH in embryonic cells}

To investigate selective loss or gain of chromosome parts, combinations of probes are necessary. When the centromeric probe was used in combination with one of the cosmid probes in two 3PN embryos, at least one hybridisa-tion signal for each probe was detected in 5 out of 6 nuclei (table 1). Of the 6 nuclei examined, one nucleus showed no signals for the centromere-specific probe and one nucleus showed only two (in stead of the expected number of three) signals for the cosmid probe. In 8 embryos, where a combination of the two cosmid probes was used, the hybridisation efficiency varied per embryo. Of the 35 nuclei hybridised, 10 showed no hybridisation signals for either one of the probes used. None of the nuclei was completely negative. 

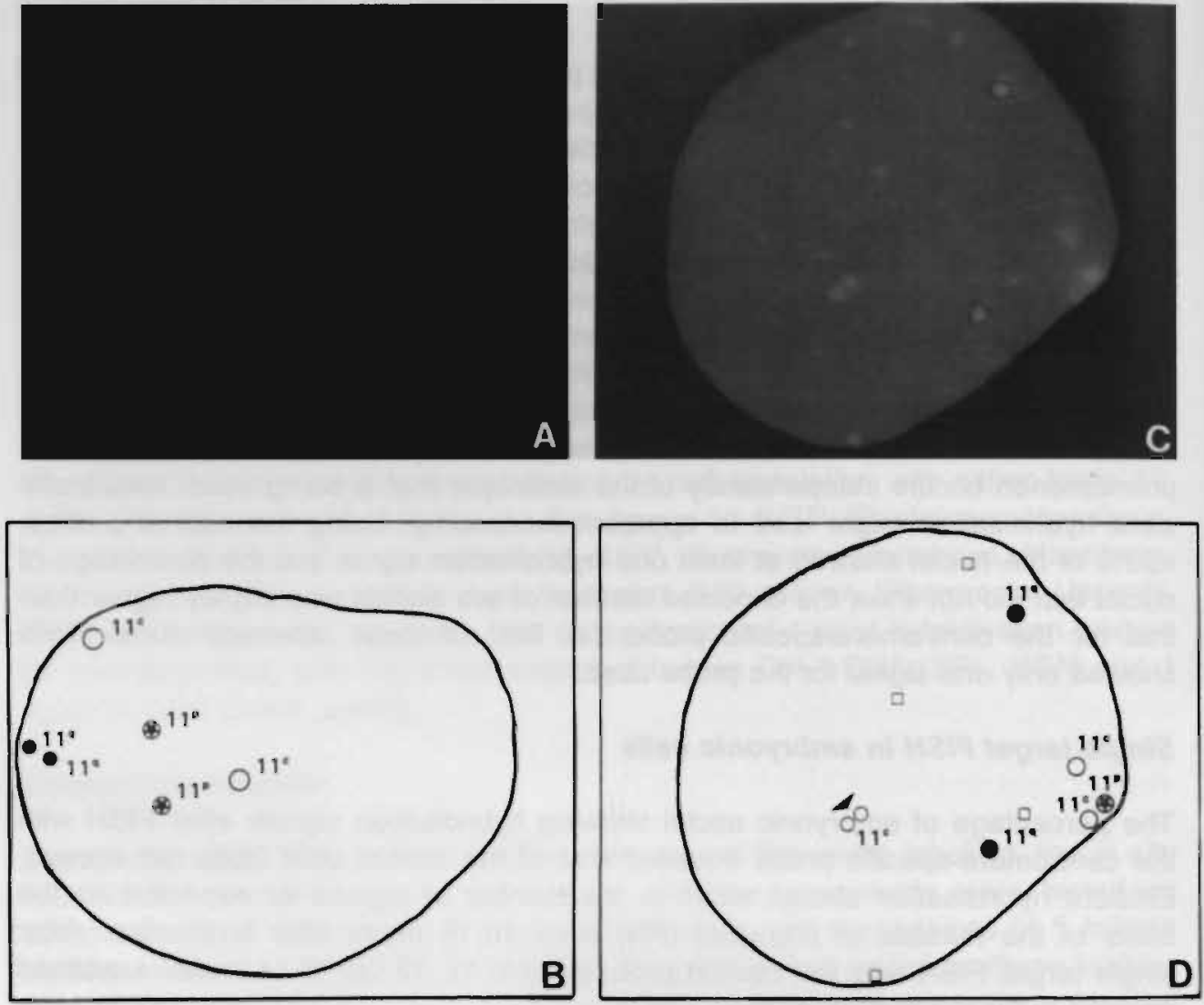

Figure 1. a/b Nucleus of a $2 \mathrm{PN}$ embryo showing two hybridisation signals for the chromosome 11 centromere-specific probe (FITC/O), two hybridisation signals for the cosmid probe located on chromosome 11p (AMCA ) and two hybridisation signals for the cosmid probe located on chromosome 11q (TRITC/ $/$ ); c/d Nucleus of a 3PN embryo showing an imbalance between the signal copy numbers generated by the different probes. After FISH, three hybridisation signals for the chromosome 11 centromere-specific probe (FITC/O) were visible, whereas the $11 p$ cosmid probe yielded one signal (AMCA ) and the 11q cosmid probe two (TRITC/•) hybridisation signals. The arrow head indicates a split-signal for the centromere-specific probe. The squares indicate aspecific fluorescence spots that were visible through all filters.

\section{Triple target FISH in embryonic cells}

Twenty-one embryos were alysed with triple-target FISH, using the repetitive probe specific for the centromeric region of chromosome 11, combined with the two cosmid probes (fig 1a-b). The percentage of reactive cells after triple target FISH was comparable to that after double-target FISH with the two cosmid probes (table 1). The addition of the centromere-specific probe thus did not influence the hybridisation 
efficiency. The occurrence of numerical aberrations and/or mosaic chromosome patterns is an important confounder in the analysis of FISH data (Lomax et al., 1994). For that reason only FISH results of embryos resulting from normal fertilisation are included in the following. We performed a triple target FISH with cosmid probes on ten 2PN embryos, from which 34 nuclei could be obtained. In about $30 \%$ of the nuclei we detected imbalances between the signal copy numbers of the different probes used. Most imbalances were caused by FISH underrepresentation of one of the cosmid probes. All 34 nuclei investigated showed hybridisation signals for the centromere-specific probe and at least one cosmid probe. The nuclei of the six $3 \mathrm{PN}$ embryos tested showed imbalances between the different regions of chromosome 11 (fig 1c-d).

Table 1. fluorescence in situ hybridisation on single human blastomeres with probes specific for repetitive and unique sequences on chromosome 11

\begin{tabular}{|c|c|c|c|c|c|c|c|c|}
\hline & \multirow[t]{2}{*}{$\begin{array}{c}\text { probe } \\
\text { (-combinations) }\end{array}$} & \multicolumn{4}{|c|}{$\begin{array}{l}\text { no embryos with } \\
\text { no pronuclei }\end{array}$} & \multirow[t]{2}{*}{$\begin{array}{l}\text { total no } \\
\text { embryos }\end{array}$} & \multirow[t]{2}{*}{$\begin{array}{l}\text { total no cells } \\
\text { after spreading }\end{array}$} & \multirow[t]{2}{*}{$\begin{array}{l}\text { FISH positive } \\
\text { cells }^{\circ}\end{array}$} \\
\hline & & 01 & 2 & 3 & 4 & & & \\
\hline $\begin{array}{l}\text { single } \\
\text { target }\end{array}$ & $\begin{array}{l}\text { 'cCl11-310/bio } \\
\text { cCl11-314/dig }\end{array}$ & . & $\begin{array}{l}2 \\
2\end{array}$ & & & $\begin{array}{l}2 \\
2\end{array}$ & $\begin{array}{l}8 \\
6\end{array}$ & $\begin{array}{l}7 / 8 \\
5 / 6\end{array}$ \\
\hline \multirow[t]{2}{*}{$\begin{array}{l}\text { double } \\
\text { target }\end{array}$} & $\begin{array}{l}\text { 'pLC11A/fitc } \\
\text { 'cCl11-314-dig }\end{array}$ & & 2 & & & 2 & 6 & $4 / 6$ \\
\hline & $\begin{array}{l}\text { 'cCl11-310/bio } \\
\text { 'cCl11-314/dig }\end{array}$ & & 5 & 3 & 8 & & 35 & $25 / 35$ \\
\hline $\begin{array}{l}\text { triple } \\
\text { target }\end{array}$ & $\begin{array}{l}\text { 'pLC11A/fitc } \\
\text { 'cCl11-310/bio } \\
\text { 'cCl11-314/dig }\end{array}$ & 13 & 10 & 6 & 1 & 21 & 80 & $49 / 80$ \\
\hline
\end{tabular}

total

- number of nuclei showing at least one hybridisation signal for each probe used/total number of nuclei available

\subsection{Discussion}

Since structural aberrations make up the majority of genomic alterations that lead to congenital diseases, the detection of such abnormalities is of utmost importance in preimplantation diagnosis. The presence of structural aberrations in embryonic nuclei could be examined by means of conventional karyotyping, but these methods are time consuming, laborious and usually inefficient. By introducing the FISH technique to detect structural aberrations in embryonic nuclei, these problems can be 
overcome (Coonen et al., 1994c). However, so far mainly repetitive genomic sequences have been the subject of investigation in order to determine the sex and/or estimate aneuploidy rate in preimplantation embryos (Coonen et al, 1994b, Griffin et al., 1992, Griffin et al., 1994; Harper et al., 1994; Munné et al., 1993a; Munné et al., 1993b). Obviously, there is a need for the application of DNA probes that enable detection of changes in topography/organization of unique sequences.

Various types of probes can be used to identify structural aberrations in interphase cells (Lichter et al., 1991; Tkachuk et al., 1991). Whole chromosome painting probes or region-specific probes that cover a certain chromosome area (e.g. yeast artificial chromosomes) show so-called hybridisation domains in interphase cells after FISH. The cell spreading method used in this study does allow FISH on basis of such whole-chromosome probe libraries but estimation of the number of nuclear domains can be problematic, due to domain overlap (Coonen et al., unpublished data). This is especially the case in nuclei from polypronucleate embryos that can contain multiple copies of a particular chromosome (Coonen et al., 1994b). This problem may, for instance hamper detection of chromosomal mosaicism within embryos. Structural aberrations can also be made visible with the use of cosmid probes, which have a restricted target area, allowing high topographical resolution of FISH signals. At the same time, however, the small target sequence imposes upon the efficiency of the pretreatment and hybridisation procedures. In our view, the use of cosmid probes therefore gives a good indication about the feasibility of detecting structural aberrations in embryonic nuclei on a single cell basis.

To ensure a reliable detection of structural chromosomal aberrations at the single cell level, the interpretation of FISH signals requires strict criteria. In particular this is the case for analysis of preimplantation embryos. To accomplish a dependable FISH analysis, it is necessary to thoroughly investigate the hybridisation characteristics (efficiency, signal appearance, polymorphism) of each probe before applying it in preimplantation diagnosis.

Because of the limited cell number, no statistical evaluation of the FISH data on embryonic nuclei can be performed and analyses are merely qualitative and descriptive. Various factors which may influence the interpretation of the FISH data have to be taken into account. The number of hybridisation signals can be under-estimated as a result of signal fusion, caused by co-localisation of the DNA targets in interphase nuclei (Matsumura et al., 1992). Even though occurring at low frequency, in this respect attention should be paid to possible differences in signal size and signal intensity within one nucleus. Apparent over-representation of chromosomes may be due to the occurrence of socalled 'split-spots'. These are separated, but closely linked signals on both chromatids, located in the centromeric region of a chromosome (Cremer et al., 1988; Devilee et al., 1988). Again, signal size and localisation may indicate this phenomenon. When using cosmid probes, doubling of signals as a result of DNA replication during the cell cycle could, if not recognised, further complicate the interpretation of the signal copy number (Selig et al., 1992). In our studies, duplicated signals or doublets were present in about $30 \%$ of all cells investigated with cosmid probes. An additional drawback in the analysis of nuclei from preimplantation embryos is the fact that internal standards are absent, since the genomic constitution of the various cells is not known in advance. Studies on embryos resulting from abnormal fertilisation have shown that the nuclei of polypronucleate em- 
bryos can exhibit complex chromosomal mosaic patterns (Coonen et al., 1994b). Recent FISH studies have confirmed earlier cytogenetic data that even in embryos resulting from apparently normal fertilisation, numerical aberrations are not uncommon (Harper et al., in preparation; Munné et al., 1993a). We do, however, not expect to find many structural abnormalities for a particular chromosome in embryos resulting from normal fertilisation. It is therefore of great importance to examine 'normal' 2PN embryos to study the applicability of cosmid probes in human preimplantation diagnosis. The genomic constitution of embryos resulting from normal fertilisation has not been studied sufficiently with respect to the presence of structural aberrations, to conclude that the one or two blastomeres removed from the embryo for analysis will be truly representitive of the whole embryo. In our studies we could demonstrate that the hybridisation efficiency of the cosmid probes on embryos did not differ significantly from that on normal metaphases (Lichter et al., 1990) or interphase cells from leukemia (Tkachuk et al., 1990). This indicates that defined structural aberrations, if present, can be detected in embryonic cells on a single cell basis. However, the hybridisation efficiency of the cosmid probes, as compared to the repetitive probes, is still subject to improvement and therefore we recommend the analysis of two blastomeres (if available) for a preimplantation diagnosis, in order to prevent false positive or false negative results.

Acknowledgements: The authors wish to thank Dr Joep Geraedts for stimulating discussions and Moniek Vallinga for the generation of FISH control data. Dr Hovers is acknowledged for providing the cosmid probes. Edith Coonen received financial support from the Netherlands Foundation for Scientific Research (NWO), the Foundation for Scientific Research Limburg (SWOL) and Simons Foundation. Joyce Harper is supported by the Wellcome Trust.

\subsection{References}

Coonen E, Dumoulin JCM, Ramaekers FCS \& Hopman AHN (1994a) Optimal preparation of preimplantation embryo interphase nuclei for analysis by fluorescent in situ hybridisation. Hum Reprod 3:533-537

Coonen E, Harper, JC, Ramaekers FCS, Delhanty JDA., Hopman A.H.N., Geraedts JPM \& Handyside AH (1994b) Presence of chromosomal mosaicism in abnormal preimplantation embryos detected by fluorescent in situ hybridisation. Human Genetics 94:609-615

Coonen E, Martini E, deDie-Smulders CEM, Ramaekers FCS, Geraedts JPM \& Hopman AHN (1994c) FISH using region-specific DNA probes for preimplantation diagnosis. Hum Reprod 9 suppl 4:30

Cremer T, Tesin D, Hopman AHN \& Manuelidis L (1988) Rapid interphase and metaphase assessment of specific chromosomal changes in neuroectodermal tumor cells by in situ hybridization with chemically modified DNA probes. Exp Cell Res $178: 199-220$

Devilee P, Thierry RF, Kievits T, Rukmini K, Hopman AHN, Huntington W (1988) Detection of chromosome aneuploidy in interphase nuclei from human primary breast tumors using chromosome-specific repetitive DNA probes. Cancer Res 48:5825-5830

Grifo JA, Boyle A, Fisher E, Lavy G, De Chemey AH, Ward DC \& Sanyal MK (1990) Preembryo biopsy and analysis of blastomeres by in situ hybridisation. Am J Obstet Gynecol 163:2013-2019 
Griffin DK, Wilton LJ, Handyside AH, Winston RML \& Delhanty JDA (1992) Dual fluorescent in situ hybridisation for simultaneous detection of $X$ and $Y$ chromosome-specific probes for the sexing of human preimplantation embryonic nuclei. Hum Genet 89:18-22

Griffin DK, Handyside AH, Harper JC, Wilton LJ, Atkinson G, Soussis I, Wells D, Kontogian ni E, Tarin J, Geber S, Ao A, Winston RML \& Delhanty JDA (1994) Clinical experience with preimplantation diagnosis of sex by dual fluorescent in-situ hybridisation. J Ass Reprod Gen (in press)

Harper JC, Coonen E, Ramaekers FCS, Delhanty JDA, Handyside AH, Winston RML \& Hopman AHN (1994) Identification of the sex of human preimplantation embryos in two hours using an improved spreading method and fluorescent in-situ hybridization (FISH) using directly labelled probes. Hum Reprod 4:721-724

Harper JC, Coonen E, Handyside AH, Winston RML, Hopman AHN \& Delhanty JDA Detection of sex chromosome and autosome mosaicism in normally fertilised preimplantation human embryos. (Prenat Diagn, in press)

Hopman AHN, Ramaekers FCS, Raap AK, Beck JLM, Devilee P, Ploeg van der M \& Vooijs GP (1988) In situ hybridization as a tool to study numerical chromosome aberrations in solid bladder tumors. Histochemistry 89:307-316

Hopman AHN, Moesker O, Smeets AWGB, Pauwels RPE, Vooijs GP \& Ramaekers FCS (1991) Numerical chromosome 1,7,9 and 11 aberrations in bladder cancer detected by in situ hybridisation Cancer Res 51:644-651

Lichter P, Tang C-JC, Call K, Hermanson G, Evans GA, Housman D \& Ward DC (1990) High-resolution mapping of human chromosome 11 by in situ hybridization with cosmid clones. Science 247:64-69

Lichter P, Boyle AL, Cremer T \& Ward DC (1991) Analysis of genes and chromosomes by nonisotopic in situ hybridization. GATA 8:24-35

Lomax BL, Kalousek DK, Kuchinka BD, Barrett IJ, Harrison KJ \& Safavi H (1994) The utilization of interphase cytogenetic analysis for the detection of mosaicism. Hum Genet 93:243-247

Matsumura K, Kallioniemi A, Kallioniemi O, Chen L, Smith HS, Pinkel D, Gray J \& Waldman FM (1992) Deletion of chromosome 17p loci in breast cancer cells detected by fluorescen ce in situ hybridization Cancer Res 52:3474-3477

Munné S, Lee A, Rosenwaks Z, Grifo J \& Cohen J (1993a) Diagnosis of major aneuploidies in human preimplantation embryos. Hum Reprod 8:2185-2191

Munné S, Weier U-H, Stein J, Grifo J \& Cohen J (1993b) A fast and efficient method for simultaneous $X$ and $Y$ in situ hybridization of human blastomeres. J Assist Reprod Genet 10: $82-90$

Selig S, OkumuraK, WardDC, Cedar H (1992) Delineation of DNA replication time zones by fluoresence in situ hybridization. EMBO J 11:1217-1225

Tkachuk DC, Westbrook CA, Andreeff M, Donlon TA, Cleary ML, Suryanarayan K, Homge M, Redner A, Gray JW \& Pinkel D (1990) Detection of bcr-abl fusion in chronic myelogene ous leukemia by in situ hybridization. Science 250:559-562

Tkachuk DC, Pinkel D, Kuo W-L, Weier H-U \& Gray JW (1991) Clinical applications of fluorescence in situ hybridization. GATA 8:67-74 
Tokino T, Takahashi E, Mori M, Tanigami A, Glaser T, Park JW, Jones C, Hori T \& Nakamura $Y$ (1991) Isolation and mapping of 62 new RFLP markers on human chromoso me 11. Am J Hum Genet 48:258-268

Voorter CEM, Vallinga M, Ramaekers FCS \& Hopman AHN (1994) Interphase spreading to study chromosome $11 \mathrm{p}$ and $\mathrm{q}$ arm imbalances in bladder tumors by FISH. Anal Cell Pathol 6:246

Waye JS, Creeper LA \& Willard HF (1987) Organization and evolution of alpha satellite DNA from human chromosome 11. Chromosoma 95:182-188

West JD, Angell RR, Thatcher SS, Gosden JR, Hastie ND, Glasier AF \& Baird D (1987) Sexing the human pre-embryo by DNA- DNA in-situ hybridisation. Lancet, 2:1345-1347 



\section{Identification of the sex of human preimplantation embryos in two hours using an improved spreading method and fluorescence in situ hybridisation (FISH) using directly labelled probes}

Joyce C Harper, Edith Coonen, Frans CS Ramaekers, Joy DA Delhanty, Alan H Handyside, Robert ML Winston \& Anton HN Hopman

Human Reproduction, 4:721-7241994

Dual fluorescence in situ hybridisation (FISH) using $X$ and $Y$ chromosome specific probes has been used to identify the sex of human embryos for preimplantation diagnosis of $X$-linked disease. With a modified spreading method and directly labelled fluorescence DNA probes, we have examined the possibility of reducing the time of the FISH procedure from 7 to $2 \mathrm{~h}$. A total of 17 normally fertilized human embryos were disaggregated and 98 intact blastomeres obtained. The spreading efficiency was $96 \%$ and FISH signals were obtained from $97 \%$ of nuclei. In all cases, sibling blastomeres from the same embryo were the same sex. Mosaicism was observed in some embryos. Five cells which lysed during the disaggregation process were spread to determine whether FISH was possible in these cells, but in all cases the morphology of the nuclei was poor and multiple signals were observed so that reliable diagnosis of sex was not possible. The data reported here confirm that by using an improved spreading method in combination with directly labelled DNA probes, we have increased the efficiency and reduced the time required for sexing embryos for preimplantation diagnosis of $\mathrm{X}$-linked disease.

\subsection{Introduction}

Preimplantation diagnosis is a possible alternative to prenatal diagnosis and recurrent abortions for some couples at risk of transmitting inherited diseases to their children (Handyside, 1993). Patients undergo routine in vitro fertilization (IVF) procedures (Hiller et al., 1985) to generate embryos in vitro. One or two blastomeres are biopsied from cleaved embryos and genetic analysis of the biopsied cells determines 
which embryos are suitable for transfer back to the patient. For $\mathrm{X}$-linked diseases, the polymerase chain reaction (PCR of a repeated sequence on the $\mathrm{Y}$-chromosome (Handyside et al., 1990) and dual fluorescence in situ hybridisation (FISH) for chromosomes $X$ and $Y$ (Griffin et al., 1992) have been used to sex human embryos, and births have been obtained (Handyside et al., 1990; Griffin et al., 1993). PCR has also been used for the detection of embryos at risk of cystic fibrosis and resulted in the live birth of an unaffected female (Handyside et al., 1992).

The sexing of human embryos by PCR is relatively quick and efficient, and improvement of the technique has led to the simultaneous amplification of sequences on chromosomes $X$ and $Y$ (Chong et al., 1993). However, mosaicism and aneuploidy such as $\mathrm{XO}$ and $\mathrm{XXX}$ have been detected using $\mathrm{FISH}$ in both normally fertilized embryos (Delhanty et al., 1993) and abnormally fertilized embryos (Coonen et al., 1994). Using conventional PCR methods these chromosomal abnormalities would not be detected since the amplification is not quantitative. Also, contamination by spermatozoa or foreign DNA can be a serious problem when using PCR for preimplantation diagnosis, whereas with FISH this would be negligible. FISH is therefore the preferred method of sexing human embryos for preimplantation diagnosis.

There are, however, two limitations to current FISH procedures: firstly, the loss of nuclei when spreading single blastomeres; and secondly, the time taken for the diagnosis. The current method used for spreading single blastomeres for FISH employs minor variations of Tarkowski's (1966) method involving fixation and removal of the cytoplasm with methanol and acetic acid (Griffin et al., 1992). However, this does not allow continuous visualization of the blastomere or nucleus, so loss of nuclei can occur and there is often insufficient removal of blastomere cytoplasm. We have recently developed an improved method of spreading whole human cleavage stage embryos which involves dissolving the cytoplasm with a combined detergent and acid treatment. This allows continuous visualization of the blastomere or nucleus, and removal of most, if not all, of the blastomere cytoplasm (Coonen et al., 1994). Here we report on the use of this technique for single blastomeres, leading to a higher efficiency of spreading than has previously been reported (Griffin et al., 1992).

For preimplantation diagnosis, the biopsy, spreading, FISH of single blastomeres and embryo transfer are alle performed in one day. Recent reports of sexing using FISH for human embryonic interphase nuclei take, $7 \mathrm{~h}$ post-spreading using indirect detection (Griffin et al., 1993) and $6 \mathrm{~h}$ using directly labelled probes (Munné et al., 1993). A short FISH procedure for chemically labelled oligonucleotide probes on human metaphase chromo-somes has recently been reported by Matera and Ward (1992). Since a reduction in the time taken to sex human blastomeres would be advantageous for a preimplantation diagnosis programme, we have examined the effeciency of a FISH procedure with a 45 min hybridisation period and no requirement for immunocytochemical detection of formed hybrids or signal enhancement lamplification, which can be performed in $2 \mathrm{~h}$ post-spreading. We report on this quick, efficient and reliable method for sexing human preimplantation embryos. 


\subsection{Materials \& methods}

\section{Preimplantation embryos}

Preimplantation embryos were obtained from patients undergoing routine IVF procedures at the Hammersmith Hospital, London, UK. Written consent was obtained from patients to confirm that the surplus embryos could be used for research purposes. The study was approved by the Human Feritilization and Embryology Authority and the Research Ethics Committee of the Royal Postgraduate Medical School, Hammersmith Hospital.

All embryos used in this study were normally fertilized (presence of two pronuclei observed $18 \mathrm{~h}$ after insemination). On day 3 post-insemination, the zonae pellucidae were removed form the embryos using acid Tyrode's solution ( $\mathrm{pH} \mathrm{2.4).} \mathrm{Blastomeres}$ were separated using a polished pipette and spread individually as described below.

\section{Blastomere spreading}

Blastomeres were washed in phosphate-buffered saline (PBS) for 2 min and transferred into a small drop of spreading solution $(0.01 \mathrm{~N} \mathrm{HCl}, 0.1 \%$ Tween 20$)$ on a poly-l-lysine coated slide. The blastomere was constantly observed using an inverted microscope and, as it lysed, spreading solution was removed and replaced to clear the nucleus of cytoplasm. The slides were left to dry, washed in PBS for $5 \mathrm{~min}$ and dehydrated through an ethanol series.

\section{Control lymphocyte analyses}

The efficiency of the FISH was tested in each experiment on interphase nuclei obtained from ethanol-fixed, single-cell suspensions of male human leukocytes. Using the conditions described below in the FISH section, hybridisation effeciency was optimal and association of probes to minor binding sites was limited. Analysis of the FISH signals was performed according to the criteria set by Hopman et al. (1988).

\section{Directly labelled human DNA probes}

Probes used for these studies were as follows. PBamX5: alphoid probe (insert size $2.0 \mathrm{~kb}$ ), specific for the centromeric region of the human $X$ chromosome (Willard et al., 1983); DYZ1: satellite probe (insert size $2.1 \mathrm{~kb}$ ), specific for the long arm of the human $Y$ chromosome (Cooke et al., 1982). Both probes were labelled by nick translation with FITC-12-dUTP (Boehringer, Mannheim, Germany)(X probe) or rhodamine-4-dUTP (Amersham, UK)(Y probe), dissolved in hybridisation mixture $(60 \%$ formamide/ $2 \times \mathrm{SSC})$ and used in a final concentration of $1-2 \mathrm{ng} / \mu \mathrm{l}$. 


\section{FISH}

After spreading and dehydration, slides were treated with pepsin $(100 \mu \mathrm{g} / \mathrm{ml})$ in $0.01 \mathrm{~N} \mathrm{HCl}$ for $20 \mathrm{~min}$ at $37^{\circ} \mathrm{C}$ to remove any remnants of cytoplasm and make the nuclei accessible for hybridisation to the probes. The slides were rinsed in bi-distilled water followed by PBS and fixed for $10 \mathrm{~min}$ in $1 \%$ paraformaldehyde in PBS at $4^{\circ} \mathrm{C}$. After fixing, the slides were rinsed in PBS followed by two rinses in bi-distilled water and dehydrated through an ethanol series. The hybridisation mixture was added to the slide under a coverslip and nuclear and probe DNA denatured simultaneously for $3 \mathrm{~min}$ at $75^{\circ} \mathrm{C}$. The slides were then incubated in a moist chamber at $37^{\circ} \mathrm{C}$ for 45 min to allow hybridisation of he DNA probes. After hybridisation the slides were washed for $5 \mathrm{~min}$ with $60 \%$ formamide $/ 2 \times \mathrm{SSC}$ and $5 \mathrm{~min}$ with $2 \times \mathrm{SSC}$ at $42^{\circ} \mathrm{C}$, followed by two additional $5 \mathrm{~min}$ washes at room temperature with $4 \times \mathrm{SSC} / 0.05 \%$ Tween 20. The slides were dehydrated through an ethanol series and mounted in glycerol $(100 \%)$ containing $1.25 \mathrm{ng} / \mathrm{ml} \mathrm{4}, 6$-diamin-idino-2-phenylindole (DAPI) to counterstain the nuclei. Nuclei were examined using a Reichert Jung Polyvar fluorescence microscope. Blue DAPI fluorescence was detected with the U1 filter set; filter B1 detected the green, FITC signal (X chromosome) and filter set $\mathrm{G} 2$ detected the red, rhodamine (TRITC) signal ( $Y$ chromosome). Photographs were taken using Scotch 640T film, using triple exposure.

\subsection{Results}

\section{Control lymphocytes}

Using lymphocytes prepared from four healthy males, 400 nuclei were analysed and all but one nucleus gave signals (100\%) (Figure 1a). In 10 nuclei signals other than $X Y$ were obtained $(2.5 \%)$ [one $X O$, one OY, one $X X Y$, three $X X Y$ in which the $X$ signals were close together and four $X X Y Y$ (all from the same male)].
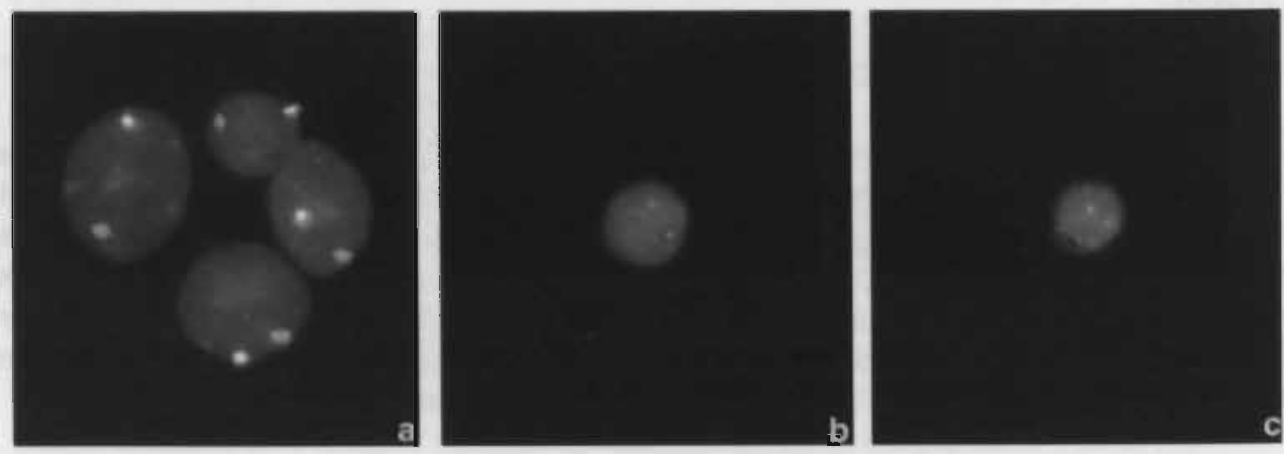

Figure 1. Fluorescence in situ hybridisation using directly labelled probes for chromosomes $X$ (green) and $Y$ (red). (a) Four interphase nuclei from male lymphocytes; (b) interphase nucleus from a male embryo; (c) interphase nucleus from a fernale embryo. Magnification $\times 400$. 
Table 1. fluorescence in situ hybridisation (FISH) results using directly labelled probes for chromosomes $X$ and $Y$ from blastomeres obtained from diaggregated human embryos

\begin{tabular}{|c|c|c|c|c|}
\hline $\begin{array}{l}\text { embryo } \\
\text { reference }\end{array}$ & $\begin{array}{l}\text { no. of } \\
\text { cells before } \\
\text { disaggregation }\end{array}$ & $\begin{array}{l}\text { no. of } \\
\text { cells after } \\
\text { disaggregation }\end{array}$ & $\begin{array}{l}\text { no. of } \\
\text { nuclei spread }\end{array}$ & $\begin{array}{l}\text { FISH } \\
\text { results }\end{array}$ \\
\hline $\mathrm{Co} 7$ & 7 & 3 & 3 & $2 x X$ \\
\hline Co11 & 7 & 6 & 7 & $7 X X^{a}$ \\
\hline Co13 & 5 & 3 & 3 & $\begin{array}{l}2 X Y \\
1 ? X X Y\end{array}$ \\
\hline Co5 & 6 & 2 & 3 & $2 X O^{a} ; 1 X Y$ \\
\hline $\mathrm{He} 7$ & 6 & 2 & 1 & $1 x x$ \\
\hline Ta4 & 7 & 7 & 6 & $6 X Y$ \\
\hline Bu15 & 8 & 8 & 7 & $\begin{array}{l}6 X Y \\
1 ? X Y Y\end{array}$ \\
\hline Mo2 & 5 & 3 & 3 & $3 X Y$ \\
\hline Mo1 & 6 & 5 & 5 & $\begin{array}{l}2 X Y \\
3 X X Y\end{array}$ \\
\hline Gu4 & 8 & 7 & 7 & $7 X X$ \\
\hline Gu2 & 8 & 7 & 7 & $7 \times x$ \\
\hline $\mathrm{P} 14$ & 8 & 5 & 5 & $5 \times x$ \\
\hline Bl17 & 8 & 8 & 7 & $7 x x$ \\
\hline $\mathrm{Ca} 2$ & 12 & 12 & 12 & $\begin{array}{l}10 \mathrm{XY} \\
2 \text { meta }^{b}\end{array}$ \\
\hline Wa1 & 4 & 4 & 4 & $3 \times x ; 1 \times 0$ \\
\hline Ro3 & 8 & 8 & 8 & $8 X Y$ \\
\hline $\mathrm{Ho8}$ & 8 & 8 & 8 & $8 X Y$ \\
\hline Total & 121 & 98 & 96 & 93 \\
\hline
\end{tabular}

" binucleate blastomere; ${ }^{\circ}$ metaphase; ? XXY or XYY signals close together.

\section{Embryonic nuclei}

The signals obtained form nuclei from male and female embryos are shown in Figure $1 \mathrm{~b}$ and $1 \mathrm{c}$ respectively. Table 1 summarizes the results for FISH on single blastomeres. A tctal of 17 embryos were disaggregated, and 98 intact blastomeres obtained. In some cases, blastomeres lysed during the removal of the zona pellucida or disaggregation. During spreading, a total of three blastomeres were lost (embryos $\mathrm{He7}$, Bu15 and BL17), one may not have had a nucleus since no interphase nucleus was observed (embryo Ta4), two were in metaphase (both from the embryo $\mathrm{Ca} 2$ ), and two appeared to be binucleate (embryos C.011 and Co5). From the 98 blastomeres spread, 96 nuclei were obtained ( 94 plus two binucleates), giving a spreading efficiency of $96 \%$. A total of 93 nuclei gave a FISH signa! ( $97 \%$ per nucleus $/ 93 \%$ per blastomere). One interphase nucleus gave no signal (embryo Co7), and the two metaphase nuclei from $\mathrm{Ca} 2$ were incomplete and were therefore not analysable.

In all 17 embryos, blastomeres from the same embryo were of the same sex. In two embryos (Co13 and Bu15) two $\mathrm{X}$ or $\mathrm{Y}$ signals were very close together and it was 
not possible to determine if they were a split signal or two separate signals. In three embryos (Co5, Mo16 and Wa1) sex chromosome mosaicism was detected among sibling blastomeres. Five lysed blastomeres were spread to examine the efficiency of FISH on these blastomeres. In all cases the nuclei were of poor morphology and multiple signals were obtained for both probes, making reliable determination of sex impossible.

\subsection{Discussion}

Embryo biopsy, genetic analysis for preimplantation diagnosis of inherited disease and embryo transfer are all performed on day 3 of the IVF cycle (Handyside, 1993). Therefore a fast and efficient method of diagnosis is required to ensure that all the procedures can be performed within one day. FISH is the preferred method for identifying the sex of human embryos since in addition to distinguishing the sex of the cell, aneuploidy involving either sex chromosome can be detected. Indeed, we recently reported the detection of mosaicism and aneuploidy in a series of X-linked recessive cases (Delhanty et al., 1993). FISH also has the advantage that there is a reduction in the risk of contamination which is associated with PCR.

Here we have demonstrated that using a modified spreading method in combination with directly labelled probes (Wiegant et al., 1991), the FISH procedure can be completed in $2 \mathrm{~h}$, with improved efficiency. Using $\mathrm{HCl} / \mathrm{T}$ ween 20 to dissolve the cytoplasm of single blastomeres enables continuous observation of the blastomere and nucleus, reducing losses. It also allows more efficient removal of the cytoplasm and gives better nuclear morphology. Overall, nuclei were obtained in $96 \%$ of the blastomeres spread (94/98). Since some blastomeres lyse during the embryo biopsy procedure, we also spread five lysed blastomeres but in alle cases, multiple, oddshaped signals were obtained and reliable determination of sex was not possible.

The FISH procedure we have previously used for preimplantation diagnosis employs an indirect detection method and takes about $7 \mathrm{~h}$ (Griffin et al., 1993). This requires the embryo biopsy to be performed very early in the morning to accommodate embryo transfer later the same evening. If the whole process from biopsy to diagnosis could be performed within $7 \mathrm{~h}$, this would allow more time for the procedures and the embryo transfer could take place at a more sociable time for both patients and staff. More importantly, in future studies it may be possible to reprobe the nulei using probes for two additional chromosomes (Munné et al., 1993). Also, it should be noted that since the biopsy is currently performed very early on day 3 , the embryos are not always at the 8-cell stage, which reduces the possibility of removing two blastomeres. Performing the biopsy later would ensure that more embryos had reached the 8-cell stage.

We have achieved a reduction in the time of the FISH procedure in three ways. First, since the nuclei are efficiently cleared of cytoplasm as a result of the spreading method, the RNase and proteinase $K$ steps, which take about $1.5 \mathrm{~h}$, are replaced by a $20 \mathrm{~min}$ pepsin digestion. Second, the hybridisation period is reduced from 2-6 $\mathrm{h}$ to $45 \mathrm{~min}$ and third, using directly labelled probes, no immunocytochemical detection stage is required. Using this method, we obtained an efficiency of $93 \%$ per blastomere and $97 \%$ per nucleus. In all cases, sibling blastomeres were of the same 
sex. We observed mosaicism in some embryos, as has been previously reported for both normal embryos (Delhanty et al., 1993) and abnormally fertilized embryos (Coonen et al., 1994).

Our results reported here show that we can increase the efficiency and reduce the time taken for the determination of sex for preimplantation diagnosis of $\mathrm{X}$-linked diseases. Since the technique is more efficient, more embryos will be successfully sexed, which may increase the probability of having a choice of female embryos to be replaced, so that morphology and cleavage stage can also be taken into consideration. The reduced time will ensure that the embryo biopsy and transfer can be performed within the $7 \mathrm{~h}$ working day, leading to a more effectively managed preimplantation diagnosis programme.

Acknowledgements: We would like to thank Karin Dawson and all the staff of the Hammersmith Hospital IVF unit. We would also like to thank Joep Geraedts for his advice and Monique Vallinga-Ummelen for technical assistance.

\subsection{References}

Chong SS, Kristjansson K, Cota J, Handyside AH \& Hughes MR (1993) Preimplantation prevention of X-linked disease: reliable and rapid sex determination of single human cells by restriction analysis of simultaneously amplified ZFX and ZFY sequences. Hum Mol Genet 2:1187-1191

Cooke HJ, Schmidtke J \& Gosden JR (1982) Characterisation of a human Y chromosome repeated sequence and related sequences in higher primates. Chromosoma 87:491- 502

Delhanty JDA, Griffin DK, Handyside AH, Harper JC, Atkinson GHG, Pieters MHEC \& Winston RML (1993) Detection of aneuploidy and chromosomal mosaicism in human embryos during preimplantation sex determination by fluorescent in situ hybridisation. Hum Mol Genet 2:1183-1185

Griffin DK, Wilton LJ, Handyside AH, Winston RML \& Delhanty JDA (1992) Dual fluorescent in situ hybridisaton for simultaneous detection of $X$ and $Y$ chromosome-specific probes for the sexing of human preimplantation embryonic nuclei. Hum Genet 89:18-22

Griffin DK, Wilton LJ, Handyside AH, Atkinson G, Winston RML \& Delhanty JDA (1993)

Diagnosis of sex in preimplantation embryos by fluorescent in situ hybridisation. Br Med $J$ 306:1382

Handyside AH (1993) Diagnosis of inherited disease before implantation. Reprod Med Rev 2:51-61

Handyside AH, Kontogianni EH, Hardy K \& Winston RML (1990) Pregnancies from biopsied human preimplantation embryos sexed by $Y$-specific DNA amplification. Nature 244:768770

Handyside AH, Lesko JG, Tarin JJ, Winston RML \& Hughes MR (1992) Birth of a normal girl after in vitro fertilisation and preimplantation diagnostic testing for cystic fibrosis. $N$ Engl $J$ Med 327:905-909 
Hillier SG, Afnan AMM, Magara RA \& Winston RML (1985) Super ovulation strategy before in vitro fertilisation. Clin Obstet Gynaecol 12:687-723

Hopman AHN, Ramaekers FCS, Raap AK, Beck JLM, Deville P, van der Ploeg M \& Vooijs GP (1988) In situ hybridisation as a tool to study numerical chromosome aberrations in solid bladder tumours. Histochemistry 89:307-316

Matera AG \& Ward DC (1992) Oligonucleotide probes for the analysis of specific repetitive DNA sequences by fluorescence in situ hybridisation. Hum Mol Genet 1:535-539

Munné S, Weier H-UG, Stein J, Grifo J \& Cohen J (1993) A fast and efficient method for simultaneous $X$ and $Y$ in situ hybridisation of human blastomeres. J Assist Reprod Genet $10: 82-90$

Tarkowski AK (1966) An air drying method for chromosome preparations from mouse eggs. Cytogenetics 5:394-400

Wiegant J, Ried T, van der Ploeg M, Nederlof P-M, Tanke HJ \& Raap AK (1991) In situ hybridisation with fluoresceinated DNA. Nucleic Acids Res 19:3237-3241

Willard HF, Smith KD \& Sutherland J (1983) Isolation and characterisation of a major tandem repeat family from the human $X$ chromosome. Nucleic Acids Res 11:2017-2033 


\section{Presence of chromosomal mosaicism in abnormal preimplantation embryos detected by fluorescence in situ hybridisation}

Edith Coonen, Joyce C Harper, Frans CS Ramaekers, Joy DA Delhanty, Anton HN Hopman, Joep PM Geraedts \& Alan H Handyside

Human Genetics, 94:609-615 1994

The extent of chromosomal mosaicism in human preimplantation embryos was examined using an improved procedure for the preparation and spreading of interphase nuclei for use in fluorescence in situ hybridisation, allowing the analysis of every nucleus within an embryo. One cell showed no hybridisation signals in only 3 of the 38 embryos that were included in this study, i.e. the hybridisation efficiency per successfully spread nucleus was $99 \%(197 / 200)$ ). Double-target in situ hybridisation analyses with $X$ and $Y$ chromosome specific probes was performed to analyse nine embryos resulting from normal fertilization, 22 polypronucleate embryos, and seven cleavage-stage embryos where no (apronucleate), or only 1 pronucleus (monopronucleate) was observed. We also analysed autosomes 1 and 7 by doubletarget in situ hybridisation in the nuclei of two apronucleate, one monopronucleate, and four polypronucleate embryos. All nine embryos that resulted from normal fertilization were uniformly $X Y$ or $X X$. None of the apronucleate or monopronucleate embryos was haploid: three were diploid, one was triploid, and three were mosaic. Fertilization was detected by the presence of a Y-specific signal in four of these embryos. Of the polypronucleate embryos, two were diploid, two were triploid, and 18 were mosaic for the sex chromosomes and/or autosomes 1 and 7.

These results demonstrate that fertilization sometimes occurs in mono-pronucleate embryos and that chromosomal mosaicism can be detected with high efficiency in apronucleate, monopronucleate and polypronucleate human embryos using fluorescence in situ hybridisation. 


\subsection{Introduction}

Oocytes are examined for the number of pronuclei $16-18$ hours after in vitro fertilization (IVF). In about $90 \%$ of the cases two pronuclei are observed. Most embryos showing abnormal numbers of pronuclei are polypronucleate, mainly as a result of dispermic fertilization (Plachot and Crozet, 1992). No (apronucleate) or only one pronucleus (monopronucleate) could result from parthenogenetic activation. Only embryos with two pronuclei are considered for transfer to the patient.

Karyotypic analysis of early human embryos is problematic (Handyside and Delhanty, 1993). The difficulties include low cell numbers, the absence or poor quality of metaphases and problems with spreading and banding. Despite these difficulties various chromosomal aberrations have been detected in embryos resulting from normal fertilization and in apronucleate, monopronucleate, and polypronucleate embryos. These aberrations mostly comprise chromosomal aneuploidy and mosaicism (Angell et al., 1986; Plachot et al., 1987; Plachot et al., 1989; Zenzes and Casper, 1992). However, conclusions from these studies are limited because only a few nuclei from each embryo have been analysed successfully. In this study, we have examined, by means of fluorescence in situ hybridisation (FISH) all the embryonic cells in order to determine the incidence of mosaicism in embryos resulting from normal and apparently abnormal fertilization. FISH allows the detection of specific chromo-somes, even in embryonic interphase nuclei (Griffin et al., 1991). Recently, double-target FISH, with $X$ - and $Y$-specific probes, has been used to identify the sex of preimplantation embryos for the prevention of $X$-linked diseases (Griffin et al., 1992; Griffin et al., 1993). By using this method, mosaicism and aneuploidy have been detected in preimplantation embryos (Delhanty et al., 1993). However, only a limited number of nuclei were evaluated in these studies, because of constraints imposed by the diagnostic situation. By double-target FISH for the detection of either the sex chromosomes or auto-somes 1 and 7 , we demonstrate that it is possible to examine human embryos for their chromosomal constitution and to detect chromosomal mosaicism or aneuploidy with great efficiency.

\subsection{Material \& methods}

\section{Human preimplantation embryos}

The preimplantation embryos used in this study were obtained from patients undergoing routine in vitro fertilization (IVF) at the Hammersmith Hospital, London. All patients gave written consent for the embryos to be used for research purposes. Oocytes were collected vaginally using ultrasound guidance and were inseminated with prepared sperm (day 0) as described pre-viously (Hillier et al., 1985). Embryos were checked for the presence of pronuclei approximately 18 hours after insemination using an Olympus SXH dissecting microscope. On day 2 or 3, embryos with two pronuclei were examined for cleavage and two (in exceptional circumstances three) embryos with the best morphology were transferred to the patient. 


\section{Embryo spreading}

Embryos resulting from normal fertilization and apronucleate, monopronucleate and polypronucleate embryos, were graded according to the number and quality (regular shape and volume) of blastomeres present. In some cases, blastomeres were not clearly visible or could not be identified as such, because they had desintegrated to form membrane-bound cytoplasmic fragments. Embryos that had cleaved regularly and showed fragmentation in less than $50 \%$ of the cells, were spread on day 2 or 3 . The method used for embryo spreading has been described in detail elsewhere (Coonen et al., 1994). Briefly, embryos were washed in phosphate-buffered saline (PBS; $137 \mathrm{mM} \mathrm{NaCl}, 13 \mathrm{mM} \mathrm{Na} \mathrm{HPO}_{4} \cdot 2 \mathrm{H}_{2} \mathrm{O}, 3 \mathrm{mM} \mathrm{KH}_{2} \mathrm{PO}_{4}$ in demineralized water, $\mathrm{pH} 7.4)$ for 2 minutes and transferred to a small drop of spreading solution ( $0.01 \mathrm{~N}$ $\mathrm{HCl} / 0.1 \%$ Tween 20 ) on a poly-l-lysine-coated glass slide. The spreading solution caused the zona pellucida to dissolve, the cells to lyse immediately, and the cytoplasm to dissolve while leaving intact interphase nuclei, that could then dry onto the slide. The process was observed continuously using an inverted microscope. The solution in the drop was carefully replaced with fresh spreading solution to remove as much of the dissolved material as possible. The slides were left to dry, washed in PBS for $5 \mathrm{~min}$ and dehydrated through an ascending ethanol series.

Some of the apronucleate, monopronucleate and polypronucleate embryos were disaggregated following removal of the zona pellucida with acid Tyrode's solution $\left(140 \mathrm{mM} \mathrm{NaCl}, 2.7 \mathrm{mM} \mathrm{KCl}, 1.6 \mathrm{mM} \mathrm{CaCl}{ }_{2} \cdot 2 \mathrm{H}_{2} \mathrm{O}, 0.5 \mathrm{mM} \mathrm{MgCl}{ }_{2} \cdot 6 \mathrm{H}_{2} \mathrm{O}, 5 \mathrm{mM}\right.$ glucose, $4 \mathrm{mg} / \mathrm{ml}$ polyvinylpyrrolidone (PVP) in demineralized water, $\mathrm{pH} 2.5$ ). This left the embryonic cells intact, allowing the allocation of blastomeres from one embryo to two different groups that, after spreading with $\mathrm{HCl} / \mathrm{T}$ ween, could be hybridised with probes either for the $X$ and $Y$ chromosomes or with probes for the autosomes 1 and 7.

\section{Control lymphocytes}

The efficiency of the FISH and immunocytochemical detection procedures was tested in each experiment on interphase nuclei obtained from ethanol- fixed, singlecell suspensions of male human leucocytes. By using the conditions as described in the FISH section, the association of probes to minor binding sites was limited. Analysis of the FISH signals was performed according to the criteria set by Hopman et al. (1988).

\section{Human DNA probes}

Chromosome-specific probes used in these studies were:

pBam X5 (alphoid, insert size $2.0 \mathrm{~kb}$ ) specific for the centromeric region of human $\mathrm{X}$ chromosome (Willard et al., 1983)

DYZ1 (satellite II, insert size $2.1 \mathrm{~kb}$ ) specific for the long arm of human $Y$ chromosome (Cooke et al., 1982) 
pUC 1.77 (satellite III, insert size1.77 kb) specific for the centromeric region of human chromosome 1 (Cooke and Hindley, 1979)

p7t1 (alphoid, insert size $0.68 \mathrm{~kb}$ ) that recognizes a tandem repeat in the centromeric region of the human chromosome 7 (Waye et al., 1987)

Probes were labelled by nick translation with either biotin 11-dUTP (Fermentas, Lithuania; probes for chromosomes $X$ and 1) or digoxigenin 11-dUTP (Boehringer Mannheim, Germany; probes for chromosomes $Y$ and 7 ).

Probes were purified on a Sephadex G50 column (Pharmacia, Sweden) and used at a final concentration of $1 \mathrm{ng} / \mu \mathrm{l}$ hybridisation solution (60\% formamide/2xSSC/10\% dextran sulphate/tRNA/ssDNA).

\section{FISH protocol}

The in situ hybridisation procedure was performed as described elsewhere (Coonen et al, 1994). In summary, after spreading and dehydration, slides were treated with pepsin (Sigma, USA; $100 \mu \mathrm{g} / \mathrm{ml}$ in $0.01 \mathrm{~N} \mathrm{HCl}$ ) for 20 mins at $37^{\circ} \mathrm{C}$ to remove any remnants of cytoplasm and to make the nuclear DNA accessable for hybridisation to the probes. Slides were rinsed in PBS and fixed for 10 mins with $1 \%$ paraformaldehyde/PBS at $4^{\circ} \mathrm{C}$. The slides were again rinsed in PBS and dehydrated through an ascending ethanol series. An aliquot of ten $\mu$ probe solution was added to the slide under a coverslip, and nuclear and probe DNA were denatured simultaneously for 3 mins at $75^{\circ} \mathrm{C}$. Slides were incubated at $37^{\circ} \mathrm{C}$ for overnight hybridisation. Post-hybridisation washes were performed at $42^{\circ} \mathrm{C}$ with $60 \%$ formamide/2xSSC and $2 \times S S C$ followed by two additional washes with $4 \times S S C 10.05 \%$ Tween 20 at room temperature. The biotin-labelled probes were detected by incubation with Avidin-FITC (Vector Laboratories, USA; dilution $1: 200$ in $4 \times S S C / 0.05 \%$ Tween $20,5 \%$ non fat dry milk) and, if necessary, the signal was amplified by subsequent incubations with biotinylated goat-anti Avidin (Vector Laboratories, USA; dilution 1:100 in 4xSSC/0.05\% Tween $20,5 \%$ non fat dry milk) and a second layer of Avidin-FITC. All incubations for the detection of the biotin-labelled probes were followed by washes with $4 \times$ SSC $10.05 \%$ Tween 20 at room temperature. The digoxigenin-labelled probes were detected by incubation with a mouse monoclonal antibody directed against digoxigenin (Sigma, USA; dilution 1:2000 in PBS $/ 0.05 \%$ Tween $20,5 \%$ normal goat serum) followed by an incubation with TRITC-conjugated rabbit-anti mouse antibody (Dakopatts, Denmark; dilution 1:80 in PBS $/ 0.05 \%$ Tween $20,5 \%$ normal goat serum). All incubations for the detection of the digoxigenin-labelled probes were followed by washes with PBS $/ 0.05 \%$ Tween 20 at room temperature. After immunocytochemical staining, slides were dehydrated through an ascending ethanol series and mounted in Vecta Shield (Vector Laboratories, California, USA) containing 4',6-diaminidino-2phenylindole (DAPI; $1,25 \mathrm{ng} / \mathrm{ml}$ ) to counterstain the nuclei. Nuclei were examined with a Zeiss Axiophot microscope equipped for fluorescence with UV, fluorescein and rhodamine filter sets. Analysis of the FISH signals was based on microscopic examination and all data were documented on Kodak Ektachrome 400 ASA film. 


\subsection{Results}

Some 1000 nuclei from leucocytes prepared from a healthy male, were analysed after FISH with probes specific for the sex chromosomes or autosomes 1 and 7 . Of the nuclei that were hybridised with $X$ and $Y$-specific probes, all but 2 nuclei showed hybridisation signals. In 9 nuclei signals other than $X Y$ were observed $(1 \%)\left(3^{*} X O\right.$, $\left.2^{*} O Y, 3^{*} X X Y, 1^{*} X Y Y, 1^{*} X X Y Y\right)$. The hybridisation efficiency of the autosomal probes was high (999/1000). In 7 nuclei the number of signals for one of the probes differed from the expected 2 copies (<1\%) $(3 * 1,7,72 * 1,1,72 * 1,1,1,7,7)$.

The FISH results for the nine embryos resulting from apparently normal fertilization (two pronucleate) are summarised in Table 1 . Of the 43 cells available, 39 nuclei were successfully spread. All 39 nuclei exhibited interpretable hybridisation signals. Four embryos were female (XX; fig 1a), five were male (XY; fig 1b). Mosaicism was not detected in any of these embryos.

From the seven embryos where no or only 1 pronucleus was detected, 38 nuclei were obtained from 38 cells. All nuclei gave hybridisation signals (Table 2). A Yspecific signal was detected in four embryos. Two embryos were male diploid according to the sex chromosome constitution of the nuclei (XY; cases SM10 and IO1). Embryos HA5 (fig 1c) and FR5 showed two and three copies, for chromosomes X, 1 and 7, suggesting (complete) diploidy and triploidy, respectively. Embryos L16, HI2 and BAH9 were mosaic (fig 1d-e).

The results obtained for polypronucleate embryos are summarised in table 3 . We succeeded in obtaining 123 nuclei from 132 cells. No hybridisation signals were detected in only three of the nuclei. Twenty-one embryos were scored as having three pronuclei and one embryo as having four pronuclei. Two embryos, LI8 and PL10, were male diploid (XY) and two others, PL17 (fig 1f) and LI5 (four pronuclei), were triploid (XXY in all nuclei examined) according to the sex chromosome constitution of the nuclei. In embryo FR12, four nuclei were tetraploid for sex chromosomes (XXYY), but mosaicism was detected in four other nuclei for autosomes 1 and 7. The remaining three pronucleate embryos were mosaic for both the sex chromosomes and autosomes 1 and 7 .

Table 1. FISH results for chromosome $X$ and $Y$ probes in embryos resulting from normal fertilization

\begin{tabular}{llll}
\hline $\begin{array}{l}\text { embryo } \\
\text { reference }\end{array}$ & $\begin{array}{l}\text { no. cells } \\
\text { in embryo }\end{array}$ & $\begin{array}{l}\text { no. nuclei } \\
\text { fixed }\end{array}$ & FISH X,Y \\
\hline SM9 & 5 & 3 & $X X(n=3)$ \\
B15 & 7 & 7 & $X Y(n=7)$ \\
BI14 & 5 & 4 & $X X(n=4)$ \\
CH1 & 4 & 3 & $X X(n=3)$ \\
CH8 & 6 & 7 & $X X(n=7)$ \\
CH9 & 4 & 3 & $X Y(n=3)$ \\
CH10 & 5 & 5 & $X Y(n=5)$ \\
ELL12 & 4 & 4 & $X Y(n=4)$ \\
ELS14 & 3 & 3 & $X Y(n=3)$ \\
Total & 43 & 39 & 39 \\
\hline
\end{tabular}



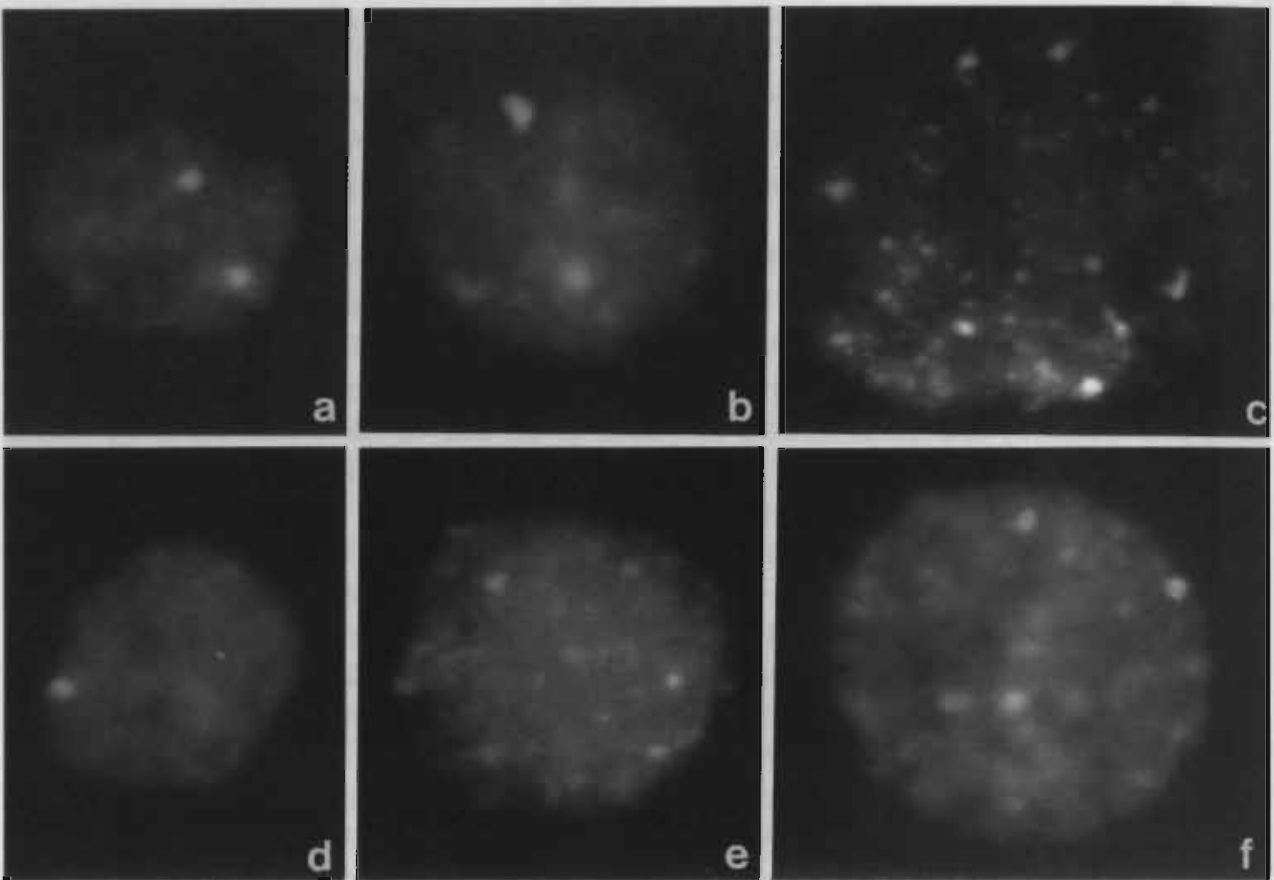

Figure 1. Double-target fluorescence in situ hybridisation results of embryonic interphase nuclei. Probes for chromosome pairs $X, 1$ and $Y, 7$ were labelled with biotin and digoxigenin and visualised with fluorescein (FITC; green) and rhodarnin (TRITC; red) conjugates, respectively. a-c Nuclei from embryos with a diploid number of sex chromosomes showing $X X$ (a), $X Y$ (b) or autosomes showing 1,1,7,7 (c); d-f Nuclei from polypronucleate embryos showing $X O(d), X X X(e)$ and $X X Y(f)$. Nuclei were counterstained with DAPI (blue). Microphotographs were taken by triple exposure for fluorescein, rhodamine and DAPI. Magnification $2500 x$

Table 2. FISH results for chromosome $X, Y$ probes and chromosome 1,7 probes in apronucleate and monopronucleate embryos

\begin{tabular}{|c|c|c|c|c|c|}
\hline $\begin{array}{l}\text { embryo } \\
\text { reference }\end{array}$ & $\begin{array}{l}\text { no. } \\
\text { pronuclei }\end{array}$ & $\begin{array}{l}\text { no. } \\
\text { cells }\end{array}$ & $\begin{array}{l}\text { no. } \\
\text { nuclei }\end{array}$ & FISH X,Y & FISH 1,7 \\
\hline $\begin{array}{l}\text { HA5 } \\
\text { FR5 } \\
\text { SM10 } \\
\text { H12 }\end{array}$ & $\begin{array}{l}0 \\
0 \\
1 \\
1\end{array}$ & $\begin{array}{l}2 \\
2 \\
8 \\
8\end{array}$ & $\begin{array}{l}2 \\
2 \\
8 \\
6\end{array}$ & $\begin{array}{l}X X(n=1) \\
X X X(n=1) \\
X Y(n=8) \\
X Y(n=5) \\
X X Y Y(n=1)\end{array}$ & $\begin{array}{l}1,1,7,7(n=1) \\
1,1,1,7,7,7(n=1)\end{array}$ \\
\hline $\begin{array}{l}101 \\
\text { Li6 }\end{array}$ & $\begin{array}{l}1 \\
1\end{array}$ & $\begin{array}{l}7 \\
7\end{array}$ & $\begin{array}{l}8 \\
8\end{array}$ & $\begin{array}{l}X Y(n=8) \\
X O(n=2) \\
X X(n=6)\end{array}$ & \\
\hline ВАH9 & 1 & 4 & 4 & $\begin{array}{l}X X Y(n=1) \\
X X X X Y Y(n=1)\end{array}$ & $\begin{array}{l}1,1,7,7,7(n=1) \\
1,1,1,7,7,7,7(n=1)\end{array}$ \\
\hline Total & 38 & 38 & 38 & & \\
\hline
\end{tabular}


Table 3. FISH results for chromosome $X, Y$ probes and/or chromosome 1,7 probes in polypronucleate embryos

\begin{tabular}{|c|c|c|c|c|c|}
\hline $\begin{array}{l}\text { embryo } \\
\text { reference }\end{array}$ & $\begin{array}{l}\text { no. } \\
\text { pronuclei }\end{array}$ & $\begin{array}{l}\text { no. } \\
\text { cells }\end{array}$ & $\begin{array}{l}\text { no. } \\
\text { nuclei }\end{array}$ & FISH $X, Y$ & $\mathrm{FISH} 1.7$ \\
\hline $\mathrm{SM} 7$ & 3 & 5 & 5 & $\begin{array}{l}X Y Y(n=2) \\
X X X X Y(n=1) \\
X X X Y Y(n=1) \\
X X X X X Y Y(n=1)\end{array}$ & \\
\hline LI7 & 3 & 4 & 4 & $\begin{array}{l}X Y(n=1) \\
X X Y(n=1) \\
X X X(n=1) \\
O O(n=1)\end{array}$ & \\
\hline $\begin{array}{l}\text { LLI8 } \\
\text { LI9 }\end{array}$ & $\begin{array}{l}3 \\
3\end{array}$ & $\begin{array}{l}6 \\
6\end{array}$ & $\begin{array}{l}3 \\
6\end{array}$ & $\begin{array}{l}X Y(n=3) \\
X X(n=2) \\
X O(n=3) \\
X X X(n=1)\end{array}$ & \\
\hline LI3 & 3 & 3 & 3 & $\begin{array}{l}X Y(n=1) \\
X X Y(n=1) \\
X X X Y(n=1)\end{array}$ & \\
\hline BAK9 & 3 & 6 & 6 & $\begin{array}{l}X X(n=1) \\
X Y Y(n=2)\end{array}$ & $\begin{array}{l}1,1,7,7(n=2) \\
1,7,7,7(n=1)\end{array}$ \\
\hline $\begin{array}{l}\text { BAK15 } \\
\text { FR12 }\end{array}$ & $\begin{array}{l}3 \\
3\end{array}$ & $\begin{array}{l}3 \\
9\end{array}$ & $\begin{array}{l}2 \\
9\end{array}$ & $\begin{array}{l}X X Y(n=1) \\
X X Y Y(n=4)\end{array}$ & $\begin{array}{l}1,1,7,7,7,7,7(n=1) \\
1,1,1(n=1) \\
1,1,1,7(n=1) \\
1,1,7,7,7(n=1) \\
1,1,7,7,7,7(n=1) \\
0 \%(n=1)\end{array}$ \\
\hline SK3 & 3 & 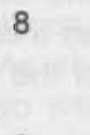 & 10 & $\begin{array}{l}X X(n=4) \\
X O(n=2) \\
X X X(n=3) \\
X Y Y(n=1)\end{array}$ & \\
\hline SK12 & 3 & 8 & 6 & $\begin{array}{l}X Y(n=3) \\
X X Y(n=1) \\
X X X X(n=1) \\
X X X Y(n=1)\end{array}$ & \\
\hline SK9 & 3 & 4 & 4 & $\begin{array}{l}X Y(n=1) \\
Y Y Y(n=1) \\
X X Y Y(n=2)\end{array}$ & \\
\hline SK10 & 3 & 8 & 7 & $\begin{array}{l}X X(n=3) \\
X O(n=2) \\
X X X(n=2)\end{array}$ & \\
\hline BA1 & 3 & 4 & 4 & $\begin{array}{l}X Y(n=2) \\
X O(n=1) \\
\text { YO }(n=1)\end{array}$ & \\
\hline BA2 & 3 & 6 & 6 & $\begin{array}{l}X Y(n=3) \\
X Y Y Y(n=1) \\
X X Y Y Y Y(n=1) \\
X O(n=1)\end{array}$ & \\
\hline BA7 & 3 & 8 & 6 & $\begin{array}{l}X Y(n=3) \\
X X Y(n=2) \\
Y O(n=1)\end{array}$ & \\
\hline SA3A & 3 & 7 & 7 & $\begin{array}{l}X Y Y(n=6) \\
X X Y Y Y Y(n=1)\end{array}$ & \\
\hline GR7 & 3 & 7 & 4 & $\begin{array}{l}X O(n=3) \\
X Y(n=1)\end{array}$ & \\
\hline PL15 & 3 & 7 & 7 & $\begin{array}{l}X X(n=2) \\
X X X(n=4) \\
X O(n=1) \\
X X Y(n=4)\end{array}$ & \\
\hline PL17 & 3 & 4 & 4 & $X X Y(n=4)$ & \\
\hline
\end{tabular}


table 3 continued

\begin{tabular}{llllll}
$\begin{array}{l}\text { embryo } \\
\text { reference }\end{array}$ & $\begin{array}{l}\text { no. } \\
\text { pronuclei }\end{array}$ & $\begin{array}{l}\text { no. } \\
\text { cells }\end{array}$ & $\begin{array}{l}\text { no. } \\
\text { nuclei }\end{array}$ & FISH X,Y & FISH 1,7 \\
PL10 & 3 & 7 & 9 & XY $(n=9)$ & \\
KN4 & 3 & 5 & 3 & & $1,7(n=1)$ \\
LI5 & 4 & 7 & 8 & $X X Y(n=8)$ & $1,1,7(n=1)$ \\
Total & & 132 & 123 & 120 & \\
\hline
\end{tabular}

\subsection{Discussion}

Cytogenetic analysis of human preimplantation embryos, especially for the detection of aneuploidy and mosaicism, has been hampered by the problems of obtaining informative chromosome spreads. As an alternative, we have used an improved spreading method for analysis of all embryonic interphase nuclei by FISH (Coonen et al., 1994; Harper et al., 1994). Our goal was to examine the extent of mosaicism. In the majority of cases, we were able to analyse all cells from an embryo because of the high spreading efficiency of our method $(200 / 213=94 \%)$. Discrepancies between the numbers of cells or nuclei obtained and expected are attributable to anucleate and multinucleate cells at cleavage stages (Hardy and Handyside, 1993). Hybridisation signals were detected in almost all of the nuclei examined (197/200; $99 \%)$.

The evaluation of the FISH results on single embryonic nuclei requires strict criteria, as the reference population (remainder of the nuclei from the same embryo) is small. The interpretation of the data needs to be performed with great care, especially in the case of apronucleate, monopronucleate or polypronucleate embryos, were abnormal chromosome copy numbers are to be expected.

The majority of mosaic chromosome patterns that were found in the embryos used for this study, was based on the gain of DNA material. It is unlikely that the presence of supernumerical signals is caused by FISH artefacts. Loss of DNA material, indicated by the presence of supra-numerical signals can be more complicated to interpret. In our study, the absence of signals is unlikely to be the result of inefficient hybridisation because of the high hybridisation efficiency of embryonic nuclei $(99 \%)$ and the low number of aberrations in control cells $(<1 \%)$. Moreover, only 3 of the 24 nuclei showed no (normal) disomy for either the sexchromosomes or the autosomes and no hybridisation signals. In all other cases, at least one FISH signal was detected, thereby establishing that the nuclear DNA was accessible and that successfull hybrid-formation was indeed possible. The under-estimation of chromosome copy number could be a result of co-localization of FISH signals. This general phenomenon occurs at low frequency and is inevitable (Hopman et al., 1988).

In the embryos resulting from normal fertilization, all nuclei were male $(X Y)$ or female $(X X)$ diploid (Table 1 ), confirming the reliability of the FISH procedure as demonstrated in lymphocytes. However, during preimplantation diagnosis of inherited 
disease, chromosomal mosaicism has been detected in some embryos that had shown two pronuclei (Delhanty et al., 1993). We have examined a larger series of embryos resulting from normal fertilization (as indicated by the presence of two pronuclei) and detected chromosomal mosaicism for the sex chromosomes and autosomes 1 and 17 (Harper et al., in preparation). Only in exceptional cases (for example $X O / X Y$ ) the presence of chromosomal mosaicism or chromosomal aneuploidy can be detected by PCR (Chong et al., 1993) and therefore FISH should be the preferred procedure for sexing embryos.

Among the seven embryos classified as parthenogenically activated, based on the observation of no or only one pronucleus, the nuclei of four of the embryos contained a Y-specific hybridisation signal, indicating that fertilization had indeed occurred. One of these embryos was polyploid mosaic (BAH9). The nuclei of embryo FR5 contained three copies of the $X$ chromosome and autosomes 1 and 7 , suggesting (complete) triploidy, most probably caused by polyspermic fertilization.

Cytogenetic studies by Plachot et al. (1989), revealed that in $86 \%$ of the cases triploid zygotes result from diandry. None of the embryos examined was haploid, although 2 of the 8 cells in one embryo (Li6) were XO. The demonstration of a diploid DNA content in an embryo initially classified as parthenogenically activated is in accordance with recent work by Staessen et al. (1993) who found that in $25 \%$ of cases where one pronucleus was observed, a second pronucleus could be identified if the oocytes were examined a few hours later because of the asynchronous formation of the pronuclei.

Mosaicism was detected in embryo BAH9. The pattern resembled the findings in most polypronucleate embryos which appeared to be polyploid mosaics for the chromosomes analysed. As shown by FISH, two polypronucleate embryos were diploid (LI8, PL10) and two were triploid (PL17, LI5), but most of these embryos exhibited mosaicism. Diploidy in stead of triploidy can result from the misidentification of a vacuole as a pronucleus (Van Blerkom et al., 1987) or non-incorporation of one of the pronuclei at syngamy (Angell et al., 1986; Plachot et al., 1989; Pieters et al., 1992). Co-localization of the FISH signals also leads to under-estimation of chromosome copy number. The triploid embryos presumably arose from chromosomes gathering on a single metaphase plate followed by normal cell division (Angell et al., 1986; Plachot et al., 1989; Pieters et al., 1992). The tetra-pronucleate (LI5) was uniformly triploid $(X X Y)$, suggesting that only three out of the four pronuclei were involved in syngamy. Mosaicism can arise from chromosomes aligning on a tripolar spindle; this leads to disorganised chromosomal movement and an uneven number of chromosomes segregating to the daughter cells (Angell et al., 1986; Kola et al., 1987; Pieters et al., 1992; Plachot and Crozet, 1992). These data are supported by the direct observation of a tripolar spindle and the formation of three daughter cells after the first cleavage division (Plachot, 1991). Tripolar spindle division may explain the chromosome distribution in embryo Li3 which had three cells. Each of the nuclei was successfully spread and analysed. The sum of the chromosomes is as would be expected after one cell division, if one $X$ and one $Y$ bearing sperm had fertilised the oocyte (i.e. $6 \mathrm{X}$ and $3 \mathrm{Y}$ ). In contrast to cytogenetic studies, FISH only yields information on the copy number of the chromosomes, or chromosome parts, under investigation. It is not possible to differentiate between trisomy or triploidy on the basis of the sex chromosomes only. This phenomenon hampers the evaluation 
of the signal patterns that are found. On the other hand, embryo FR12 showed a tetraploid complement for the sex chromosomes in four nuclei but mosaicism for autosomes 1 and 7 in four other nuclei. This embryo was grossly abnormal. The chromosomal imbalances apparently resulted from the irregular distribution of chromosomes after cell division.

Recently it has been possible to reprobe nuclei after a first hybridisation procedure with an additional probe for an autosome (Munné et al., 1993a) or to apply multicolour FISH to increase the scope of the FISH procedure (Coonen et al., 1993, Munné et al., 1993b). In the future, the comparative genomic hybridisation (CGH) method might enable analysis of the whole genome on a single cell basis, after universal amplification of the DNA (Speicher et al., 1993).

Acknowledgements: We would like to thank Dr. Robert Winston, Karin Dawson and all the staff of the Wolfson Family Clinic, Hammersmith Hospital. This work was approved by the Research Ethics Committee of the Royal Postgraduate Medical School, Hammersmith Hospital, and the Human Fertilization and Embryology Authority, UK. Edith Coonen received financial support from the Netherlands Foundation for Scientific Research (NWO), the Foundation for Scientific Research Limburg (SWOL) and Simons Foundation. Joyce Harper is supported by the Wellcome Trust.

\subsection{References}

Angell RR, Templeton AA \& Messinis IE (1986) Consequences of poyspermy in man. Cytogenet Cell Genet 42:1-7

Chong SS, Kristjansson K, Cota J, Handyside AH \& Hughes MR (1993) Preimplantation prevention of $\mathrm{X}$-linked disease: a reliable and rapid sex determination of single human cells by restriction analysis of simultaneously amplified ZFX and ZFY sequences. Hum $\mathrm{Mol}$ Genet 2:1187-1191

Cooke HJ \& Hindley J (1979) Cloning of human satellite III DNA: different components are on different chromosomes. Nucleic Acid Res 6:3177

Cooke HJ, Schmidtke J \& Gosden JR (1982) Characterisation of a human Y chromosome repeated sequence and related sequences in higher primates. Chromosoma 87:491-502

Coonen E, Harper JC, Geraedts JPM, Handyside AH, Ramaekers FCS \& Hopman AHN (1993) Multicolor fluoresent in situ hybridisation with repetitive and cosmid DNA probes on single embryo cells for human preimplantation diagnosis. Am J Hum Gen 53 (suppl): abstract 1394

Coonen E, Dumoulin JCM, Ramaekers FCS \& Hopman AHN. Optimal preparation of preimplantation embryo interphase nuclei for analysis by fluoresence in situ hybridisation (1994) Hum Reprod 3:533-537

Delhanty JDA, Griffin DK, Handyside AH, Harper JC, Atkinson GHG, Pieters MHEC \& Winston RML (1993) Detection of aneuploidy and chromosomal mosaicism in human embryos during preimplantation sex determination by fluorescence in situ hybridisation, (FISH). Hum Mol Gen 2:1183-1185

Griffin DK, Handyside AH, Penketh RJA, Winston RML \& Delhanty JDA (1991) Fluorescent in-situ hybridisation to interphase nuclei of human preimplantation embryos with $X$ and $Y$ chromosome specific probes. Hum Reprod 6:101-105 
Griffin DK, Wilton LJ, Handyside AH, Winston RML \& Delhanty JDA (1992) Dual Fluorescent in situ hubridisation for simultaneous detection of $X$ and $Y$ chromosome-specific probes for the sexing of human preimplantation embryonic nuclei. Hum Gen 89:18-22

Griffin DK, Wilton LJ, Handyside AH, Atkinson GHG, Winston RML \& Delhanty JDA (1993) Diagnosis of sex in preimplantation embryos by fluorescent in situ hybridisation. Brit Med J 306:1382

Handyside AH \& Delhanty JDA (1993) In; Edwards, RG (ed.) Preconception and Preimplan tation diagnosis of Genetic Disease. Cambridge University Press, Cambridge pp239-270

Hardy K, Winston RML \& Handyside AH (1993) Binucleate blastomeres in preimplantation human embryos in vitro: failure of cytokinesis during early cleavage. J Reprod Fert 98:549558

Harper JC, Coonen E, Ramaekers FCS, Delhanty JDA, Handyside AH, Winston RML \& Hopman AHN (1994) Identification of the sex of human preimplantation embryos in two hours using an improved spreading method and fluorescent in-situ hybridization (FISH) using directly labelled probes. Hum Reprod 4:721-724

Harper JC, Coonen E, Handyside AH, Winston RML, Hopman AHN \& Delhanty JDA Detection of sex chromosome and autosome mosaicism in normally fertilised preimplantati on human embryos. (Prenat Diagn, in press)

Hillier SG, Afnan AMM, Margara RA \& Winston RML (1985) Superovulation strategy before in vitro fertilization. Clin Obstet Gynaecol 12:687-723

Hopman AHN, Ramaekers FCS, Raap AK, Beck JLM, Devilee P, Ploeg van der M \& Vooijs GP (1988) In situ hybridization as a tool to study numerical chromosome aberrations in solid bladder tumors. Histochemistry 89:307-316

Kola I, Trounson A, Dawson G \& Rogers P (1987) Tripronuclear human oocytes:altered cleavage patterns and subsequent karyotypic analysis of embryos. Biol Reprod 37:395-401

Munné S, Weier H-UG, Stein J, Grifo J \& Cohen JA (1993a) A fast and efficient method for simultaneous $X$ and $Y$ in situ hybridization of human blastomeres. J Ass Reprod Genet 10:82-90

Munné S, Lee A, Rosenwaks Z, Grifo J \& Cohen J (1993b) Diagnosis of major chromosome aneuploidies in human preimplantation embryos. Hum Reprod 8:2185-2191

Pieters MHEC, Dumoulin JCM, Ignoul-Vanvuchelen RCM, Bras M, Evers JLH \& Geraedts JPM (1992) Triploidy after in vitro fertilization: cytogenetic analyis of human zygotes and embryos. J Ass Reprod Gen 9:68-76

Plachot M, Junca A-M, Mandelbaum J, Grouchy J de, Salat-Baroux J \& Cohen J (1987) Chromosome investigations in early life. II. Human preimplantation embryos. Hum Reprod 2:29-35

Plachot M, Mandelbaum J, Junca A-M, Grouchy J de, Salat-Baroux J \& Cohen J (1989) Cytogenetic analysis and developmental capacity of normal and abnormal embryos after IVF. Hum Reprod 4:99-103

Plachot M \& Crozet N (1992) Fertilization abnormalities in human in-vitro fertilization. Hum Reprod 7:89-94

Plachot M (1991) Chromosome analysis of oocytes and embryos. In: Verlinsky $Y$, Kuliev A (eds) Preimplantation Genetics. Plenum Press, New York, pp103-112 
Speicher MR, Manoir du S, Schröck E, Holtgreve-Grez H, Schoell B, Lengauer C, Cremer T \& Ried T (1993) Molecular cytogenetic analysis of formalin-fixed, paraffin-embedded solid tumors by comparative genomic hybridization after universal DNA-amplification. Hum Mol Gen 11:1907-1914

Staessen C, Janssenswillen C, Devroey P \& Van Steirteghem AC (1993) Cytogenetic and morphological observation of single pronucleated human oocytes after in vitro fertilization. Hum Reprod 8:221-223

Van Blerkom J, Bell H \& Henry G (1987) The occurrence,recognition and development of pseudo-multipronuclear eggs after in-vitro fertilization of human oocytes. Hum Reprod 2:217-225

Waye JS, England SB \& Willard HF (1987) Genomic organization of alpha satellite DNA on human chromosome 7: evidence for two distinct alphoid domains on a single chromosme. Mol Cell Biol 7:349

Willard HF, Smith KD \& Sutherland $J(1983)$ Isolation and characterization of a major tandem repeat family from the human $X$ chromosome. Nucleic Acid Res 11:2017-2033

Zenzes MT \& Casper RF (1992) Cytogenetics of human oocytes, zygotes and embryos after in vitro fertilization. Hum Genet 88:367-375 


\section{Detection of sex chromosome and autosome mosaicism in normally fertilised preimplantation human embryos}

Joyce C Harper, Edith Coonen, Alan $\mathrm{H}$ Handyside, Robert Winston, Anton HN Hopman \& Joy DA Delhanty

Prenatal Diagnosis, in press 1994

We have previously detected chromosome abnormalities in human embryos whilst identifying the sex for preimplantation diagnosis of $X$-linked disease. In this study we assess the incidence of these abnormalities, both for sex chromosomes and autosomes 1 and 17, using dual fluorescence in situ hybridisation (FISH). Sixty nine normally fertilised embryos of good morphology at the 6-10 cell stage (day 3 post insemination) were examined. The embryos were spread whole using $\mathrm{HCl}$ and Tween 20 to dissolve the cytoplasm. Thirty four embryos were analysed for the sex chromosomes and thirty five for autosomes 1 and 17. All probes were directly labelled with fluorochromes allowing analysis in two hours. Control lymphocytes demonstrated that the probes were of high specificity. For the sex chromosomes, five embryos were mosaic (15\%) with the remaining 29 being uniformly $X X$ or $X Y$. In no case was an $X X$ nucleus found in an otherwise $X Y$ embryo, indicating that even though mosaicism for the sex chromosomes is present, such abnormalities would not lead to a misdiagnosis of sex. For the autosomes, sixteen embryos were abnormal $(46 \%)$. The presence of haploidy or double monosomy, which occurred in $15 \%$ of nuclei, has important implications for the diagnosis of trisomies and dominant disorders.

\subsection{Introduction}

Since 1991 we have used dual fluorescence in situ hybridisation (FISH) with $X$ and $Y$ chromosome specific probes to sex human embryos for preimplantation diagnosis in patients at risk of transmitting X-linked disorders (Griffin et al., 1992, Griffin et al., 1994. Harper and Handyside, 1994). Patients undergo routine IVF procedures (Hillier et al., 1985) and 1-2 blastomeres are biopsied from normally fertilised embryos on day 3 (6-10 cell stage) (Han-dyside, 1991). The blastomeres are spread and dual 
FISH performed with $X$ and $Y$ chromosome specific probes (Griffin et al., 1993). This can now be performed within two hours using directly-labelled probes (Harper et al., 1994a). Only if two $X$ chromosome signals are present in the absence of a $Y$ signal is the embryo diagnosed as female. Following selection of up to two, $\mathrm{XX}$, female embryos for transfer to the patient, the rejected embryos are spread and dual FISH performed to confirm the original diagnosis. In the process of identifying the sex of embryos we have also detected abnormalities in the number of sex chromosomes present both in the biopsied blastomeres and on analysis of the rejected embryos, such as $X O, X X X, X X Y$ and $X X X X$ (Delhanty et al., 1993).

For preimplantation diagnosis, it is important to establish the type and incidence of chromosomal abnormalities to determine whether they could lead to a misdiagnosis. Karyotyping studies of human embryos have identified chromosome abnormalities and mosaicism (reviewed in Zenzes and Casper, 1992) but these studies are limited by the low proportion of cells that can be analysed in each embryo (Handyside and Delhanty, 1993). The use of FISH has the advantage that it allows the analysis of almost every nucleus in the embryo. Recent studies using multicolour FISH on mainly arrested embryos have detected chromosomal aberrations of various types in over $70 \%$ of embryos (Munne et al., 1993) and with polyspermic embryos we have demonstrated a high level of mosaicism (Coonen et al., 1994b). To determine the extent of sex chromosome and autosome 1 and 17 abnormality in normally developing, monospermic human preimplantation embryos we have used directly-labelled probes for chromosomes $X$ and $Y$ and 1 and 17 in a dual FISH procedure.

\subsection{Materials \& methods}

\section{Preimplantation embryos}

After obtaining written consent, preimplantation embryos were donated from patients undergoing routine IVF procedures at the Hammersmith Hospital, London, UK. The study was approved by the Human Fertilization and Embryology Authority and the Research Ethics Committee of the Royal Postgraduate Medical School, Hammersmith Hospital. The embryos used in this study were all normally fertilised (presence of two pronuclei observed $18 \mathrm{~h}$ after insemination) and of good morphology (i.e. less than $25 \%$ blastomere fragmentation).

\section{Embryo spreading}

All embryos were spread on day 3 post insemination using the method previously described for whole mouse embryos (Coonen et al., 1994a), whole human embryos (Harper et al., 1994b, Coonen et al., 1994b) and single blastomeres (Harper et al., 1994a). In brief, any cumulus cells still adhering to the zona pellucida were removed by gentle pipetting and the embryo washed in phosphate-buffered saline (PBS) for 2 min and transferred to a small drop of spreading solution $(0.01 \mathrm{~N} \mathrm{HCl}, 0.1 \%$ Tween20) on a poly-L-lysine coated slide. The embryo was constantly observed using an inverted microscope and the spreading solution removed and replaced. 
As the zona pellucida and the cytoplasm dissolved, the nuclei were washed by gentle agitation until clear. The slides were left to air dry and dehydrated through an ethanol series.

\section{Control lymphocyte analysis}

The efficiency of the FISH was tested in each experiment on interphase nuclei obtained from ethanol-fixed, single cell suspensions of male and female human leukocytes as described previously (Harper et al., 1994a).

\section{Directly labelled human DNA probes}

Probes used in this study were as follows: pBam X5; alphoid probe (insert size $2.0 \mathrm{~kb}$ ), specific for the centromeric region of the human $X$ chromosome (Willard et al., 1983): DYZ1; satellite probe (insert size 2.1kb), specific for the long arm of the human Y chromosome (Cooke et al., 1982): pUC 1.77, satellite III probe (insert size $1.77 \mathrm{~kb})$ specific for the centromeric region of human chromosome 1 (Cooke and Hindley, 1979) and p17H8, alphoid repeat probe (insert size $2.70 \mathrm{~kb}$ ) specific for human chromosome 17 (Waye and Willard, 1986).

The probes for chromosome $X$ and 1 were directly labelled by nick translation with FITC-12-dUTP (Boehringer, Mannheim, Germany) and $Y$ and 17 with rhodamine-4dUTP (Amersham, UK) and used in a final concentra-tion of 1-2 $\mathrm{ng} / \mu \mathrm{l}$ of hybridisation mixture.

\section{FISH}

The method used was as described previously (Harper et al., 1994a). In brief, the slides were treated with pepsin $(100 \mu \mathrm{g} / \mathrm{ml})$ for $20 \mathrm{~min}$ at $37^{\circ} \mathrm{C}$, rinsed in bi-distilled water and PBS, and fixed for $10 \mathrm{~min}$ in $1 \%$ paraformaldehyde in PBS at $4^{\circ} \mathrm{C}$. The slides were rinsed in PBS and bi-distilled water and dehydrated. The probes (either $X$ and $Y$ or 1 and 17) were added to the slide under a coverslip and nuclear and probe DNA denatured simulta-neously at $75^{\circ} \mathrm{C}$ for $3 \mathrm{~min}$. To allow hybridisation, the slides were incubated for $45 \mathrm{~min}$ at $37^{\circ} \mathrm{C}$ in a moist chamber. Post-hybridisation washes consisted of $5 \mathrm{~min}$ in $60 \%$ formamide/2xSSC at $42^{\circ} \mathrm{C}, 5 \mathrm{~min}$ in $2 \times S S C$ at $42^{\circ} \mathrm{C}$ and two, 5 min washes in $4 \times S S C / 0.05 \%$ Tween 20 at room temperature. The slides were dehydrated through an ethanol series and mounted in Vectashield (Vector Laboratories, USA) anti-fade medium containing $1 \mathrm{ng} / \mathrm{ml}$ DAPI to counterstain the nuclei and examined under a Reichert Jung Polyvar fluorescence microscope using the U1, B1 and G2 filter sets. Using the above conditions, hybridisation efficiency was optimal and binding of the probes to minor binding sites was minimal. Analysis of the FISH signals was as described previously (Hopman et al., 1988). Photographs were taken using Scotch 640T film using triple exposure. 


\subsection{Results}

\section{Control lymphocytes}

A total of 200 female and 200 male leukocytes were examined for $X$ and $Y$ probe hybridisation and $100 \%$ gave signals. All were normal $X X$ or $X Y$ except seven nuclei $(1.8 \%$ ) (male nuclei - $2 \mathrm{XO}, 1 \mathrm{XXY}, 1 \mathrm{XYY}$, female nuclei - $3 \mathrm{XO}$ ). For the probes for chromosomes 1 and 17, 200 leukocytes were examined and $100 \%$ gave signals. All were normal diploid except five ( $2.5 \%$ ) ( 2 nuclei gave $1,1,17$ signals and 3 nuclei gave $1,17,17$ signals).
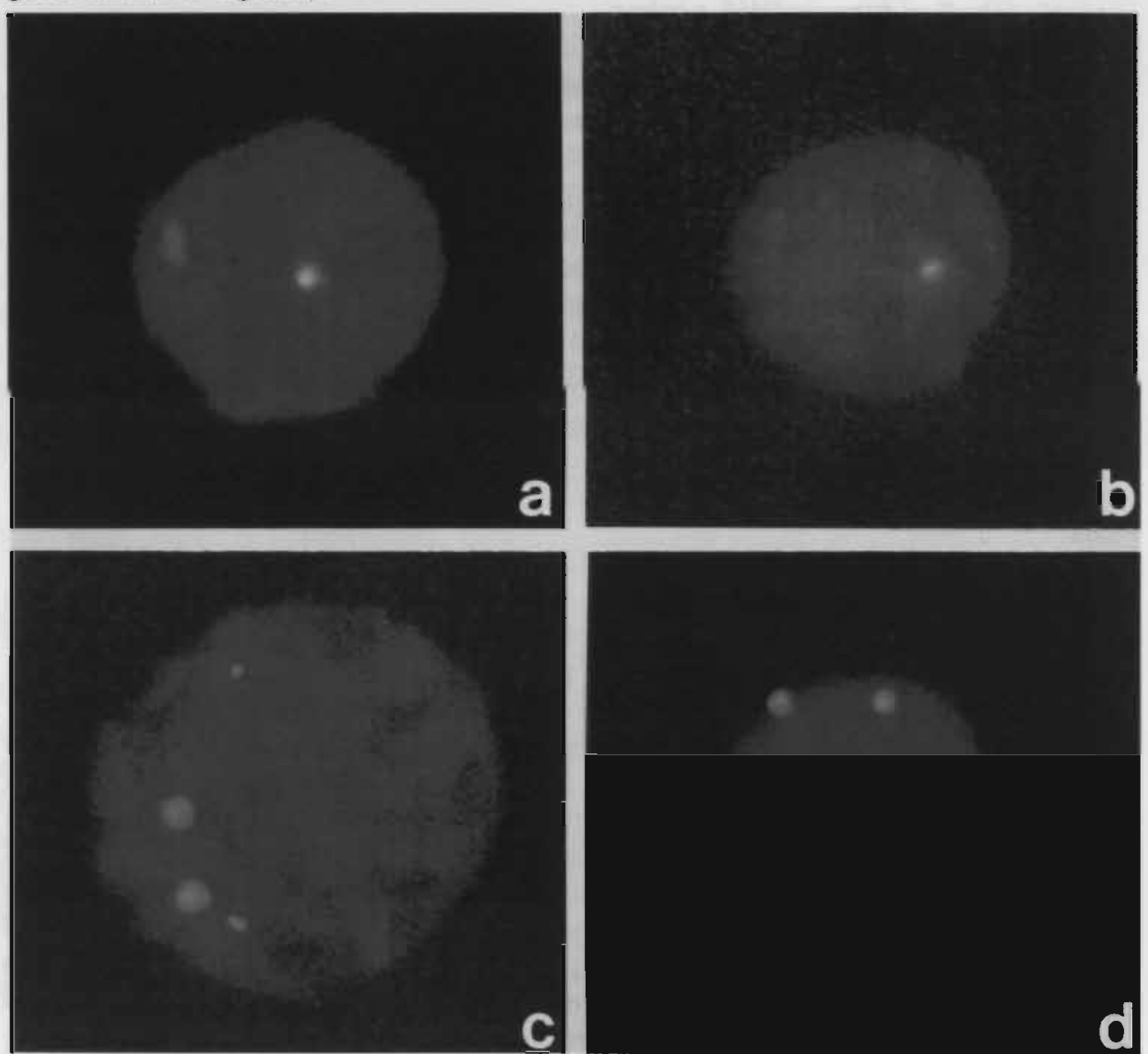

Figure 1. a/b Dual fluorescent in situ hybridisation using directly-labelled DNA probes for chromosomes $X$ (green) and $Y$ (red) on human embryonic nuclei; a male nucleus; $b$ XO nucleus. c/d Dual fluorescent in situ hybridisation using directly-labelled DNA probes for the autosomes 1 (green) and 17 (red) on human embryonic nuclei; $\mathbf{c}$ normal diploid; $\mathbf{d}$ tetraploid nucleus 


\section{Preimplantation embryos}

In total, 69 normally fertilised embryos were analysed; 34 for chromosomes $X$ and $Y$ and 35 for chromosomes 1 and 17 . Nuclei were located in 451 of 475 blastomeres $(95 \%)$ and 439 gave FISH signals $(97 \%)$. This included six nuclei where signals could not be interpreted as they were incomplete metaphases.

In some embryos, fewer nuclei than blastomeres were obtained either due to anucleate blastomeres or loss of nuclei during the spreading procedure and in some cases more nuclei were obtained, probably due to binucleate blastomeres (Hardy et al., 1993, Harper et al., 1994a).

Table 1 summarises the results for embryos hybridised to probes for chromosomes $X$ and $Y$ (embryos with the same letter were from the same patient). A total of 34 embryos from 18 patients were examined. In seventeen embryos, all nuclei which gave a signal were uniformly $X Y$ (figure 1a) and twelve were $X X(85 \%)$. In five embryos, mosaicism for the sex chromosomes was identified (15\%). In one embryo, ten nuclei were $X X$ and one had $X X X X$ signals. In one embryo in which five nuclei were examined, two nuclei were $X Y$ and three were $X X Y$. For three embryos, between one and three nuclei were shown to be $X O$ (figure $1 \mathrm{~b}$ ). In the case of embryo $R$, three nuclei were $X X$ and only one was found to be $X O$. For embryo Kiii, three $X O$ nuclei were detected in an XX embryo and in embryo Eiv, two XO nuclei were detected in an XY embryo. From the 34 embryos probed for the sex chromosomes, a total of 200 nuclei gave signals, with only ten showing abnormal numbers $(5 \%)$.

Table 2 summarises the results for embryos analysed for chromosomes 1 and 17 (embryos with the same number were from the same patient). A total of 35 embryos from 17 patients were examined. Nineteen embryos uniformly gave two signals for each probe (54\%) (figure 1c). One embryo was assumed to be completely triploid as three signals were observed for each chromosome (embryo 3ii). In the remaining embryos, evidence for chromosomal mosaicism was detected. Ten embryos were mostly normal diploid with one or two abnormal nuclei; in two there was evidence that this was due to mitotic non-disjunction and two had one nucleus classed as tetraploid (figure 1d). In the case of embryo 14, in the abnormal nucleus only three chromosome 17 signals were detected but the nucleus was classified as tetraploid as it is likely that with such a large number of signals some were overlapping. Embryo 12iii had two nuclei out of seven with three signals for each probe indicating that this embryo was a mosaic either for triploidy or double trisomy. For embryos $1 \mathrm{ii}$, 2iv, 8iii and 13ii, haploid (or double monosomy) nuclei were present. For embryo 16i in one nucleus only one chromosome 1 signal was present which may have been due to overlapping signals or inefficient hybridisation, but the loss of one copy of chromosome 1 cannot be dismissed. Five embryos were classified as 'highly abnormal' as the majority of nuclei showed varying abnormalities. One of these was monosomic for chromosome 1, with one of the four nuclei being tetraploid (embryo 7ii).

From the 35 embryos probed for chromosomes 1 and 17, a total of 239 nuclei gave signals of which 47 showed abnormal numbers $(20 \%)$. Thirty five nuclei gave fewer $\& 2$

signals $(15 \%)$ and twelve gave more $(5 \%)$ than the expected normal diploid number. 
Table 1. results of dual FISH using probes for chromosome $X$ and $Y$ on human preimplantation embryos

\begin{tabular}{lccc}
\hline $\begin{array}{l}\text { embryo } \\
\text { reference }\end{array}$ & $\begin{array}{c}\text { no. cells } \\
\text { (pre spreading) }\end{array}$ & $\begin{array}{c}\text { no. nuclei } \\
\text { (post spreading) }\end{array}$ & FISH result \\
\hline
\end{tabular}

\section{normal female}

$\begin{array}{ll}\mathrm{A} & 5 \\ \mathrm{Bi} & 5 \\ \mathrm{Ci} & 4 \\ \mathrm{Cii} & 6 \\ \mathrm{Di} & 8 \\ \mathrm{Ei} & 3 \\ \mathrm{Eii} & 6 \\ \mathrm{~F} & 5 \\ \mathrm{Gi} & 7 \\ \mathrm{Gii} & 7 \\ \mathrm{H} & 5 \\ \mathrm{I} & 8\end{array}$

3

4

3

7

8

3

7

4

7

7

5
7

normal male

Bii

Ciii

Civ

Dii

Diii

Div

Eiii

Ji

Jii

$\mathrm{Ki}$

Kii

L

$M$

N

O

$P$

Q

mosaic

Kiv

Nii

Eiv

Kiii

$\mathrm{R}$ $3(x X)$

$4(X X)$

$3(X X)$

$7(X X)$

$8(X X)$

$2(X X), 1(00)$

$7(X X)$

$4(X X)$

$7(X X)$

$7(X X)$

$5(x X)$

$7(X X)$

$7(X Y)$

$3(X Y)$

$5(X Y)$

$6(X Y)$

$6(X Y)$

$12(X Y)$

$3(X Y)$

$4(X Y)$

$3(X Y)$

$11(X Y)$

$2(X Y), 2(00)$

$6(X Y)$

$7(X Y)$

$3(X Y)$

$10(X Y), 2$ met $^{\text {a }}$

$8(X Y)$

$8(X Y)$

$10(X X), 1(X X X X)$

$2(X Y), 3(X X Y)$

$1(X Y), 2$ (XO)

$6(X X), 3(X O)$

$3(X X), 1(X O)$

Embryos with the same letter are from the same patient

- metaphase 
Table 2. results of dual FISH with probes for chromosomes 1 and 17 on human preimplantation embryos

\begin{tabular}{|c|c|c|c|}
\hline $\begin{array}{l}\text { embryo } \\
\text { reference }\end{array}$ & $\begin{array}{c}\text { no. cells } \\
\text { (pre spreading) }\end{array}$ & $\begin{array}{c}\text { no. nuclei } \\
\text { (post spreading) }\end{array}$ & FISH result \\
\hline
\end{tabular}

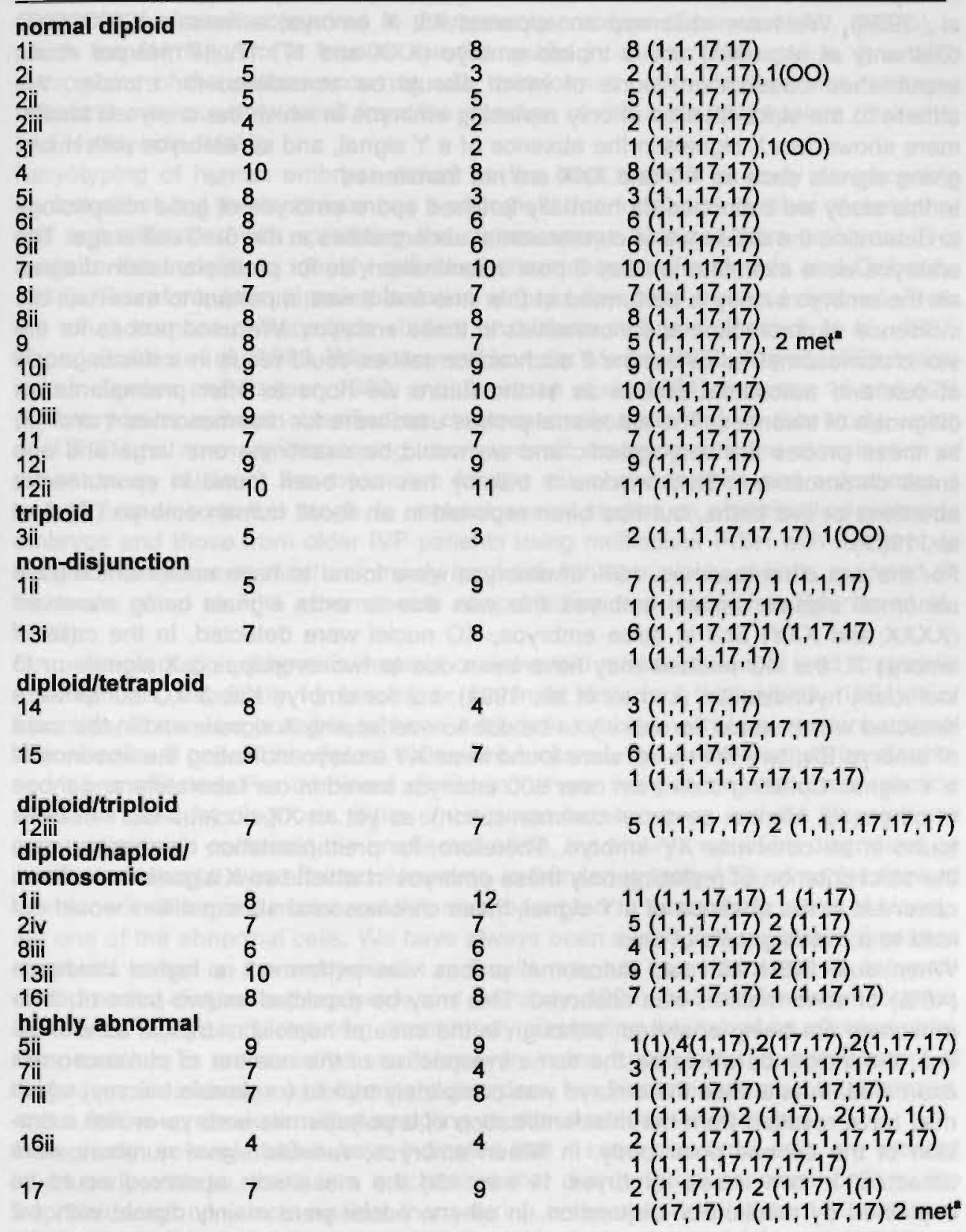

Embryos with the same number are from the same patient; "metaphase 


\subsection{Discussion}

During the last three years in our preimplantation diagnosis programme for $\mathrm{X}$-linked disease using dual FISH with $X$ and $Y$ chromosome probes, we have detected chromosomal abnormalities in both the biopsied cells and on analysis of those embryos which were not transferred to the patient (Delhanty et al., 1993, Griffin et al., 1994). We have observed an apparent $45, X$ embryo, a mosaic $X X X X X X X X O$ (Delhanty et al., 1993) and a triploid embryo (XXX and 17, 17, 17 ; Harper et al., unpublished observation) none of which should be considered for transfer. We adhere to the strict criterion of only replacing embryos in which the analysed blastomere shows two $X$ signals in the absence of a $Y$ signal, and so embryos with nuclei giving signals such as $X O$ and $X X X$ are not transferred.

In this study we examined 69 normally fertilised spare embryos of good morphology to determine the incidence of chromosomal abnormalities at the $6-10$ cell stage. The embryos were examined on day 3 post insemination, as for preimplantation diagnosis the embryo biopsy is performed at this time and it was important to ascertain the incidence of chromosomal abnormalities in these embryos. We used probes for the sex chromosomes to determine if such abnormalities could result in a misdiagnosis of sex and autosomal probes as in the future we hope to offer preimplantation diagnosis of trisomies. The autosomal probes used were for chromosomes 1 and 17 , as these probes are very specific and we would be examining one large and one small chromosome. Chromosome 1 trisomy has not been found in spontaneous abortions or live births, but has been reported in an 8-cell human embryo (Watt et al., 1987).

For the sex chromosomes, $15 \%$ of embryos were found to have nuclei which gave abnormal signals. In two embryos this was due to extra signals being observed ( $X X X X$ and $X X Y$ ) and in three embryos, $X O$ nuclei were detected. In the case of embryo $R$, the $X O$ nucleus may have been due to two overlapping $X$ signals or to inefficient hybridisation (Lomax et al., 1994), but for embryo Kiii, 3 XO nuclei were detected which would be unlikely to be due to overlapping $X$ signals and in the case of embryo Eiv, two XO nuclei were found in an XY embryo indicating the absence of a $Y$ signal. Collating data from over 600 embryos sexed in our laboratory and those of others (S. Munne, personal communication), as yet an XX nucleus has not been found in an otherwise $X Y$ embryo. Therefore, for preimplantation diagnosis, using the strict criterion of replacing only those embryos in which two $X$ signals have been observed in the absence of a $Y$ signal, these chromosomal abnormalities would not lead to a misdiagnosis of sex.

When dual FISH with two autosomal probes was performed, a higher incidence $(46 \%)$ of abnormalities was observed. This may be expected as two pairs of chromosomes are being analysed, although in the case of haploid or triploid abnormalities, the incidence would be the same irrespective of the number of chromosomes examined. In one case the embryo was completely triploid (or double trisomy) which may have resulted from the misidentification of a polyspermic embryo or non extrusion of the second polar body. In fifteen embryos, variable signal numbers were detected. In two cases (embryos 1ii and 13i) the mosaicism observed could be explained by mitotic non-disjunction. In others, nuclei were mainly diploid with 1-2 nuclei being haploid, triploid or tetraploid (or monosomic, trisomic or tetrasomic for 
both probes), all of which have previously been observed after karyotyping human embryos (Plachot et al., 1987, Jamieson et al., 1994). A tetraploid nucleus could arise due to failure of cytokinesis, but it is less clear how haploid or triploid mosaicism arises. In one embryo, three nuclei were monosomic for chromosome 1 and the remaining nucleus was tetraploid (7ii). In the remaining four embryos, the majority of nuclei were found to have varying numbers of chromosomes 1 and 17 which is similar to the results observed in polyspermic embryos (Coonen et al., 1994b) in which the formation of a tripolar spindle results in chaotic segregation. It is also reminiscent of the pattern occurring with transformed cells in culture and in cancer cells and may possibly result from the absence of cell cycle checkpoints (Delhanty and Handyside, 1994).

Karyotyping of human embryos would be the best method to study chromosome abnormalities but the technique has a poor yield due to the low number of metaphases and difficulties with spreading the chromosomes obtained from embryos. This leads to the inability to identify individual chromosomes (Handyside and Delhanty, 1993). Therefore, from a preimplantation embryo, few cells can be examined. From the small number of karyotype studies on human embryos (Plachot et al., 1987, Papadopoulos et al., 1989, Wimmers and van der Merve, 1988, Angell, 1989, reviewed in Zenzes and Casper, 1992, and Jamieson et al., 1994), between 16 and 40\% of embryos have been classified as chromosomally abnormal. In this study, using dual FISH on normally developing, monospermic embryos with the examination of almost every nucleus, the mosaicism for the sex chromosomes and autosomes 1 and 17 falls close to this range. In contrast, recent studies on abnormally developing embryos and those from older IVF patients using multicolour FISH with five probes for the chromosomes most commonly involved with aneuploidy at birth, reported an incidence of up to $70 \%$ chromosome abnormalities and mosaicism (Munne et al., 1993).

For preimplantation diagnosis, haploid or aneuploid mosaicism could lead to genetic misdiagnosis, especially for trisomy or dominant disorders (Handyside, 1994). For trisomies, it may be possible to have a trisomic embryo with one or more normal diploid cells. If one of the diploid cells were biopsied, the embryo would be diagnosed as unaffected. For dominant disorders, where the polymerase chain reaction would be used for diagnosis, if the embryo was heterozygous and the biopsied cell was haploid and contained the unaffected allele, the embryo would be diagnosed as unaffected when it was affected. However, in this series, only $15 \%$ of nuclei showed monosomic or haploid nuclei and this must be added to the unlikely event of biopsying one of the abnormal cells. We have always been aware that any preimplantation diagnosis based on the analysis of 1 or 2 cells may not be as accurate as conventional prenatal diagnosis (Handyside and Delhanty, 1993), but that for some couples, by at least significantly reducing, if not totally eliminating the risk of an affected child, the procedure is an attractive one. However, in the future with the development of diagnoses for trisomies and dominant disorders, two blastomeres must be analysed, and a follow-up chorionic villus sampling or amniocentesis encouraged.

Biologically, several studies have indicated that if some abnormal cells are present in an early embryo, there is a mechanism that diverts these abnormal cells to the trophectoderm or selects against them during embryonic development (James and West, 1994). It has also been reported that mixoploid cells (mosaicism of diploid and 
polyploid cells) are common in human blastocysts (Benkhalifa et al., 1993). Although we may be detecting a high frequency of mosaicism in these IVF generated embryos, the majority of abnormal cells may be selected into the trophectoderm and not form the embryo proper. These findings could explain the detection of confined placental mosaicism (Kalousek et al., 1992) and uniparental disomy (Engel and DeLozier-Blanchet, 1991). In the cases with random combinations of chromosomes, the abnormalities are such that these embryos are unlikely to develop further. The incidence of these abnormalities in normally conceived embryos remains an open question.

This study, as with other studies on human embryos, is limited to small numbers due to the ethical problems of obtaining human embryos. However, the development of multicolour FISH techniques leading to the identification of up to twelve 'real' colours in metaphase chromosomes (Dauwerse et al., 1992) or seven psuedocolours in metaphase and interphase nuclei (Reid et al., 1992) will increase the scope for analysis of embryos. This will reveal important information on chromosomal abnormalities in human embryos and their diagnostic as well as biological significance.

Acknowledgements: We would like to thank Karin Dawson and all the staff of the Hammersmith Hospital IVF unit. We would also like to thank the Wellcome Trust for their financial support.

\subsection{References}

Angel RR (1989) Chromosome abnormalities in human preimplantation embryos. In: Development of preimplantation embryos and their environment. Alan R. Liss, Inc. 181-187

Benkhalifa M, Janny L, Vye P, Malet P, Boucher D, \& Menezo Y (1993) Assessment of polyploidy in human morulae and blastocysts using co-culture and fluorescent in situ hybridisation Hum Reprod 8:895-902

Cooke HJ \& Hindley J (1979) Cloning of the human satellite III DNA: Different components are on different chromosomes. Nucl Acid Res 6:3177-3179

Cooke HJ, Schmidtke J. \& Gosden JR (1982) Characterisation of a human Y chromosome repeated sequence and related sequences in higher primates Chromosoma 87:491-502

Coonen E, Dumoulin JCM, Ramaekers FCS \& Hopman AHN (1994a) Optimal preparation of preimplantation embryo interphase nuclei by fluorescent in situ hybridisation Hum Reprod 9:533-537

Coonen E, Harper JC, Ramaekers FCS, Delhanty JDA, Hopman AHN, Garaedts JPM \& Handyside AH (1994b) Presence of chromosomal mosaicism in abnormal preimplantation embryos detected by fluorescent in situ hybridisation. Hum Genet 94:609-615 1994 .

Dauwerse JG, Wiegant J, Raap AK, Breuning MH \& van Ommen G-JB (1992) Multiple colors by fluorescence in situ hybridisation using ratio-labelling DNA probes create a molecular karyotype. Hum Mol Genet 1(8):593-598

Delhanty JDA, Griffin DK, Handyside AH, Harper J, Atkinson GHG, Pieters MHEC \& Winston RML (1993) Detection of aneuploidy and chromosomal mosaicism in human embryos during preimplantation sex determination by fluorescent in-situ hybridisation. Hum Mol Genet 2:1183-1185 
Delhanty JDA \& Handyside AH (1994) The origin of genetic defects in man and their detection in the preimplantation embryo In: Charlton HC (Ed) Oxford Reviews of Reproduc tive Biology 17 Oxford University Press, (in press)

Engel E \& DeLozier-Blanchet D (1991) Uniparental disomy, isodisomy, and imprinting: probable effects in man and strategies for their detection Am J Med Genet 40:432-439

Griffin DK, Wilton LJ, Handyside AH, Winston RML \& Delhanty JDA (1992) Dual fluorescent in-situ hybridisation for the simultaneous detection of $X$ and $Y$ chromosome specific probes for the sexing of human preimplantation embryonic nuclei Hum Genet 89:18-22

Griffin DK, Wilton LJ, Handyside AH, Atkinson GHG, Winston RML \& Delhanty JDA (1993). Diagnosis of sex in preimplantation embryos by fluorescent in-situ hybridisation $B M J$ 306:1382

Griffin DK, Handyside AH, Harper JC, Wilton LJ, Atkinson GHG, Soussis I, Wells D, Kontogianni EH, Tarin J, Geber S, Ao A, Winston RML \& Delhanty JDA (1994) Clinical experience with preimplantation diagnosis of sex by dual fluorescent in-situ hybridisation, $J$ Assist Reprod Genet (in press).

Handyside AH (1991) Biopsy of human cleavage stage embryos and sexing by DNA amplification In: Verlinsky $Y$ \& Strom B (Eds) Proceedings of the first symposium on preimplantation genetics. Plenum, New York, 75-83

Handyside AH (1994) Genetic defects in the human preimplantation embryo and the diagnosis of inherited disease. In: van Blerkom. J. (Ed) The biological basis of early human reproductive failure, Oxford University Press, 345-374

Handyside AH \& Delhanty JDA (1993) Cleavage stage biopsy of human embryos and diagnosis of $X$-linked recessive disease. In: Edwards, R.G. (Ed) Preimplantation diagnosis of human genetic disease, Cambridge University press, 239-270

Hardy K, Winston RML \& Handyside AH (1993) Binucleate blastomeres in preimplantation human embryos in vitro: failure of cytokinesis during early cleavage $J$ Reprod Fert 98:549558

Harper JC, Coonen E, Ramaekers FCS, Delhanty JDA, Handyside AH, Winston RML \& Hopman AHN (1994a) Identification of the sex of human preimplantation embryos in two hours using an improved spreading method and fluorescent in situ hybridisation using directly labelled probes Hum Reprod 9:721-724

Harper JC, Robinson F, Duffy S, Griffin DK, Handyside AH, Delhanty JDA \& Winston RML (1994b) Detection of fertilisation in embryos with accelerated cleavage by fluorescent in situ hybridisation (FISH) (submitted)

Harper JC \& Handyside AH (1994). The current status of preimplantation diagnosis, Cument Obstet and Gynaecol, September issue (in press).

Hillier SG, Afnan AMM, Magara RA, \& Winston RML (1985) Superovulation strategy before In Vitro Fertilisation. Clin Obstet Gynaecol 12:687-723

Hopman AHN, Ramaekers FCS, Raap AK, Beck JLM, Devilee P, Ploeg van der M \& Vooijis GP (1988) In situ hybridisation as a tool to study numerical chromosome aberrations in solid bladder tumours Histochemistry 89:307-316

James RM \& West JD (1994) A chimaeric animal model for confined placental mosaicism, Hum Genet 93:603-604 
Jamieson ME, Coutts JRT \& Connor JM (1994) The chromosome constitution of human preimplantation embryos fertilised in vitro. Hum Reprod 9:709-715

Kalousek DK, Barrett IJ \& Gartner AB (1992) Spontaneous abortion and confined placental mosaicism. Hum Genet 88:642-646

Lomax BL, Kalousek DK, Kuchinka BD, Barrett IJ, Harrison KJ \& Safavi H (1994) The utilisation of interphase cytogenetic analysis for the detection of mosaicism. Hum Genet 93:243-247

Munne S, Lee A, Rosenwaks Z, Grifo J \& Cohen J (1993) Diagnosis of major chromosome aneuploidies in human preimplantation embryos. Hum Reprod 8:2185 - 2191

Papadopoulos G, Templeton AA, Fisk N \& Randall J (1989) The frequency of chromosome anomalies in human preimplantation embryos after IVF. Hum Reprod 4:91-98

Plachot M, Junca A-M, Mandelbaum J, Grouchy J de, Salat-Baroux J \& Cohen J (1987) Chromosome investigations in early life. II Human preimplantation embryos. Hum Reprod 2:29-35

Reid T, Baldini A, Rand T \& Ward DC (1992) Simultaneous visualisation of seven different DNA probes by in situ hybridisation using combinational fluorescence and digital imaging microscopy Proc Natl Acad Sci USA 89:1388-1392

Watt JL, Templeton AA, Messinis I, Bell L, Cunningham P \& Duncan RO (1987) Trisomy 1 in an eight cell human pre-embryo. J Med Genet 24:60-64

Waye GS \& Willard HG (1986) Molecular analysis of a deletion polymorphism in a-satellite of human chromosome 17: Evidence for homologous, unequal crossing over and subsequent fixation. Nucl Acid Res 14:6915-6927

Willard HF, Smith KD \& Sutherland J (1983) Isolation and characterisation of a major tandem repeat family from the human X chromosome. Nucl Acid Res 19:3237-3241

Wimmers MSE \& van der Merve JV (1988) Chromosome studies on early human embryos fertilised in vitro. Hum Reprod 3:894-900

Zenzes MT \& Casper RF (1992) Cytogenetics of human oocytes, zygotes and embryos after in vitro fertilisation. Hum Genet 88:367-375 


\section{Future Perspectives}

Athough the first ISH experiments were performed more than two decades ago (Gall and Pardue 1969; John et al., 1969), it was not untill 1987 that the technique was implemented in the study of preimplantation embryos (West et al., 1987). Since then, several groups have explored the feasibility of the use of the ISH technique as a diagnostic tool to study the genomic constitution of human preimplantation embryos. Though a fair number of such ISH studies has already found its way to publicity and unraveling of the embryos' genomic secrets proceeds with great strides, there are still many challenging aims in this area of research.

\subsection{Structural aberrations}

Sofar, most ISH studies involving human embryos have concentrated on the detection of numerical aberrations. However, initial studies have demonstrated that the detection of unique, non-repetitive sequences in embryonic cells is also feasible (Coonen et al., 1993c). Nevertheless, a drastic increase in ISH sensitivity is still needed to permit reliable detection of structural errors on a single cell basis. If a high enough level of sensitivity can be achieved, preimplantation diagnosis of structural genomic abnormalities with a high recurrence risk, such as the Robertsonian translocations, might come within reach. However, the structural aberration under investigation in case of preimplantation diagnosis, will usually represent a unique mutation). It will no doubt require much effort to design a general approach applicable to each of these individual cases. We expect however, that the procedures to be applied in this matter will have to be tailored for each specific diagnostic problem.

\subsection{Combination of genotypic and phenotypic analyses}

One of the merits of the FISH technique is that it can be simultaneously applied to the same preparation with other cytochemical assays used for phenotype analysis (Speel et al., 1994). This combination of methods allows direct correlation between genetic aberrations, identified by FISH and specific phenotypic characteristics, such as those indicating cell type or cell cycle stage.

For example, FISH on human morulae and blastocysts revealed that they contain polyploid cells (Benkhalifa et al., 1993). James and West (1994) formulated a hypo- 
thesis that such genomically aberrant cells, formed in the course of early embryogenesis, are diverted to form the trophectoderm during blastocyst formation, and as a consequence do not take part in the formation of the embryo proper. A combination of FISH, to supply information on the ploidy status of the embryonic cell, and immunocytochemistry, using a marker to discriminate between inner cell mass and trophectoderm, may provide supporting or excluding evidence in this matter.

\subsection{Comparative Genomic Hybridisation (CGH)}

The CGH method represents a new approach for the global screening of genetic imbalances in test material (Kallioniemi et al., 1992,1994; duManoir et al., 1993). The analysis is based on the relative FISH signal intensity of test DNA as compared to normal total DNA. The relative copy number of homologous sequences is directly reflected by the ratio of the different fluorescence intensities after in situ hybridisation of a 1:1 mixture of test and normal DNA to normal human metaphases.

Speicher et al. (1993) first reported on the application of CGH in cancer studies using genomic tumor cell DNA amplified by degenerate oligonucleotide primed PCR (DOP-PCR), hence making the amount of test material available no longer a limiting factor. Using this approach succesful CGH was achieved with an initial amount of 50 pg of genomic DNA. Given the fact that the genomic content of one single human cell is approximately $7 \mathrm{pg}$. Speicher et al. (1993) stated that ten cells would suffice to perform CGH after DOP-PCR mediated DNA amplification. However, it has to be kept in mind that a considerable amount of DNA is lost during isolation. It is therefore most probable that more cells are needed to yield $50 \mathrm{pg}$ of total genomic DNA. An alternative would be to perform DOP-PCR directly on intact cells, thereby circumventing the necessity to isolate DNA prior to amplification. If these sensitivity problems can be solved, CGH could be applied to human embryos for preimplantation diagnosis. There are, however a number of drawbacks. At present, $\mathrm{CGH}$ allows detection of deletions and amplifications of $1-10 \mathrm{Mb}$, whereas the detection limit for amplified genomic sequences can be even lower, i.e. $100 \mathrm{~kb}$, provided that the amplicon is repeated at least twenty times (Joos et al., 1993). Unfortunately, the $\mathrm{CGH}$ method can not reveal translocations, inversions or other aberrations that do not change the copy number of DNA sequences, nor does it provide information on the exact ploidy status of the test material used. Furthermore, aberrations involving repeated sequences, e.g. those occurring in the centromeric and telomeric regions, are not reliably detectable because of the DNA suppression principle. Another major problem is the fact that with $\mathrm{CGH}$, only aberrations that are present in a substantial proportion of the cells tested (at least $50 \%$ ) are detectable. This fact makes the CGH method an inadequate tool for detection of chromosomal mosaicism in human preimplantation embryos since the simultaneous amplification of DNA from genomically distinct cells with DOP-PCR will level out the differences in chromosomal constitution of the individual blastomeres.

Although we feel that the $\mathrm{CGH}$ method is at present not suitable for preimplantation analysis, it could serve as a powerful method for the study of human abortion material. Karyotyping of such specimens is often hampered by low mitotic indices, and the necessity to culture cells may veil the visualization of crucial aberrations due to selective growth of certain cell populations. Recently, several studies were published 
performing FISH on sections of paraffin embedded embryonic material with DNA probes specific for repetitive centromeric sequences to retrospectively determine the embryos genomic constitution (Mori and Shiota, 1994; Nakamura et al., 1994; Van Lijnschoten et al., 1994). If sufficient DNA can be extracted from archival abortion material, and subsequently be amplified by DOP-PCR, retrospective $\mathrm{CGH}$ analyses become feasible.

\subsection{FISH analysis of ICSI failures}

Assisted fertilization protocols, for instance the intracytoplasmic sperm injection (ICSI) procedure, have been introduced to help couples in which standard IVF treatment fails due to severe male factor infertility (Palermo et al., 1992). The ICSI method is a microinjection procedure during which a single spermatozoon is injected in the cytoplasm of an oocyte. Apart from the advantage that with the ICSI method only one spermatozoon per oocyte is needed for fertilization, it also ensures monospermic fertilization of each oocyte. In $55 \%$ of all oocytes fertilised by ICSI, two pronuclei are detected, and the majority of the embryos arising therefrom shows normal cleavage and morphology (Van Steirteghem et al., 1994). However, a small percentage of the oocytes shows either only one pronucleus or does not undergo cleavage at all (Van Steirteghem et al., 1994). Since these embryos are not eligible for transfer or cryopreservation, they may become available for research purposes. It would be of interest to know whether these apparent monopronucleate embryos and non-dividing oocytes have indeed been fertilised and/or if their genomic constitution shows abnormalities. The application of the FISH technique to analyse these socalled ICSI failures could provide certainty about fertilisation by the identification of a $Y$ chromosome, or yield information on the ploidy status of the embryo.

Another intriguing phenomenon is the fact that, after ICSI, a small proportion of oocytes shows three or even more pronuclei (Van Steirteghem et al., 1994). As the ICSI procedure eliminates the possibility of tripronucleate oocytes as a result of diandry, this implies either digyny after non extrusion of the second polar body or (less probable) injection of a diploid spermatozoon. FISH on tripronucleate oocytes after ICSI, using probes for both sex chromosomes, should reveal whether digyny indeed accounts for the majority of the additional pronuclei seen.

\subsection{Analysis of spermatozoa}

Preimplantation diagnosis carried out on embryos is restricted by the small amount of material, but offers the chance of assaying DNA from cells that is fully representative of the embryonic genome. Spermatozoa on the other hand, are in most cases readily available but their DNA represents only half the genome of a potential embryo. The value of analysing spermatozoa for preimplantation diagnosis lies, amongst others, in the possibility to avert the birth of males with sex-linked disorders by identifying and separating $X$ and $Y$ bearing spermatozoa as a means of controlling the sex ratio. Numerous attempts have been made to implement such an approach in a clinical setting (Wang et al., 1994 and references cited therein).

At present, genomic analysis of spermatozoa by means of (F)ISH is not possible without destroying their viability. The method can however be very helpful in asses- 
sing the success rate of different separation protocols or to make a general inventory of the genomic numerical changes ocurring in spermatozoa (aneuploidy, nondisjunction). The latter could be valuable for preimplantation diagnosis by identifying individuals that are predisposed to increased rates of genomic alterations.

The (F)ISH analysis of spermatozoa is hampered by the fact that the DNA in the sperm head is condense and difficult to access. An efficient decondensation to improve the accessibility of the DNA is therefore an essential step for successful hybridisation. DNA decondensation is, however, often achieved at cost of sperm morphology, making the interpretation of the (F)ISH results rather complex. Moreover, the majority of spermatozoa loses the tail during pretreatment procedures and thus become hardly distinguishable from somatic cells present in the ejaculate. Many studies have reported on the use of $(F) I S H$ in human spermatozoa in order to determine the incidence of aneuploidy for particular chromosomes (Joseph et al., 1984; Guttenbach et al., 1990; Pieters et al., 1990; Wyrobek et al., 1990; Coonen et al., 1991; Guttenbach et al., 1991; Han et al., 1992; Wyrobek et al., 1992; Han et al., 1993; Holmes et al., 1993; Martin et al., 1993; Robbins et al., 1993; Bischoff et al., 1994; Guttenbach et al., 1994; Miharu et al., 1994). The results of these studies lack, however, general consensus with respect to the percentages of such numerical chromosome aberrations in spermatozoa, possibly due to the varying evaluation criteria. Recently, Martini et al. (1994b) described a new approach for ISH in spermatozoa, making it possible to discriminate between disomic-. diploid- and abnormal spermatozoa and to recognize somatic cells present in the ejaculate, hence making an accurate estimation of chromosomal aneuploidy in spermatozoa possible.

Karyotyping studies have revealed that also structural aberrations can be found in spermatozoa of normal, healthy men (reviewed by Pellestor et al., 1991). As the detection of structural genomic aberrations in embryos is one of the future aims of human preimplantation diagnosis, there is an obvious need for information on the presence of such anomalies in human gametes.

Preimplantation diagnosis of structural abnormalities will be of benefit to couples in which one of the partners carries of a balanced translocation. The likelihood of such a patient to produce abnormal offspring depends on both the proportion of chromosomally unbalanced gametes that is being produced as well as on the phenotypic effects of this particular imbalance upon the zygote (Goldman and Hultén, 1993; Martin et al., 1994). General information on the latter is usually available from empirical data, but details on the segregational properties and gamete output of translocations are more elusive. The FISH technique, using whole chromosome and paracentromeric DNA probes, has been used to study chiasma frequency and meiotic segregation in testicular material of male carriers of a balanced translocation (Goldman and Hultén, 1992, 1993). From such data information can be derived on how combinations of normal, balanced and unbalanced gametes arise, while changes on each possibility can be calculated. However, this method is both labour-intensive and expensive and does not account for the fact that some fusion products may be formed easier than others. An alternative for the screening of spermatozoa to detect structural aberrations would be the application of (F)ISH using DNA probes specific for unique sequences, flanking or spanning the chromosomal breakpoints.

We expect that correct pretreatment of the spermatozoa, combined with a sensitive hybridisation method will allow detection of structural abnormalities in these cells. 
We feel that the evaluation of spermatozoa, as part of a general protocol for detection of structural aberrations in preimplantation diagnosis, would increase the reliability of the whole procedure.

Although the results described in this thesis provide further information on the genomic constitution of human gametes and preimplantation embryos, our knowledge on the mechanisms that govern early embryogenesis is still very limited. It is to be expected however, that future research in this area will benefit from the techniques that have been developed and/or optimized during our studies.

\subsection{References}

Benkhalifa M, Janny L, Vye P, Malet P, Boucher D \& Menezo Y (1993) Assessment of polyploidy in human morulae and blastocysts using co-culture and fluorescent in-situ hybridization. Hum Reprod 8:895-902

Bischoff FZ, Nguyen DD, Burt KJ \& Shaffer LG (1994) Estimates of aneuploidy using multicolor fluorescence in situ hybridization on human sperm. Cytogenet Cell Genet 66:237-243

Coonen E, Pieters MHEC, Dumoulin JC, Meyer H, Evers JL, Ramaekers FCS \& Geraedts JPM (1991) Nonisotopic in situ hybridization as a method for nondisjunction studies in human spermatozoa. Mol Reprod Dev 28:18-22

Coonen E, Martini E, deDie-Smulders CEM, Ramaekers FCS, Geraedts JPM \& Hopman AHN (1994c) FISH using region-specific DNA probes for preimplantation diagnosis. Hum Reprod 9 suppl 4:30

duManoir S, Speicher MR, Joos S, Schröck E, Popp S, Döhner H, Kovacs G, Robert-Nicoud M, Lichter P \& Cremer T (1993) Detection of complete and partial chromosome gains and losses by comparative genomic in situ hybridization. Hum Genet 90:590-610

Gall JG \& Pardue ML (1969) Formation and detection of RNA-DNA hybrid molecule in cytological preparations. Proc Natl Acad Sci USA 63:378-383

Goldman ASH \& Hultén MA (1992) Analysis of chiasma frequency and first meiotic segregation in a human male reciprocal translocation heterozygote, $t(1 ; 11)(p 36.3 ; q 13.1)$, using fluorescence in situ hybridisation. Cytogenet Cell Genet 63:16-23

Goldman ASH \& Hultén MA (1993) Meiotic analysis by FISH of a human male $46, X Y$, $t(15 ; 20)(q 11.2 ; q 11.2)$ translocation heterozygote: quadrivalent configuration, orientation and first meiotic segregation. Chromosoma 102:102-111

Guttenbach $M$ \& Schmid $M$ (1990) Determination of $Y$ chromosome aneuploidy in human sperm nuclei by nonradioactive in situ hybridization. Am J Hum Genet 46:553-558

Guttenbach M \& Schmid M (1991) Non-isotopic detection of chromosome 1 in human meiosis and demonstration of disomic sperm nuclei. Hum Genet 87:261-265

Guttenbach M, Schakowski R \& Schmid M (1994) Incidence of chromosome 18 disomy in human sperm nuclei as detcted by nonisotopic in situ hybridization. Hum Genet 93:421423 
Han TL, Webb GC, Flaherty SP, Correll A, Matthews CD \& Ford JH (1992) Detection of 17 and $\mathrm{X}$-bearing human spermatozoa using fluorescence in situ hybridization. Mol Reprod Dev 33:189-194

Han TL, Ford JH, Webb GC, Flaherty SP, Correll A \& Matthews CD (1993 )Simultaneous detection of $\mathrm{X}$ - and $\mathrm{Y}$-bearing human sperm by double fluorescence in situ hybridization. Mol Reprod Dev 34:308-313

Holmes JM \& Martin RH (1993) Aneuploidy detection in human sperm nuclei using fluore scence in situ hybridization. Hum Genet 91:20-24

James RM \& West JD (1994) A chimaeric animal model for confined placental mosaicism. Hum Genet 93:603-604

John H, Birnstiel ML \& Jones KW (1969) RNA-DNA hybrids at the cytological level. Nature 223:578-582

Joos S, Scherthan H, Speicher MR, Schlegel J, Cremer T \& Lichter P (1993) Detecetion of amplified DNA sequences by reverse chromosome painting, using genomic tumor DNA as a probe. Hum Genet 90:584-589

Joseph AM, Gosden JR \& Chandley AC (1984) Estimation of aneuploidy levels in human spermatozoa using chromosome specific probes and in situ hybridisation. Hum Genet 66:234-238

Kallioniemi A, Kallioniemi O-P, Sudar D, Rutovitz D, Gray JW, Waldman FM \& Pinkel D (1992) Comparative genomic hybridization for molecular cytogenetic analysis of solid tumors. Science 258:818-821

Kallioniemi O-P, Kallioniemi A, Piper J, Isola J, Waldman FM, Gray JW \& Pinkel D (1994) Optimizing comparative genomic hybridization for analysis of DNA sequence copy number changes in solid tumors. Genes Chrom Canc 10:231-243

Martin RH, Ko E \& Chan K (1993) Detection of aneuploidy in human interphase spermatozo a by fluorescence in situ hybridization (FISH). Cytogenet Cell Genet 64:23-26

Martini E, Speel E-JM, Geraedts JPM, Ramaekers FCS \& Hopman AHN (1994a) Multicolor brightfield microscopical detection of numerical aberrations in morphologically intact human sperm by means of in situ hybridization. (Human Reproduction, in press)

Martini E, Speel E-JM, Coonen E, Ramaekers FCS, Geraedts JPM \& Hopman AHN (1994) New methodologies for ISH on chromosomal DNA in human spermatozoa. Hum Reprod 9 suppl 4:30

Miharu N, Best RG \& Young SR (1994) Numerical chromosome abnormalities in spermato zoa of fertile and infertile men detected by fluorescence in situ hybridization. Hum Genet 5:502-506

Mori C \& Shiota, K. (1994) Sexing of human embryos and fetuses by fluorescent in situ hybridization (FISH) to paraffin-embedded tissues with sex chromosome-specific DNA probes. Am J Med Gen 50:180-186

Nakamura N, Mori C, Narita M, Uwabe C \& Shiota K (1994) A rapid method of fluorescent in situ hybridization (FISH) to paraffin-embedded tissues for sexing human embryos and fetuses: optimal conditions of fixation and proteinase $\mathrm{K}$ treatment. Acta Histochem Cytochem 27:81-87

Palermo G, Joris H, Devroey P, Van Steirteghem AC (1992) Pregnancies after intracytoplasmic injection of single spermatozoon into an oocyte. Lancet 340:17-18 
Pellestor F (1991) Differential distribution of aneuploidy in human gametes according to their sex. Hum Reprod 6:1252-1258

Pieters MHEC, Geraedts JPM, Meyer H, Dumoulin JC, Evers JL, Jongbloed RJ, Nederlof PM \& van-der-Flier S (1990) Human gametes and zygotes studied by nonradioactive in situ hybridization. Cytogent Cell Genet 53:15-19

Robbins WA, Segraves R, Pinkel D \& Wyrobek AJ (1993) Detection of aneuploid human sperm by fluorescence in sity hybridization: evidence for a donor difference in frequency of sperm disomic for chromosomes 1 and Y. Am J Hum Genet 52:799-807

Speel, E-JM, Jansen MPHM, Ramaekers FCS \& Hopman AHN (1994) A novel triple-color detection procedure for brightfield microscopy, combining in situ hybridization with immu nocytochemistry. $J$ Histochem Cytochem (in press)

Speicher MR, duManoir S, Schröck E, Holtgreve-Grez H, Schoell B, Lengauer C,Cremer T \& Ried T (1993) Molecular cytogenetic analysis of formalin-fixed, paraffin-embedded solid tumors by comparative genomic hybridization after universal DNA-amplification. Hum Mol Gen 2:1907-1914

Van Lijnschoten G, Albrechts J, Vallinga M, Hopman AHN, Arends JW \& Geraedts, JPM (1994) Fluorescence in situ hybridization on paraffin-embedded abortion material as a means for retrospective chromosome analysis (Human Genetics, in press).

Van Steirteghem A, Joris H, Liu J, Nagy Z, Tournaye H, Liebaers I \& Devroey P (1994) Assisted fertilization by subzonal insemination and intracytoplasmic sperm injection. $\mathbf{n}$ : Mastroianni, M., Coeling Bennink, H.J.T., Suzuki, S. and Vemer, H.M. (eds) Gamete and embryo quality. Chapter 8 pp117-125 Parthenon Publishing Group Ltd, Casterton Hall, UK

Wang H-X, Flaherty SP, Swann NJ \& Matthews CD (1994) Assessment of the separation of $X$ - and $Y$-bearing sperm on albumin gradients using double-label fluorescence in situ hybridization. Fertil Steril 61:720-726

West JD, Angell RR, Thatcher SS, Gosden JR, Hastie ND, Glasier AF \& Baird D (1987)

Sexing the human pre-embryo by DNA-DNA in-situ hybridisation. Lancet 2:1345-1347

West JD, West KM \& Aitken RJ (1989) Detection of Y-bearing spermatozoa by DNA-DNA in situ hybridisation. Mol Reprod Dev 1:201-207

Wyrobeck AJ, Alhborn T, Balhorn R, Stanker L \& Pinkel D (1990) Fluorescence in situ hybridization to $Y$ chromosomes in decondensed human sperm nuclei. Mol Reprod Dev 27:200-208

Wyrobeck AJ, Weier HU, Robbins W, Mehraein Y \& Pinkel D (1992) Detection of sexchromosomal aneuploidies in human sperm using two-color fluorescence in situ hybridizati on. Environ Mol Mutagen 19 Suppl 2072 


\section{Summary}

Preimplantation diagnosis is a new method to detect genetic disorders in embryos at the earliest stages of development and may serve as an alternative to prenatal diagnosis for couples at risk of transmitting inherited diseases to their children. A reliable technique that can be widely applied for the detection of chromosomal abnormalities in preimplantation diagnosis, is the in situ hybridisation (ISH) procedure using DNA probes. In this study the ISH approach was chosen for the identification of the genotype of human gametes and preimplantation embryos. Different aspects of the application of the ISH procedure in preimplantation diagnosis are addressed in the general introduction (chapter 1). The ISH method allows analysis of both numerical and structural aberrations in metaphase chromosomes, but more important, also in interphase nuclei. Although the information obtained by ISH is limited to the DNA targets examined, it has the advantage that virtually every cell is informative, in contrast to conventional karyotyping. Furthermore, the ISH procedure is not hampered by contamination, which is a distinct advantage over the PCR method for analysis of single cells.

The application of the ISH technique in human spermatozoa has allowed an evaluation of aneuploidy levels in these gametes (chapter 2).

The application of the ISH technique to determine the sex of preimplantation embryos has been established some years ago. However, the conventionally applied method for spreading of whole human embryos or single human blastomeres involved methanol:acetic acid fixation and had some disadvantages with respect to cell morphology and cell yield. Moreover, this cell spreading procedure was labourious and required an exact timing of the subsequent preparation steps. Because of the limited number of cells that are available for diagnosis ( 1 or 2 blastomeres in case of a biopsy on day three), much effort has been put into the improvement of efficiency and reproducibility of the spreading procedure and subsequent ISH of embryonic cells. Pilot studies using murine embryos enabled the development of a new procedure to prepare and isolate interphase nuclei from preimplantation embryos for analysis by fluorescence ISH. Using this method we could perform successful genomic analyses on all studied preimplantation stages of the mouse embryo (pronuclei, 2-cell, 4-cell, morula and blastocyst). From the results described we conclude that the preparation and isolation of interphase nuclei from murine embryos with the improved procedure, using an extraction step with hydrochloric acid $(\mathrm{pH} 2)$ and a detergent (Tween20), offers a high reproducibility, a good morphology of the cells and a high hybridisation efficiency (chapter 3 ).

The improvement in sensitivity of the developed ISH procedures also enabled implementation of more advanced ISH technologies, in particular the use of DNA probes specific for unique sequences. We assessed the feasibility of this approach in human blastomeres using the improved spreading method for single embryonic cells in combination with fluorescence ISH based on cosmid probes. Efficient cell spreading and pretreatment procedures are prerequisites for reliable detection of unique sequences at the single cell level, in particular for preimplantation embryonic cells. Preliminary results on human blastomeres indicate that the application of ISH using cosmid probes can be performed with reasonable efficiency but is, when compared to the use of probes recognizing repetitive sequences, still subject to further improvement. Future studies should elucidate whether diagnostic application for the detection of structural aberrations in single cells in human preimplantation diagnosis will become applicable in a routine setting (chapter 4 ).

For preimplantation diagnosis, the biopsy, spreading and ISH analysis of single blastomeres and subsequent embryo transfer should preferably be performed within one day. There were, however, two limitations to current ISH procedures: Firstly, the loss of 
nuclei when spreading single blastomeres and secondly, the time taken for the diagnosis. Since a reduction in the time needed for determination of the sex of human blastomeres is a prerequisite for an efficient preimplantation diagnosis programme, we have examined the possibility to condense the ISH procedure in such a way that it can be performed within one day. Using the modified spreading method and directly labelled DNA probes for the $X$ - and $Y$ chromosome, we could reduce the time needed for the analysis of human blastomeres to 2 hrs without a decrease in hybridisation efficiency. For this study normally fertilized human embryos were disaggregated, after which single blastomeres could be obtained. The spreading efficiency was $96 \%$ and ISH signals were obtained from $97 \%$ of the nuclei. In all cases, sibling blastomeres from the same embryo were of the same sex. The data reported confirm that by using an improved spreading method in combination with directly labelled DNA probes, we have increased the efficiency and reduced the time required for sexing embryos for preimplantation diagnosis of $X$-linked diseases (chapter 5).

Further studies were performed to gain insight into the degree of genomic heterogeneity displayed by human embryos. Such information is needed to determine whether blastomeres, removed from the embryo for preimplantation diagnosis, reflect the genomic make-up of the whole embryo.

The extent of chromosomal mosaicism in human preimplantation embryos resulting from abnormal fertilization was examined using the improved procedures for the preparation and spreading of embryonic interphase nuclei. In only 3 of the 38 embryos that were included in this study, one of the cells showed no hybridisation signals $(99 \%$ hybridisation efficiency per successfully spread nucleus). Double-target ISH analyses with $X$ and $Y$ chromosome specific probes were performed to analyse embryos resulting from normal fertilization, polypronucleate embryos and cleavage-stage embryos with no (apronucleate), or only 1 (monopronucleate) visible nucleus. We also analysed embryos from these categories with double-target ISH for autosomes 1 and 7 . All embryos that resulted from normal fertilization were uniformly $X Y$ or $X X$. None of the apronucleate or monopronucleate embryos was haploid: three were diploid, one was triploid, and three were mosaic. The fact that fertilization had occurred was indicated by the presence of a $Y$-specific signal in four of these embryos. Of the polypronucleate embryos, two were diploid, two were triploid, and 18 were mosaic for the sex chromosomes and/or autosomes 1 and 7 . These results demonstrate that fertilization does occur in some monopronucleate embryos and that chromosomal mosaicism can be detected with high efficiency in apronucleate, monopronucleate and polypronucleate human embryos using fluorescence in situ hybridisation (chapter 6).

Embryos resulting from normal fertilization and showing a good morphology were examined at the 6-10 cell stage to assess the incidence of chromosomal mosaicism, for both sex chromosomes and autosomes 1 and 17 by using double-target ISH. For the sex chromosomes, $15 \%$ of the embryos were mosaic. In none of the cases was an $X X$ nucleus found in an otherwise $X Y$ embryo, indicating that even when mosaicism for the sex chromosomes occurs, this does not lead to misdiagnosis of the sex of the embryo. For the autosomes, one embryo was triploid, one was monosomic for chromosome 1 and ten others were (diploid) mosaics. A further four embryos had variable chromosome numbers in the majority of the nuclei, which appeared to be the result of uncontrolled mitotic division. Haploidy or double monosomy occurred in $15 \%$ of the nuclei. For preimplantation diagnosis based on ISH, genetic heterogeneity could lead to misdiagnosis, especially in case of a disomy/trisomy mosaicism (chapter 7).

On basis of these data we highly recommend the analysis of two blastomeres (if possible) for preimplantation diagnosis. In case the results from both cells are conflicting, embryo transfer should not take place. 


\section{Samenvatting}

Pre-implantatie diagnoștiek is een recent ontwikkelde methode die het mogelijk maakt om genetische afwijkingen te detecteren in embryo's tijdens de vroegste stadia van de ontwikkeling. Pre-implantatie diagnostiek kan een alternatief zijn voor prenatale diagnostiek bij paren die een hoog risico hebben op het krijgen van kinderen met een erfelijke aandoening. Een betrouwbare methode, die op veel manieren toegepast kan worden voor de detectie van chromosomale afwijkingen ten behoeve van de pre-implantatie diagnostiek is de in situ hybridisatie (ISH) procedure. Voor het onderzoek beschreven in dit proefschrift is gekozen voor ISH om het genotype van humane gameten (spermatozoa en oöcyten) en pre-implantatie embryo's te kunnen bestuderen. De verschillende aspecten die samenhangen met de toepassing van de ISH methode binnen de pre-implantatie diagnostiek komen in de algemene introductie aan de orde (hoofdstuk 1). Met behulp van de ISH methode kunnen zowel numerieke als structurele afwijkingen worden aangetoond in metafase chromosomen en, nog belangrijker, in interfase kernen. De genetische informatie die door middel van ISH verkregen wordt, blijt beperkt tot specifieke chromosomale regio's. Het voordeel is dat deze methode veel efficiënter is dan de klassieke karyotypering. Tevens is het een duidelijk voordeel dat de ISH methode, in tegenstelling tot de polymerase ketting reactie (PCR), niet nadelig beïnvloed wordt door de aanwezigheid van DNA van externe bronnen (bv zaadcellen).

De analyse van spermatozoa met behulp van fluorescentie ISH heeft het mogelijk gemaakt een uitspraak te doen over de incidentie van aneuploïdie in deze gameten (hoofdstuk 2).

De geslachtsbepaling van pre-implantatie embryo's met behulp van ISH werd enkele jaren geleden geïntroduceerd. De methode die toen gebruikt werd voor de fixatie van humane embryo's en/of losse blastomeren maakte gebruik van een methanol: ijsazijn mengsel. Deze methode had grote nadelen waar het de cel morfologie en de cel opbrengst betrof. Tevens was deze preparatie methode erg arbeids-intensief en was veel ervaring vereist om de opeenvolgende stappen in de procedure juist uit te kunnen voeren. Omdat een pre-implantatie analyse slechts op zeer weinig cellen uitgevoerd kan worden (er zijn maar 1 à 2 cellen beschikbaar wanneer de biopsie op dag 3 plaatsvindt) is het van eminent belang dat de efficiëntie en reproduceerbaarheid van de blastomeer preparatie en aansluitende hybridisatie zo groot mogelijk is. Onderzoek uitgevoerd met muize-embryo's heeft geleid tot de ontwikkeling van een verbeterde preparatie methode voor embryonale interfase kernen die vervolgens met behulp van fluorescentie ISH geanalyseerd kunnen worden. Gebruikmakend van deze methode zijn we in staat geweest om embryo's van alle onderzochte preimplantatie stadia (pronuclei, 2-cellig en 4-cellig stadium, morula en blastocyst) met succes te analyseren. Uit onze resultaten kunnen we concluderen dat de preparatie en isolatie van embryonale interfase kernen met behulp van een extractie op basis van zoutzuur en een detergens (Tween20) uitstekend te reproduceren is, dat de kernen een goede morfologie behouden en dat de efficiëntie van de ISH analyse hoog is (hoofdstuk 3).

De verbeterde gevoeligheid van de ontwikkelde methode heeft tevens tot resultaat gehad dat technisch moeilijker uitvoerbare ISH toepassingen, met name het gebruik van DNA probes die specifiek zijn voor unieke DNA sequenties, binnen bereik 
gekomen zijn. We hebben onderzoek gedaan naar de toepasbaarheid van deze aanpak bij humane blastomeren, gebruikmakend van de ontwikkelde preparatie methode in combinatie met ISH op basis van cosmide probes. Een efficiënte spreiding van de cellen en een juiste voorbehandeling zijn noodzakelijk voor de betrouwbare detectie van unieke DNA sequenties in de geïsoleerde cellen van pre-implantatie embryo's. Onze eerste resultaten verkregen bij humane blastomeren tonen aan dat ISH met cosmide probes weliswaar redelijk efficiënt is maar, vergeleken met het gebruik van DNA probes voor repetitieve sequenties, nog altijd veel verbetering behoeft. Toekomstig onderzoek zal moeten uitwijzen of een diagnostische toepassing voor de detectie van structurele afwijkingen op routinebasis beschikbaar zal komen (hoofdstuk 4).

Het is belangrijk dat de gehele pre-implantatie diagnose (biopsie en spreiding van cellen, ISH analyse en eventuele embryo transplantatie) binnen een dag kan worden uitgevoerd. Bestaande ISH procedures hadden echter twee nadelen. Het verlies aan cellen tijdens de spreiding was groot en de ISH analyse vergde veel tijd. Gezien het feit dat een aanzienlijke tijdwinst de efficiëntie van een pre-implantatie diagnose zou verhogen, hebben we getracht de ISH analyse zodanig te condenseren dat de totale procedure binnen 1 dag zou kunnen plaatsvinden. Gebruikmakend van de verbeterde preparatie methode in combinatie met rechtstreeks gelabelde probes voor het $X$ en het Y-chromosoom, zijn we in staat geweest de tijd, nodig voor een pre-implantatie diagnose terug te brengen tot 2 uur, zonder dat dit ten koste ging van de hybridisatie efficiëntie. Voor dit onderzoek werd gebruik gemaakt van geïsoleerde blastomeren van normale embryo's. De spreidings efficiëntie was $96 \%$ en van de geprepareerde kernen vertoonde $97 \%$ signalen na de ISH procedure. In alle gevallen waren blastomeren, afkomstig uit eenzelfde embryo, van hetzelfde geslacht. Deze resultaten geven aan dat we in staat geweest zijn om met behulp van de nieuwe preparatie methode en het gebruik van rechtstreeks gelabelde probes, de tijd, nodig voor een geslachtsbepaling ten behoeve van de pre-implantatie diagnostiek van geslachtsgebonden ziektes, te verkorten (hoofdstuk 5).

Tevens werden er studies uitgevoerd om de incidentie van chromosomaal mozaïcisme in humane embryo's te bestuderen. Deze informatie is van uitermate groot belang om te kunnen vaststellen in hoeverre gebiopteerde blastomeren representatief zijn voor het gehele embryo. Het voorkomen van chromosomaal mozaïcisme in embryo's ontstaan uit abnormaal bevruchte oöcyten werd onderzocht met behulp van de verbeterde procedures voor de preparatie en spreiding van embryonale cellen. Slechts in 3 van de 38 embryo's vertoonde een cel geen hybridisatie signalen na de ISH procedure ( $99 \%$ hybridisatie efficiëntie per geprepareerde cel). Met simultaan gebruik van X- en Y-specifieke DNA probes werd een ISH analyse uitgevoerd ter bestudering van normale embryo's, polypronucleaire embryo's en embryo's in verschillende klievingsstadia, waarin oorspronkelijk geen (apronucleair) of slechts een (monopronucleaire) zichtbare pronucleus aanwezig was. Deze embryo's werden ook onderzocht met DNA probes voor de autosomen 1 en 7 . Alle normale embryo's uit deze studie bevatten uitsluitend $X X$ of $X Y$ cellen. Geen enkel mono- of a-pronucleair embryo bleek haploïd te zijn: drie embryo's waren diploïd, een was er triploïd en drie vertoonden er een mozaïek patroon. Op basis van de aanwezigheid van een hybridisatie signaal voor het Y-chromosoom, konden we bij vier (oorspronkelijk) haplö̈de embryo's vaststellen dat er toch een bevruchting had plaatsgevonden. 
Twee van de polypronucleaire embryo's waren diploïd, twee waren er triploïd en 18 vertoonden een mozaïek patroon voor de geslachtschromosomen en/of de autosomen 1 en 7 . Onze resultaten geven aan dat monopronucleaire embryo's in een aantal gevallen toch bevrucht zijn en dat we, op basis van ISH, in staat zijn om met een hoge efficiëntie chromosomaal mozaïcisme aan te tonen in apronucleaire, monopronucleaire en polypronucleaire embryo's (hoofdstuk 6).

Normale embryo's met een goede morfologie werden bestudeerd tijdens het 6-10 cellig stadium om een uitspraak te kunnen doen over het voorkomen van chromosomaal mozaïcisme. Mozaïcisme voor de geslachtschromosomen werd aangetoond in ongeveer $15 \%$ van de onderzochte embryo's. Er werden echter geen $X Y$ dragende cellen gevonden in een vrouwelijk $(X X)$ embryo. Deze bevindingen geven aan dat, ondanks het chromosomaal mozaïcisme voor de geslachtschromosomen, het geslacht van een embryo niet verkeerd geïnterpreteerd zal worden bij pre-implantatie diagnostiek. Ook werden resultaten verkregen na hybridisatie met DNA probes voor de autosomen 1 en 17. Een embryo bleek triploîd, een embryo vertoonde monosomie 1 en tien andere vertoonden mozaïcisme. In vier embryo's werden ongelijke aantallen chromosomen in verschillende kernen aangetroffen. Gelijktijdige monosomie voor de chromosomen 1 en 17, hetgeen een sterke aanwijzing is voor haploïdie, werd aangetoond in ongeveer $15 \%$ van de onderzochte kernen. Genetische heterogeniteit voor autosomen zou kunnen leiden tot een foutieve pre-implantatie diagnose, en wel specifiek in het geval van een diploïd/triploïd mozaïcisme (hoofdstuk 7) Op basis van deze resultaten bevelen we ten zeerste de analyse aan van twee blastomeren voor pre-implantatie diagnostiek. Wanneer beide cellen na hybridisatie niet hetzelfde resultaat tonen, dient van embryotransplantatie te worden afgezien. 


\section{Curriculum vitae}

Edith Coonen werd geboren op 27 april 1967 te Roermond. In 1985 behaalde zij het gymnasium- $B$ diploma aan de Scholengemeenschap St Ursula te Horn. In datzelfde jaar begon zij haar studie Gezondheidswetenschappen, met als afstudeerrichting Biologische Gezondheidkunde aan de Rijksuniversiteit Limburg te Maastricht. In september 1989 werd het doctoraal diploma behaald. In januari 1990 werd zij tijdelijk aangesteld als onderzoeks-assistent bij de vakgroep Moleculaire Celbiologie \& Genetica van de Rijksuniversiteit Limburg te Maastricht, een dienstverband dat later dat jaar werd omgezet in een aanstelling als assistent in opleiding bij dezelfde vakgroep (Prof. dr F.C.S. Ramaekers, Prof. dr J.P.M. Geraedts, Dr A.H.N. Hopman). Gedurende deze periode werd het in dit proefschrift beschreven onderzoek uitgevoerd. Tevens werd tijdens deze aanstelling de opleiding tot functionaris ex artikel 9 van de Wet op de dierproeven gevolgd aan de Rijksuniversiteit Limburg te Maastricht en werd het diploma stralingshygiëne, deskundigheidsniveau 3 , behaald aan het Interfacultair Reactor Instituut te Delft. Vanaf januari 1995 is zij aangesteld als wetenschappelijk medewerker bij de afdeling Obstetrie \& Gynaecologie van het academisch ziekenhuis Maastricht. 


\section{Publications}

Coonen E, Pieters MHEC, Dumoulin JCM, Meyer H, Evers JLH, Ramaekers FCS \& Geraedts JPM (1991) Nonisotopic in situ hybridisation as a method for nondisjunction studies in human spermatozoa. Mol Reprod Dev 28:18-22

Coonen E, Dumoulin JCM \& Ramaekers FCS (1993) Intermediate filament protein expression in early developmental stages of the mouse. Histochemistry 99:141-149

Geraedts JPM, Pieters MHEC, Dreesen JCFM \& Coonen E (1994) IVF en preimplantatie diagnostiek. In: Slager, Schoenmaker en Gerris (red), Fertiliteitsonderzoek en behandeling anno 1994, p251-256, Organon Nederland

Verlinsky Y, Handyside A, Simpson JL, Edwards R, Kuliev A, Muggleton-Harris A, Readhead C, Liebaers, I, Coonen E, Plachot M et al. (1993) Current progress in preimplantation genetic diagnosis. J Assist Reprod Genet 10:353-360

Coonen E, Dumoulin JCM, Ramaekers FCS \& Hopman AHN (1994) Optimal preparation of preimplantation embryo interphase nuclei for analysis by fluorescence in-situ hybridization. Hum Reprod 9:533-537

Harper JC, Coonen E, Ramaekers FCS, Delhanty JDA, Handyside AH, Winston RML \& Hopman AHN (1994) Identification of the sex of human preimplantation embryos in two hours, using an improved spreading method and fluorescent in-situ hybridization (FISH) using directly labelled probes. Hum Reprod 9:721-724

Coonen E, Harper JC, Delhanty JDA, Ramaekers FCS, Geraedts JPM, Hopman AHN \& Handyside AH (1994) Presence of chromosomal mosaicism in abnormal preimplantation embryos detected by fluorescence in situ hybridization. Hum Genet 94:609-615

Harper JC, Coonen E, Handyside AH, Winston RML, Hopman AHN \& Delhanty JDA (1994) Detection of sex chromosome and autosome mosaicism in normally fertilised preimplantation human embryos (Prenatal Diagnosis, in press)

Coonen E, Harper JC, Pieters MHEC, Ramaekers FCS \& Hopman AHN (1994) Fluorescence in situ hybridisation using cosmid probes to detect unique sequences in human embryonic cells: implications for preimplantation diagnosis (submitted)

Coonen E, Hopman AHN, Geraedts JPM \& Ramaekers FCS (1995) Application of in situ hybridsation techniques for the study of human preimplantation embryos; relevance to human preimplantation diagnosis (review; submitted) 


\section{Abstracts}

Coonen E, Dumoulin JCM, Handyside AH, Pieters MHEC, Ramaekers FCS \& Hopman AHN (1993) Optimal preparation of embryonic interphase nuclei for analysis by fluorescent in situ hybridisation. Hum Reprod 8 suppl. abstr 421 Awarded with the Most Promising Young Scientist Award of the European Society of Human Reproduction and Embryology

Coonen E, Harper JC, Geraedts JPM, Handyside AH, Ramaekers FCS \& Hopman AHN (1993) Multicolor fluorescent in situ hybridisation with repetitive and cosmid DNA probes on single embryo cells for human preimplantation diagnosis. Am J Hum Gen 53 suppl. abstr 1394

Geraedts JPM, Harper JC, Handyside AH, Delhanty J, Ramaekers FCS, Hopman AHN \& Coonen E (1993) Identification of chromosomal mosaicism in human preimplantation embryos using fluorescent in situ hybridisation. Am J Hum Gen 53 suppl. abstr 91

Pieters MHEC, Coonen E, Handyside AH, Dreesen JCFM, Hopman AHN, Evers JLH \& Geraedts JPM (1993) Pre-embryobiopsie en geslachtsdiagnostiek. Ned Tijdschr Geneesk 137:2005

Coonen E, Martini E, de Die-Smulders CEM, Ramaekers FCS, Geraedts JPM \& Hopman AHN (1994) FISH using region-specific DNA probes for preimplantation diagnosis. Hum Reprod 9 suppl. abstr 59

Dumoulin JCM, Coonen E, Michiels AHJC, Bras M, Geraedts JPM \& Evers JLH (1994) Taurine can act as an oxygen radical scavenger in mouse embryos. Hum Reprod 9 suppl. abstr 137 


\section{Dankwoord}

Aan het einde gekomen van dit proefschrift wil ik graag mijn waardering uitspreken voor een ieder die op welke wijze dan ook heeft bijgedragen aan de totstandkoming ervan.

Als eerste mijn dank aan Frans Ramaekers en Joep Geraedts, promotores.

Beste Frans, ik herinner me ons eerste gesprek nog goed. Je wees me toen op het feit dat ik (de eerste) AIO zou worden bij een vakgroep in oprichting, met alle bijbehorende kinderziektes. Terugkijkend kan ik alleen maar zeggen dat ik het leuk heb gevonden om er vanaf het eerste begin bij te zijn geweest. Je interesse en flexibele opstelling ten aanzien van mijn werk hebben er zeker toe bijgedragen dat ik met plezier terugdenk aan de tijd die ik bij de vakgroep heb doorgebracht.

Beste Joep, mijn eerste herinnering aan jou stamt uit mijn studententijd, toen we met een klein groepje studenten bij je aanklopten voor een onderzoeksstage. Sindsdien ben je eigenlijk altijd bij mijn onderzoek betrokken gebleven, soms wat directer, soms wat meer op de achtergrond. Ik wil je bedanken voor alles wat je voor mij gedaan hebt en het doet me enorm veel plezier dat ik weer 'op het oude nest' heb kunnen terugkeren.

Natuurlijk mag hier niet ontbreken Ton Hopman, co-promotor en dagelijks begeleider. Beste Ton, bij tijden heb ik je hang naar perfectie en methodologie verwenst, maar het heeft mij in gunstige zin gevormd en nu heb ik er nog dagelijks profijt van.

Ik heb grote waardering voor de manier waarop je borg staat voor je mensen en men mag je dus met recht een 'FISH-ermen's' friend noemen.

De leden van de beoordelingscommissie wil ik bedanken voor het kritisch doornemen van dit manuscript en hun welkome adviezen en suggesties.

This thesis would not have been as it is now, without the contribution of my friends from the Hammersmith Hospital and University College in London. I think we all met at the right time and the right place to turn our collaboration into a success. Dear Joyce, my special thanks go to you. Working with you meant working hard and working late, but it always was a joy. Alle mensen van de vakgroep Moleculaire Celbiologie en met name de leden van de FISH club, wil ik bedanken voor de leuke sfeer waarin ik heb kunnen werken. Voor alle AIO's die nog na mij komen; heel erg veel succes!

Een van de aantrekkelijke aspecten van het beschreven onderzoek was de samenwerking met andere (vak)groepen. Ik heb het als een voorrecht ervaren dat ik altijd en meestal op ongelegen momenten bij jullie kon aankloppen. Daarom, alle mensen van de pre- en postnatale afdeling cytogenetica bedankt voor jullie 'allermooiste' preparaten als er weer eens iets getest moest worden. Bedankt ook de mensen van het IVF lab, met name John, Marijke en Math, voor alle tijd en moeite die jullie in mijn onderzoek gestoken hebben.

De culinaire hoogtepunten van de afgelopen jaren komen zonder meer op het conto van het Appie-Happie clubje. Frank, Gert, Helma en Moniek, dank jullie wel voor de gezellige 'bourgondische' avonden; ik had ze voor geen goud willen missen.

Familie Engelen, hoe belangrijk zijn vrienden in goede en slechte tijden. John, Roos, Luc, Bob en Koen, jullie zijn het meest effectieve middel tegen een opkomende depressie.

Beste paranymphen, ik moet bijna het puntje van mijn tong bijten om het niet te verklappen, maar ik zal toch nog maar even volhouden. Mijn taak zit er nu bijna op; de rest laat ik met een gerust hart aan jullie over. Alvast bedankt voor al jullie hulp en support.

$\mathrm{Pa}$, ma en Rianne, niets is zo belangrijk als een fijn 'thuis', waar je jezelf kunt zijn en waar je altijd op terug kunt vallen. Gelukkig ben ik in dat opzicht erg verwend. Dank jullie wel.

Leve Wil, de laatste regels van dit dankwoord zijn voor jou. De afgelopen jaren waren voor ons niet de makkelijkste en vaak heb ik me afgevraagd of al die mensen, die ons stiekem voor gek verklaarden, niet een heel klein beetje gelijk hadden. Toch begint het einde nu in zicht te komen en ik ben best trots op wat we bereikt hebben. Het is onze gezamenlijke verdienste en een betere partner en kameraad had ik me er niet bij kunnen wensen.

Tenslotte, op verzoek, een pootje voor Nicky en Juul. 

